\title{
2 Taktungen lachender Körper und heitere Zuschauergefühle
}

\subsection{Auftakt}

Eine Frau allein. Sie geht die Straße entlang, leicht gebeugt, in sich gekehrt, bräunlich fahl ist ihre Kleidung. Im Hintergrund die Leuchtschrift eines Kinos. Dann: Ein Kinosaal von innen, der Film läuft bereits, die Frau setzt sich, die vom Kajal verwischten Augen blicken trüb auf die Leinwand. Für eine Weile erhellt das Lichtspiel ihre Stirn. Ihr Gesichtsausdruck beginnt sich zu wandeln, ruhig beobachtet sie das Geschehen, die tanzenden und scherzenden Menschen auf der Leinwand. Das, was mit der Szene aus THE PURPLE ROSE OF CAIRO ${ }^{1}$ thematisiert ist, bezeichnet die Seherfahrung der Screwball Comedy in Ort und Zeit: Die kulturelle Praxis der heiteren Gefühlsgestaltung im klassischen Erzählkino der 1930er und 1940er Jahre. Es ist, als ob Woody Allens Film inszenatorisch eine von der Forschung zur Screwball Comedy gesetzte Grundthese untermauerte: Der fiktive Eskapismus in den Komödien bzw. der Zusammenhang zwischen wirtschaftlicher Depression der 1930er Jahre und der sich etablierenden Traumfabrik Hollywoods in den Vereinigten Staaten von Amerika. ${ }^{2}$ Man erlebt eine Frau, die, in ihrer finanziellen Existenz bedroht, sich immer wieder in den warmen Lichtschein des Kinos flüchtet, um sich heiter zu stimmen. Die Armut und Trostlosigkeit auf der einen Seite, der Reichtum und die Unbeschwertheit auf der anderen Seite sind nicht allein narrative Themen, sondern finden ihre Entsprechungen in konkreten Bildaufteilungen von THE PURPLE ROSE OF CAIRO: die dunklen, fahlen Ecken und Ränder des alltäglichen Lebens Cecilias (Mia Farrow) zu Hause oder bei der Arbeit und die kurzweiligen, hellen Momente im Lichtkegel des Kinematographen. Diese beiden Pole sind jedoch kein abstraktes Thema, sondern werden über die Zeit des Films so kontrastiv einander gegenübergestellt, dass sie für die Zuschauer als konkret durchlaufener Erfahrungszusammenhang erscheinen.

THE PURPLE ROSE OF CAIRO ist ein Beispiel dafür, wie in Filmen ästhetische Formationen und zeitliche Arrangements der Inszenierung darüber entscheiden, welche Formen der Involvierung in der Kinoerfahrung möglich werden. Filme agieren mit ihren audiovisuellen Bewegungsbildern, als seien sie Gesten. Sie entwickeln sich über die Zeit der Seh- und Hörerfahrung von Zuschauern als

1 THE PURPLE ROSE OF CAIRo (Woody Allen, USA 1985).

2 Vgl. Cynthia Willett: Baudrillard, AFTER HOURS and the Postmodern Supression of SocioSexual Confict. In: Cultural Critique, No. 34. Minnesota 1996, S. 143.

๖ Open Access. ๑ 2020 Sarah Greifenstein, publiziert von De Gruyter. (cc)BY-NC-ND Dieses Werk ist lizenziert unter der Creative Commons Attribution-NonCommercial-NoDerivatives 4.0 Lizenz. 
Kompositionen wechselnder, aufeinander sich beziehender Ausdrucksbewegungen. ${ }^{3}$ Ihre ineinandergreifenden, sich überlagernden und kontrastierenden Dynamiken und Bewegungsqualitäten möchte ich im Rahmen dieser Arbeit als Tempi beschreiben. Diese hängen weder allein von der Art und Weise ab, wie sich die Schauspieler im Bild bewegen, noch ist damit lediglich der Rhythmus der Montage gemeint. Eine solche Verzahnung von Schauspielkörpern und filmischer Inszenierung ist in THE PURPLE ROSE OF CAIRO auf der Meta-Ebene eines Films-imFilm thematisiert: Die Herauslösung der Hauptfigur aus dem Filmbild - als Tom (Jeff Daniels) aus der Leinwand ins Kino herabsteigt - wirft alle davon abhängigen Bild- und Plotelemente des Films (im Film) durcheinander. Die Dramaturgie funktioniert nicht mehr, der Platz von Tom ist leer, die Dialoge stocken, es ist, als wäre dem sich bewegenden Geschehen auf der Leinwand - betrachtet man es als organische Einheit - ein Bein amputiert worden. Und gleichzeitig bezeichnet das Heraustreten Toms exakt die Eigenständigkeit, mit der eine narrative Figur in der Fantasietätigkeit von Zuschauern illusioniert wird, sich vom Bild- und Tonmaterial des Films zu lösen scheint und ein fiktionalisiertes Eigenleben beginnt, das Zuschauer nicht unbedingt auf die eigenen Gefühle zurückführen bzw. auf deren Ursprung in ästhetisch-bildlichen Formationen.

Solche Verzahnungen von Schauspielkörper und Leinwandbild/Bildschirm lassen sich in Filmen als Ausdrucksfigurationen auf der Ebene der affektiv-perzeptiven Zuschauererfahrung einerseits und als fiktionalisierte, filmische Figuren im kognizierten Filmverstehen andererseits beschreiben. Im Genre der Screwball Comedy ist dieses Verhältnis zugespitzt, denn die Filme sind stark an verbalgestische Kommunikation, an das Interagieren von Körpern gebunden, gleichzeitig aber aufs Engste mit Montagebewegungen verknüpft. Die ästhetische Dimension wird von den Forschungen zum Genre aber kaum betrachtet. Vielmehr beziehen sich die Arbeiten zur Screwball Comedy überwiegend auf narrative Figuren und fiktive Erzählmuster im Verständnis von Darstellung und Repräsentation. ${ }^{4}$ In dieser Untersuchung steht hingegen der inszenatorische Zusammenhang zwischen Schauspielbewegung und Filmbild im Zentrum, welcher die zeitliche Dramaturgie affektiver Wahrnehmungsgestaltung bei Zuschauern bedingt. Doch anhand welcher Parameter solche temporalen Veränderungen $\mathrm{zu}$ bestimmen sind, ist $\mathrm{zu}$ klären.

3 Das Konzept hat seinen Ausgangspunkt in Hermann Kappelhoffs Arbeit zum Melodrama Kappelhoff 2004a - und wurde in zahlreichen Studien theoretisch zentral diskutiert und methodisch-analytisch angewandt (Auswahl): Bakels 2017; Grotkopp 2017; Lehmann 2016; Müller und Kappelhoff 2018; Schmitt 2020. Das Konzept wird in Kap. 2.4 und in 4.2 ausführlich erläutert.

4 Beispielsweise bei Steve Neale und Frank Krutnik: Popular Film and Television Comedy. London/New York 1990, Kapitel 7: The Comedy of the Sexes, S. 132-175. 
Im Hinblick auf dieses Desiderat, das im Einzelnen noch zu erörtern sein wird, frage ich

- erstens danach, wie man die Tempi filmischer Bewegung, bezogen auf die Verbindung zwischen Schauspiel und rahmender Bildinszenierung, fassen kann. Wie lässt sich expressives Verhalten (von Schauspielern inszeniert) in einem durch und durch expressiven Medium (von Regie, Schnitt und Kamera etc. gestaltet) beschreiben? Die Perspektive der Eingebettetheit schauspielerischer Expressivität in filmisch-expressive Bewegungsbilder dient als Zugang zur Bestimmung der Tempi (Bewegungsqualitäten) im komplexen Zeitmedium Film.

- zweitens, auf welche Weise die Tempi der Bewegung als Modi des Gefühls (von Zuschauern) fungieren. Hierbei sind die temporalen Eigenschaften filmischer Inszenierung auf die Gefühlsorchestrierungen bezogen und nehmen den Status von Erfahrungsqualitäten, affektiven Intensitäten und gefühlten Stimmungen an. Die Perspektive der Tempi der Bewegung als Modi des Gefühls untersucht die medialen und ästhetisch-zeitlichen Orchestrierungen der Filme und betrachtet sie als Addressierungen und Modulationen affektiver Zuschauererfahrung.

Die beiden Frageperspektiven sind aufs Engste miteinander verschränkt. Damit erörtere ich, auf welchen Ebenen Komik und Lachanlass stattfinden und wie sich Phasen, Formen und Verläufe von Erheiterung anhand zeitlicher Phänomene beschreiben lassen. Das Lachen stellt neben dem Weinen im Kino eine Extremform der Erfahrung dar: Zuschauer werden durch filmische Bilder in positive Schwingung versetzt, mit Helmuth Plessner gesprochen: „Körperliche Vorgänge emanzipieren sich“5, der Mensch erfährt einen „Verlust der Beherrschung im Ganzen“6 die Situation erzeugt eine „Unbeantwortbarkeit“" , welche das Lachen als eine Art „Automatismus“8 ${ }^{\text {"8 }}$ beantwortet. Die Zuschauer überlassen sich einer fremden, nicht-menschlichen Imagination, werden zu Resonanzbzw. „Leihkörpern“ für die Komödien. ${ }^{9}$

5 Helmuth Plessner: Lachen und Weinen. Eine Untersuchung der Grenzen des menschlichen Verhaltens (1945). In: ders.: Gesammelte Schriften in zehn Bänden. Bd. 7: Ausdruck und menschliche Natur, hg. von Günter Dux, Odo Marquard und Elisabeth Ströker. Frankfurt am Main 2003, S. 201-387, hier S. 274.

6 Plessner 2003 (1945) S. 274.

7 Plessner 2003 (1945), S. 363.

8 Plessner 2003 (1945), S. 333.

9 Vgl. Christiane Voss: Der Film lacht. In: Gertrud Koch, Anke Henning, Christiane Voss, Georg Witte (Hg.): Jetzt und dann. Zeiterfahrung in Film, Literatur und Philosophie. München 2010, S. 35-50; Christiane Voss: Der Leihkörper. Erkenntnis und Ästhetik der Illusion, München 2013. 
Wie die Prozesse zwischen Lachanlass in der Komödienform und resonanten Erheiterungen in der verkörperten Filmerfahrung theoretisch $\mathrm{zu}$ fassen sind, werde ich im Hauptteil des Kapitels (2.3 und 2.4) erläutern. Bevor ich die Konzepte der allgemeinen sowie filmbezogenen Ausdrucks- und Verkörperungstheorien darlege und an ihnen meine Frageperspektiven vertiefe, möchte ich zunächst die Forschungszugänge zur Screwball Comedy vorstellen und an ihnen die konkreten Desiderate in Bezug zu den Frageperspektiven dieser Untersuchung erläutern.

\subsection{Bilder berauschender Vitalität - Komödie, Gefühl und Bewegung}

$\mathrm{Zu}$ den literarischen und kulturgeschichtlichen Einflüssen, wie sie für die Ursprungskonstellation der Screwball Comedy ausschlaggebend sind, zählen neben den Stücken Shakespeares ${ }^{10}$ als weitere Ahnenschaft die Restoration Comedy des siebzehnten Jahrhunderts und die Comedy of Manners bis ins zwanzigste Jahrhundert hinein. ${ }^{11}$ Dabei kennzeichnen die Restoration Comedy unter anderem ein rascher Wechsel der Dialoge, ein kluges Gespräch, die gleichberechtigte Darstellung von Mann und Frau sowie das Verbergen von Gefühlen. ${ }^{12}$ Allesamt sind dies Aspekte, die auch in der Screwball Comedy, wenn auch in völlig anderen Ausdrucksformen, zentral werden. Ist von literarischen Vorläufern die Rede, ist außerdem der Einfluss der Romane von Jane Austen offensichtlich. ${ }^{13}$ Austens Romane kreisen um die Spielregeln der Paarbildung in einer großbürgerlichen und aristokratischen Gesellschaft, rund um Heirat, Kennenlernen, die Zeit des Werbens, die Verlobung aber auch um Intrigen, monetäre Diskurse und den

10 Stanley Cavell beschäftigt sich intensiv mit den Verwandtschaftslinien zwischen den Shakespearschen Komödien und den Remarriage Comedies. Stanley Cavell: Pursuits of Happiness. The Hollywood Comedy of Remarriage. Cambridge 1981, z.B. S. 47-70.

11 Die Restoration Comedy des 17. Jahrhunderts ist enger definiert durch thematische Spezifika ihres historischen Kontexts, während die englische Comedy of Manners als zeitübergreifender am Thema der sozialen Codes der middle und upper class ausgerichtet ist. Zur Definition siehe Heike Anna Hierlwimmer: Geschlechterkampf mit Happy-End. Die angelsächsische Sittenkomödie von der Restoration Comedy bis zur Screwball Comedy of Manner (2005), unter: http://ubt.opus.hbz-nrw.de/volltexte/2005/339/index.html (letzter Zugriff: 04.02.2020); Siehe auch Elizabeth Kraft: Restoration Stage Comedies and Hollywood Remarriage Films. Conversation with Stanley Cavell. New York 2016, S. 14.

12 Vgl. Hierlwimmer 2005, S. 23-26.

13 Vgl. Judith Levy: Austen's Persuasion and the Comedy of Remarriage. In: Journal of Literature and the History of Ideas (2014), Volume 12, Number 2, S. 255-265. 
sozialen Stand. Eine dritte Verwandtschaftslinie sind Theater-Komödien der 1920er Jahren, worauf viele der Genre-Filme in ihren Drehbüchern und Stoffen zurückgehen. ${ }^{14}$ In DESIGN FOR LIVING - Ben Hecht schrieb Noël Cowards erfolgreiches Bühnenstück Design for Living (1932) zum Drehbuch um - kommt der Dramatiker noch mit seinem Bühnenerfolg zu Geld, in Howard Hawks' TWENTIETH CENTURY $(1934)^{15}$ hingegen steht die existenzielle Not der Theaterleute angesichts der Abwerbung von Schauspielern und Regisseuren nach Hollywood im Vordergrund. Der rege Austausch zwischen Bühne und Film fand bereits in den 1920er Jahren statt, wo aus vielen erfolgreichen Broadway-Stücken Stummfilme gemacht wurden. Ein und derselbe Stoff durchwanderte Theater, Stumm- und Tonfilm. ${ }^{16}$

\section{Lachen und Heiterkeit in der Screwball Comedy}

In Frank Capras IT HAPPENED ONE NIGHT ${ }^{17}$ taucht vermutlich nicht zum ersten Mal in einem Film das Wort „screwy“ auf, dennoch scheint das Wort, das Clark Gable ausspricht, um sich und seine Geliebte zu charakterisieren, nirgendwo vorher so passend zu sein. Im selben Jahr kommt mit Howard Hawks' TWENTIETH CENTURY der zweite Film heraus, in dem es ebenfalls um wortreiche Auseinandersetzungen eines Paares geht; hier wird ebenfalls das Wort „screw“ bzw. „screwy“ als Beschreibung für einen verrückten Charakter ausgesprochen. 1936 erscheint dann der Film MY MAN GODFREY ${ }^{18}$ in den Kinos, doch erst 1938, im Rückblick, verwendet die Filmkritik das Wort „screwball“19, um das verrückte, exzentrische Verhalten

14 Tino Balio: Production Trends. In: ders. (Hg.): Grand Design. Hollywood as a Modern Business Enterprise 1930-1939. Berkeley/Los Angeles/London 1995 (History of the American Cinema. Bd. 5), S. 256-279, hier: S. 268.

15 Das Drehbuch basiert auf dem Theaterstück Twentieth Century (1932) von Ben Hecht und Charles MacArthur, welches wiederum auf den dramatischen Text Napoleon of Broadway von Charles B. Millholland zurückgeht.

16 Charles Musser siedelt den Ursprung der Komödien bereits in den 1910er und 1920er Jahren an (in DeMilles' Scheidungskomödien und Lubitschs Gesellschaftskomödien). Diese seien dann vom Theater aufgegriffen worden und schließlich von Hollywood wiederentdeckt worden. Siehe Charles Musser: Divorce, DeMille and the Comedy of Remarriage. In: Kristine Brunovska Karnick und Henry Jenkins (Hg.): Classical Hollywood Comedy. New York/London 1995, S. 282-313, hier S. 284-285.

17 IT HAPPENED ONE NIGHT (Frank Capra, USA 1934).

18 MY MAN GODFREY (Gregory La Cava, USA 1936).

19 Der Term „screwball“ kommt aus dem Baseball und bezeichnet dort einen quergeschlagenen Ball, der in unerwarteter Weise sich drehend, bzw. verschraubend fliegt. Richard Maltby: It Happened One Night. Comedy And The Restoration Of Order. In: Jeffrey Geiger und R. L. Rutsky (Hg.): Film Analysis. A Norton Reader. New York 2005, S. 216-237, hier S. 216. 
Carole Lombards in TWENTIETH CENTURY und MY MAN GODFREY zu beschreiben. ${ }^{20}$ Mit dem Wort „screwball“ ist nun nicht mehr ein einzelner Film gemeint, sondern eine Reihe von Filmen. Die Frage, was das Screwball Comedy Genre auszeichnet, wie es einzugrenzen und zu bestimmen ist, hat die Forschung unterschiedlich perspektiviert. Joel Finler schreibt etwa:

The sophisticated screwball comedy was a very special type of American film which flourished in Hollywood for a relatively short period from mid-1930s to the early 1940s. A lively but very modern mixture of knockabout, farce and romantic drawing-room comedy, it was characterized especially by its witty wisecracks and repartee and by the eccentric or unconventional behavior of the leading characters, both male and female, who were treated equally on the screen. As described by one author, "Screwball comedy combined sophisticated, fast-paced dialogue of the romantic comedy with the zany action, comic violence and kinetic energy of slapstick comedy."21

An diesem Zitat lassen sich einige zentrale Bestimmungen ablesen, in welchen viele Zugänge zum Genre übereinstimmen: Die zeitliche Eingrenzung, die Exzentrik der Figuren, die Gleichberechtigung zwischen den Geschlechtern, das Element des Slapsticks und das viele und schnelle Sprechen in den Filmen. So treffend die Beschreibung zu sein scheint, so zielt sie doch fast ausschließlich auf die repräsentierten Inhalte der Komödien ab. An ihr kann man mehrere Problematiken aufzeigen, die sich grundsätzlich mit den Arbeiten zur Screwball Comedy verbinden und auch für meine Untersuchung relevant sind: Im Zitat spricht Finler von Witzeleien und Schlagfertigkeit. Zwar verbindet man mit dem Genre der Screwball Comedy vielfach eine Komik, die im Wesentlichen durch die Dialogbücher geprägt ist, durch Wortwitz, Sprachakrobatik und schlagfertige Eloquenz. ${ }^{22}$ Die verbale Ebene wird in der Forschung zwar als sehr dominant wahrgenommen betont wird ihre Herkunft aus der Broadway-Theatertradition, ihre Fülle an

20 Siehe Jane M. Greene: A Proper Dash of Spice: Screwball Comedy and the Production Code. In: Journal of Film and Video, Volume 63, Number 3. Illinois 2011, S. 25-63, hier S. 46. 21 Joel Finler: The Rise and Fall of American Screwball Comedy 1934-1944. In: Franco La Polla, Franco Monteleone und Jean Loup Bourget (Hg.): Il cinema che ha fatto sognare il mondo. La commedia brillante e il musical. Rom 2002, S. 25-64, hier: S. 27. Er zitiert Tina Olsin Lent: Romantic Love and Friendship. The Redefinition of Gender Relations in Screwball Comedy. In: Kristine Brunovska Karnick und Henry Jenkins (Hg.): Classical Hollywood Comedy. New York/London 1995, S. 314-331, hier: S. 327.

22 Vgl. Debora Knight: Tragedy and Comedy. In: Paisly Livingstone und Carl R. Plantinga (Hg.): The Routledge Companion to Philosophy and Film. Abingdon/Oxon 2009, S. 536-545, hier: S. 544; Ted Sennett: Lunatics and Lovers. A Tribute to the Giddy and Glittering Era of the Screen's „Screwball“ and Romantic Comedies. New Rochelle 1973, S. 256-288; Maria DiBattista: Fast-Talking Dames. New Haven 2003. 
Sprachspielen und literarischen Einflüssen sowie ihr Substitutcharakter für eine nicht-darstellbare Sexualität während des Production $\operatorname{Code}^{23}-$, doch in der These der Sprachdominanz wird das Sprechen in den Filmen fast ausschließlich auf das Verständnis von repräsentierten Figuren enggeführt. Stattdessen möchte ich zeigen, wie das komische Sprechen mit bildästhetischen, audiovisuellen Kompositionen verquickt ist und so als Teil der Inszenierung $\mathrm{zu}$ verstehen ist; wie filmische Tempi und schauspielerische Performances des Sprechens an Modellierungen heiterer Zuschauergefühle beteiligt sind. Diese weniger offensichtliche Dimension gilt es zu ergründen: Das Herausarbeiten des Zusammenspiels von sprachlicher und audiovisueller Inszenierung ist ein wichtiges Ziel der Arbeit und berührt die zwei zentralen Linien der Arbeit, die Tempi und die Einbettung des Schauspiels in die filmische Inszenierung.

Zudem wird in der Forschung zum Genre immer wieder davon ausgegangen, dass die für die Genrefilme charakteristische Komik neben dem sprachlichen Schlagabtausch im Wesentlichen durch Slapstick oder visuelle Gags und Handlungen geprägt sei. ${ }^{24}$ Hierbei spielen vor allem die narrative Figur, das Schauspiel aber auch die Starimagines eine große Rolle. ${ }^{25}$ Viele Autoren stellen in der Beschreibung der Filme vor allem die Figurentypen und ihre dargestellten Charaktereigenschaften in den Mittelpunkt. ${ }^{26}$ Die Screwball Comedy - so kann man das Gros der Forschungsliteratur zusammenfassen - scheint eine Hinwendung zum Figürlichen, zu sozialen Verhaltensweisen und außergewöhnlichen Charakteren festzustellen. ${ }^{27}$ Was jedoch in einer solchen Lesart völlig offenbleibt, ist,

23 Vgl. Musser 1995, S. 303-305; Steve Vineberg: High comedy in American Movies. Class and Humor from the 1920s to the Present. Lanham 2005, S. 6-7; Gerald Mast: The Comic Mind. Comedy and the Movies. Indianapolis/New York 1973, S. 249-279. Zum Substitutcharakter siehe Jane M. Greene 2011, S. 45; vgl. Neale und Krutnik 1990, S. 161-164.

$24 \mathrm{Vgl}$. Andrew Horton: Introduction. In: ders. (Hg.): Comedy/Cinema/Theory. Berkeley/Los Angeles 1991, S. 1-24; Noël Carroll: Notes on the Sight Gag. In: Andrew Horton (Hg.): Comedy/Cinema/Theory. Berkeley/Los Angeles 1991, S. 25-42, hier: S. 27; Maria DiBattista 2003, z.B. S. 30.

25 Siehe Kathrina Glitre: Cary Grant: Acting Style and Genre in Classical Hollywood Cinema. In: Jörg Sternagel, Deborah Levitt, Dieter Mersch (Hg.) Acting and Performance in Moving Image Culture. Bodies, Screens, Renderings. Bielefeld 2012, S. 71-86.

26 Z.B. Jenkins und Karnick, die zwar auf Schauspiel-Performances abzielen, diese jedoch immer wieder sehr stark mit narrativen Figuren oder Handlungen erklären. Siehe Henry Jenkins und Kristine Brunovska Karnick: Introduction. Acting Funny. In: Karnick und Jenkins (Hg.): Classical Hollywood Comedy. New York/London 1995, S. 149-167, hier: S. 165; Richard Maltby 2005, S. 221.

27 Thomas Schatz hat den Unterschied in den Genres charakterisiert: während in Gangsterfilm, Kriegsfilm oder Western eine ganz bestimmte Handlungsabfolge stattfinde, sei die Screwball Comedy mehr auf die Situation und Interaktion von Figuren ausgerichtet. Siehe Thomas Schatz: Hollywood Genres. Formulas, Filmmaking, and the Studio System. Philadelphia 1981; 
wie Figurenzeichnungen bzw. die Darstellung von Persönlichkeit und Charakter überhaupt hergestellt werden. An diesem Punkt lässt sich bereits eine Feststellung machen, die über die Screwball Comedy hinausweist und allgemeiner Natur ist. Sie betrifft die Analyse von Filmen generell: Der Idee, man könne filmische Bilder behandeln als seien sie Repräsentationen - mit alleinigem Fokus auf Narration und Figurencharakteren - widerspricht Hermann Kappelhoff ${ }^{28}$, indem er das kinematografische Bild als „ästhetische Dimension“ zum Ausgangspunkt für weitere Reflexionen macht, womit er eine „spezifische Form der Wahrnehmung“ bezeichnet - eine eigens durch das filmische Bild modulierte Erfahrung -, welche das medienspezifische ,Zuschauen' vom alltäglichen ,Sehen' unterscheidet. ${ }^{29}$ Die diegetische Welt ist aus dieser Sicht nicht einfach gegeben, sondern konstituiert sich erst in ihrer jeweiligen medienästhetischen Ausformung, als ganz bestimmter Wahrnehmungsmodus im spezifischen Filme-Sehen und Hören. ${ }^{30}$ Nimmt man diese Setzung ernst, dann ist mit der Nacherzählung von narrativen Handlungen nicht viel gewonnen. Vielmehr stellt sich die Frage, wie die kinematografischen Bilder eines Films ganz spezifische Wahrnehmungsformen ausbilden, die bei den Zuschauern Gefühlswandlungen und Prozesse der Sinnbildung zu steuern vermögen.

Als weitere Problematik kann man benennen, dass das Komödiengenre lange Zeit von der Filmwissenschaft diskreditiert oder nicht beachtet wurde. Einerseits liegt dies an der traditionellen Abwertung der Komödie gegenüber der Tragödie, andererseits ist dies aber auch in der Polarität von Kunst und Unterhaltung begründet, die ebenfalls Einzug in den akademischen Bereich mit seinen Forschungsgegenständen erhielt. ${ }^{31}$ Anstatt neutraler Untersuchungen wurden immer wieder Bewertungen der Screwball Comedy vorgenommen: die Filme seien apolitisch, profan und zeichneten eine hedonistisch orientierte

vgl. Wes D. Gehring: Screwball Comedy. A Genre of Madcap Romance. New York 1986, S. 6, S. 156; zur Exzentrik der Figuren siehe Willet 1996, S. 145.

28 Hermann Kappelhoff: Empfindungsbilder. Subjektivierte Zeit im melodramatischen Kino. In: Theresia Birkenhauer und Anette Storr (Hg.): Zeitlichkeiten - zur Realität der Künste. Theater, Film, Photographie, Malerei, Literatur. Berlin 1998 (Traversen. Bd. 3), S. 93-119, hier: S. 99.

29 Kappelhoff 1998, S. 101.

30 Siehe Kappelhoff 2018, S. 36-57.

31 So schreibt Andrew Horton: ,[...] there is a historical bias against a close and serious consideration of comedy [...] in a long history of criticism that has viewed comedy as inferior to other genres in Western culture. Since Aristotle designated comedy ,an artistic and imitation of men of an inferior moral bent', it has escaped the close schematization that the epic and tragedy have undergone in Western literary theory.“ Horton 1991, S. 2. 
Weltflucht. ${ }^{32}$ Diese Abwertung mag der Grund dafür sein, dass es wenige Zugänge gibt, die sich ernsthaft mit Komödie, Lachen und heiteren Gefühlen auseinandersetzen.

Darüber hinaus taucht in den Forschungsansätzen immer wieder die Problematik einer Polarität zwischen Gefühl und Verstand auf. Die Übermacht der Worte, die mitunter komplexen Wortspiele und kulturellen Anspielungen werden zum Teil so aufgefasst, als ob sich die Komödien allein an den Intellekt der Zuschauer richteten. ${ }^{33}$ So werden das Genre der Screwball Comedy und seine Ausformungen von Komik und Humor überwiegend als Zusammenhang von Verbalität, Erzählkonventionen und narrativem Verstehen entworfen. ${ }^{34}$ Die Zuschauererfahrung in den Filmen wird überwiegend als rein vorstellunggebunden betrachtet. ${ }^{35}$ Dabei wird vor allem die Narration als kognitiv verstehbare Geschichte in den Vordergrund gerückt. Zwar lassen sich wiederkehrende Handlungsmuster der Filme nachzeichnen, damit ist aber meist noch nicht erklärt, warum diese als komisch wahrgenommen werden. ${ }^{36}$

Die Position, die Faszination an der Komödie eher als intellektuelles Spiel zu beschreiben, denn als affektive, körperliche Involvierung, geht zurück auf Theorien zu Komik, Humor und Komödie, die das Lachen immer wieder als kalt und emotionslos qualifiziert haben. ${ }^{37}$ Henri Bergsons Formulierung, das Lachen sei

32 Das Apolitische der Filme, so Gehrings These, entspreche dem Unernsten, dem Unterhaltungsformat der Komödien. Vgl. Wes D. Gehring: Screwball Comedy. Defining a Film Genre. Muncie 1983, S. 13-14; vgl. Kristine Brunovska Karnick und Henry Jenkins: Introduction. Comedy and the Social World. In: Kristine Brunovska Karnick und Henry Jenkins (Hg.): Classical Hollywood Comedy. New York/ London 1995, S. 265-281, hier: S. 265; Maurice Charney: Comedy High and Low. An Introduction to the Experience of Comedy (1987). New York/Bern/ Frankfurt a. M./Paris 1991, S. 8. Zum Eskapismus siehe Maltby 2005, S. 222.

33 Vgl. Neale und Krutnik 1990, S. 48-49.

34 Vgl. Neale und Krutnik 1990; Kristine Brunovska Karnick: Commitent and Reaffirmation in Hollywood Romantic Comedy. In: Kristine Brunovska Karnick und Henry Jenkins (Hg.): Classical Hollywood Comedy. New York/London 1995, S. 123-146; Gerald Mast 1973; James Harvey: Romantic Comedy in Hollywood. From Lubitsch to Sturges. New York 1987. Thomas Schatz 1981.

35 Ausnahmen sind Dirk Eitzen: Comedy and Classicism. In: Richard Allen und Murray Smith (Hg.): Film Theory and Philosophy. Oxford 1997, S. 394-411; Kathrina Glitre: Hollywood Romantic Comedy: States of the Union, 1934-1965. Manchester/New York 2006, S. 14; Claudia Liebrand: „Here, we'll start all over again“. Game Over und Restart in Screwball Comedies mit dem Fokus auf Preston Sturges' Unfaithfully Yours. In: Rainer Leschke und Jochen Venus (Hg.): Spielformen im Spielfilm. Zur Medienmorphologie des Kinos nach der Postmoderne. (Medienumbrüche. Bd. 22) Bielefeld 2007, S. 21-40, hier: S. 24.

36 Siehe Jenkins und Karnick 1995, S. 80.

37 Den im Lachen verankerten Widerspruch zwischen Gefühl und Verstand in den Lach-, Komik- und Humortheorien resümiert Renate Jurzik: Der Stoff des Lachens. Studien über Komik. Frankfurt a. M./New York 1985, S. 16-21; vgl. Dirk Eitzen: The Emotional Basis of Film 
durch eine „Anästhesie des Herzens“ geprägt, ist hierfür ein Beispiel. ${ }^{38}$ Dagegen kann man die Nicht-Kontrollierbarkeit von Lachanfällen setzen; Freude und Ausgelassenheit in der Komödienerfahrung sind eine unbestreitbare Tatsache. ${ }^{39}$ Doch der Zusammenhang von Affektivität und Komödie wird kaum ausführlicher thematisiert.

Alle vier skizzierten Problematiken (Sprachdominanz - der Vorrang von Schauspiel und narrativer Figur - Unterschätzung der Komödie - die Ausklammerung von Leiblichkeit und Gefühl) sind miteinander verwoben. Man kann eine gewisse Ratlosigkeit beobachten angesichts der ausgefeilten Dialogmuster, der elaborierten Sprechweisen und kunstfertigen Argumentationen auf der einen Seite und dem Schematismus der Grunderzählung auf der anderen. ${ }^{40}$ Inwiefern die Poetiken und Ästhetiken der Filme selbst Anteil an Komik, Humor und Lachen haben, wird kaum untersucht. Der starke Fokus auf Sprachlichkeit und Narration verwischt zudem die Frage danach, wo in den Filmen das Gefühl zu verorten ist. So schreiben Neale und Krutnik zur Gegensätzlichkeit von Melodrama und Komödie:

[In] romantic melodramas as NOW, VOYAGER, and LETTER FROM AN UNKNOWN WOMAN [...] the ,emotional' identification with the desiring character is intensified by suspense, by the play with relative levels of knowledge, but in comedies such processes are deployed to disengage the spectator from the trajectory of the character's wish. ${ }^{41}$

In einer solchen Formulierung bleibt völlig offen, wie man sowohl die Zuschauerposition („the ,emotional“ identification [...] intensified by suspense“) als auch die repräsentierten Figurengefühle (,the desiring characters“, „the character’s wish") überhaupt an den Filmen dingfest machen kann. Die dargestellten Gefühle der komödiantischen Protagonistin werden einfach als in der Diegese existent

Comedy. In: Carl R. Plantinga und Greg Smith (Hg.): Passionate Views. Film, Cognition, and Emotion. Baltimore/London 1999, S. 84-102.

38 Henri Bergson: Das Lachen. Ein Essay über die Bedeutung des Komischen (1900). Zürich 1972, S. 13.

39 Susanne K. Langer betont das vitale Gefühl in der Komödienerfahrung: Susanne K. Langer: Die großen dramatischen Formen. Der Rhythmus der Komik. In: Reinhold Grimm (Hg.): Wesen und Formen des Komischen im Drama. Darmstadt 1975, S. 127-158.

40 Vineberg beschreibt etwa die Paradoxität zwischen elaboriertem Dialog und banalem Plot: Steve Vineberg 2005, S. 4. Die Grunderzählung spiele immer wieder die patriarchale „boy meets girl“-Formel als auch eine alternative Formel durch. Zur „boy meets girl“-Formel siehe: Tamar Jeffers McDonald: Romantic Comedy. Boy Meets Girl Meets Genre. London 2007 (Short Cuts. Bd. 34), S. 12. Zur alternativen Formel der raubtierhaften Frau (,the predatory female who stalks the protagonist") siehe Thomas Sobchack und Vivian Sobchack: An Introduction to Film. Boston 1980, S. 241. Siehe auch Gehring 1986, S. 6.

41 Vgl. Neale und Krutnik 1990, S. 140. 
verortet. Doch auf welcher Ebene kann man das Gefühl einer Figur behaupten, wo im filmischen Bild seinen Ausgangspunkt verorten? Das Fiktive von Figuren und Handlungen nicht als gegeben zu nehmen, sondern zu ergründen, wie man als Zuschauer im Fluss der Bewegungsbilder überhaupt erst ein Wollen und Wünschen von Figuren konstruiert, bleibt ein Desiderat.

Auf einige der skizzierten Problematiken antwortet Stanley Cavell mit dem wohl prominentesten Zugang zur Remarriage Comedy (ein Sub-Genre der Screwball Comedy), etwa wenn er die Gleichrangigkeit von Dialog und kinematografischer Gestaltung betont oder die Komödien als Phantasietätigkeit fasst, das Niedrige mit dem Hohen auf eine Augenhöhe bringt (Capra mit Kant liest) und die Filme in ihren Möglichkeiten des Philosophierens beschreibt. ${ }^{42}$ Da für Cavell die Eigenständigkeit der Filme und ihr Denken ein wichtiger Fokus sind, bleibt in seinem Zugang aber die affektive und expressive Dimension, das Timing der Komödie eher unbeachtet.

Die aufgeführten Positionen zeigen, dass in den Untersuchungen zu den Filmen die gesprochene Sprache, das Schauspiel, die dargestellten Figuren zentral gesetzt werden, nicht aber die Tatsache, dass Filme Bewegungsbilder sind, die sich in der Zeit entfalten. Es wird kaum untersucht, wie Zuschauer affektiv amüsiert, erheitert werden. Dieser Aspekt berührt in der filmwissenschaftlichen Forschung das Feld von Zugängen, die sich in den letzten Jahren unter dem Stichwort ,Emotion und Film‘ herausgebildet haben.

\section{Forschungsperspektiven zu Emotion und Film}

Nach Margit Tröhler und Vinzenz Hediger lassen sich grundsätzlich zwei Strömungen innerhalb der Filmtheorie unterscheiden, die das Feld von Emotion und Film erforschen: Die ästhetisch-philosophische Filmtheorie und die kognitionswissenschaftlich-psychologische Filmtheorie. ${ }^{43}$ Beide Richtungen verfolgen die Frage nach der Emotionalität im Kino auf unterschiedliche Weise. Erstere entwickelt Modelle, welche die Empfindungen, Emotionen,

42 Siehe Cavell 1981.

43 Das Forschungsfeld, das die verschiedenen Terme (Emotion, Stimmung, Affekt, Gefühl und Bewegtsein) verwendet, fasse ich nach Vinzenz Hediger unter Film und Emotion zusammen: Vinzenz Hediger: Gefühlte Distanz. Medien und Emotionen in der Moderne. In: Frank Bösch und Manuel Borutta (Hg.): Die Massen bewegen. Medien und Emotionen in der Moderne. Frankfurt a. M./New York 2006, S. 42-62, hier: S. 51. Siehe auch Margrit Tröhler und Vinzenz Hediger: Ohne Gefühl ist das Auge der Vernunft blind. Eine Einleitung. In: Matthias Brütsch et al. (Hg.): Kinogefühle. Emotionalität und Film. Marburg 2005, S. 7-20. 
Affekte oder Gefühle im Filmerleben tendenziell auf der Ebene körperlicher, wahrnehmungsbedingter sowie zum Teil vorbewusster als auch kognitiver Vorgänge verorten. Die zweite Richtung geht davon aus, dass sich bei den Zuschauern erst auf der Basis des bewussten und kognitiven Verstehens Emotionen ausbilden. ${ }^{44}$

Aus der psychoanalytischen Theorie, poststrukturalistischen Philosophie und Kulturtheorie erwachsen stellen Vertreter der philosophisch-ästhetischen Filmtheorie audiovisuelle Gestaltungen, Bildästhetiken und Poetiken in den Mittelpunkt. Im Nachdenken über die „vorbegrifflichen Anteile des Filmsehens“45 entwickelten sich Ansätze, welche Affektivität und gefühlsbedingtes Erleben nicht getrennt von den Inszenierungsformen der Filme beschreiben. Prominent ist etwa Gilles Deleuzes Begriff des Affektbildes zu nennen, das die expressive Gesichthaftigkeit am filmischen Bild betont. ${ }^{46}$ Mit Rekurs auf Charles Sanders Peirce begreift er audiovisuelle Affekte als Potentiale und Qualitäten einer Erstheit, die auf nichts anderes als auf sich selbst verweisen. Der Zuschauer wird bei Deleuze nur an wenigen Stellen thematisiert. ${ }^{47}$ Deleuze versucht, die Subjekt-Objekt-Dichotomie zu überwinden, indem er die Filme in ihren eigenständigen Anordnungen von Wahrnehmung, Affekt und Denken betrachtet. ${ }^{48}$ Deleuze denkt Bergsons Auffassung des Affekts („eine Art motorische Strebung in einem sensomotorischen Nerv“49) als

44 Vgl. Margrit Tröhler und Vinzenz Hediger 2005, S. 9-13; vgl. Anne Bartsch, Jens Eder und Kathrin Fahlenbrach: Einleitung: Emotionsdarstellung und Emotionsvermittlung durch audiovisuelle Medien. In: Anne Bartsch, Jens Eder und Kathrin Fahlenbrach (Hg.): Audiovisuelle Emotionen. Emotionsdarstellung und Emotionsvermittlung durch audiovisuelle Medienangebote. Köln 2007, S. 8-38, hier: S. 13-14.

45 Siehe Tröhler und Hediger 2005, S. 11.

46 Gilles Deleuze: Das Bewegungs-Bild. Kino 1 (1983). Frankfurt a. M. 1997, S. 123-170.

47 Das Vorgehen Deleuzes beschreibt Marie-Luise Angerer so: „Deleuze hat in seinen KinoSchriften den Affekt vom Zuschauer abgekoppelt, hat ihn apersonalisiert bzw. dem Wahrnehmungs-, Aktions- und Affektbild überantwortet. Dadurch wird der Zuschauer mit seinem Körper im Sinne der Theorie Bergsons zum Bild.“ Marie-Luise Angerer: Vom Begehren nach dem Affekt. Zürich/Berlin 2007, S. 67. Raymond Bellour macht das Fehlen des Zuschauers bei Deleuze explizit zu seinem Ausgangspunkt: Raymond Bellour: Das Entfalten der Emotionen. In: Matthias Brütsch et al. (Hg.): Kinogefühle. Emotionalität und Film. Marburg 2005, S. 51-102, hier: S. 59; vgl. Christian Pischel: Die Orchestrierung der Empfindungen. Affektpoetiken des amerikanischen Großfilms der 1990er Jahre. Bielefeld 2013, S. 50.

48 Auf eine Weise denkt Deleuze den Zuschauer als mit den ästhetischen Formen des Films verwoben, proklamiert aber auch die Eigenständigkeit des Films, in seiner automatischmaschinellen bzw. künstlerischen Schaffung von Affekten und Perzepten als Empfindungsund Wahrnehmungsblöcke, was im Prinzip alle künstlerischen Medien auf die eine oder andere Art betrifft. Gilles Deleuze und Félix Guattari: Was ist Philosophie? Frankfurt a. M. 2000, S. 191.

49 Zitiert nach Deleuze 1997 (1983), S. 97. 
zweifache Bilderordnung, welche auf die Zusammenführung von äußeren und inneren Vorgängen abzielt. ${ }^{50}$ Deleuzes Verständnis zielt auf das Faciale des Filmbilds, welches sich dem Gesicht ähnlich, als Schnittstelle von leiblicher Materialität und geistiger Flüchtigkeit ausformt, oszillierend zwischen verkörperter Präsenz im Kino und licht-klanghafter Immaterialität des Kinematographischen.

Bildtheoretische Ansätze von z.B. Jacques Aumont oder Nicole Brenez lassen sich daran anschließen. Sie zeichnen das Figurale, das Plastische der verschiedenen mimischen Bilder und ihrer filmischen Äquivalenzen nach. ${ }^{51}$ Auch Raymond Bellour und Hermann Kappelhoff drücken eine starke Nähe zum Deleuzschen Affektbegriff aus, führen aber stärker den Zuschauer wieder ein. Bellours „Entfalten der Emotionen“ ist an der Deleuzschen Theorie orientiert und verbindet diese mit Daniel Sterns entwicklungspsychologischem Zugang einer mimischen Kommunikation zwischen Säugling und Mutter. ${ }^{52}$ Hermann Kappelhoffs Theorie filmischer Expressivität fokussiert die Affektpoetiken kinematographischer Bewegung und die zeitliche Modellierung von Zuschauergefühlen. ${ }^{53}$ In der Beschreibung der ästhetischbildlichen Inszenatorik der Filme werden die Wahrnehmungs- und Affektmodi als Modulationen von Zeit manifest. Die mediale Inszenierungsform eines Films erhält den Status einer Ausdrucksinstanz, in die die Kinozuschauer wahrnehmend eingefasst sind. Aus dieser Sicht sind die Bilder von Affekt, Trieb, Empfindung, Aktion oder Zeit immer schon dynamische und grenzüberschreitende Verwebungen von Körpern, Phantasien und Leinwand. ${ }^{54}$ Die skizzierten Zugänge reflektieren dabei in Anlehnung an die

50 Vgl. Henri Bergson: Materie und Gedächtnis. Eine Abhandlung über die Beziehung zwischen Körper und Geist (1896). Hamburg 1991.

51 Siehe Jacques Aumont: Du visage au cinéma. Paris 1992. Nicole Brenez: De la figure en général et du corps en particulier. L'invention figurative au cinéma. Brüssel 1998.

52 Bellour 2005.

53 Mit seinen Arbeiten perspektiviert Kappelhoff auf gewisse Weise einen Satz von Deleuze, demnach das Affektbild „zugleich Bildtypus und Bestandteil aller Bilder“ sei: Deleuze 1997 (1983), S. 123; Kappelhoff 2004a, S. 164. Demnach geht es ihm um eine historische Perspektive des Wahrnehmungsmodus filmischer Bilder. Poetologien von Bewegungsbildern sind demnach als spezifische historische und kulturelle Ausdrucksformen von Perzepten, Affekten, Gefühlen und kognitiven Reflexionen zu verstehen, die jedoch jeweils in den Zuschauerkörpern spezifisch situiert erst realisiert werden und dabei ebenfalls einem historischen und kulturellspezifischen Aneignungsprozess unterworfen sind. Kappelhoff 2018, S. 25.

54 Siehe Hermann Kappelhoff: Die vierte Dimension des Bewegungsbildes. Das filmische Bild im Übergang zwischen individueller Leiblichkeit und kultureller Fantasie. In: Anne Bartsch, Jens Eder, Kathrin Fahlenbrach (Hg.): Audiovisuelle Emotionen. Emotionsdarstellung und Emotionsvermittlung durch audiovisuelle Medienangebote. Köln 2007, S. 297-311. 
frühe Filmtheorie die Schnittstelle von expressiver Zeitform des Kinematographischen zu einem affektgeleiteten Wahrnehmen. ${ }^{55}$

Das sich bewegende Filmbild selbst wird in seiner Kongruenz zur Dynamik des affektiven Empfindens verstanden. Zahlreiche Studien zur mimischen Kommunikation und medialen Darstellung des Gesichts sind in diesem Kontext zu benennen. ${ }^{56}$ Die Besonderheiten der audiovisuellen Poetiken, Ästhetiken und Bildtypen zielen hier nicht mehr auf künstlerisch-handwerkliche Stilistik oder technische Fertigkeiten ab. Vielmehr werden sie als Präsentationen kinematografischer Muster von Affekten, Wahrnehmungen und Erfahrungen verstanden, ${ }^{57}$ die in je unterschiedlichen kulturellen und historischen Praktiken begründet liegen. Die phänomenologischen Zugriffe sowie weitere Positionen der Affekttheorie stehen diesen Zugängen nahe, da sie audiovisuelle Bilder als verkörpert auffassen und leiblich-viszerale, immersive, sinnlich-haptische, synästhetische Aspekte beleuchten. ${ }^{58}$ Die ästhetisch-philosophische Filmtheorie perspektiviert demnach unterschiedliche Begriffe (Affekt, Gefühl, Empfindung oder Emotion)

55 Mit dem Begriff der Expressivität baut Kappelhoff auf ästhetisch-emotive Zugänge der klassischen Filmtheorie auf, wie sie etwa bei Münsterberg, Arnheim, Balázs und Eisenstein hervorgebracht wurden. Siehe Kapitel 2.4. Hervorgegangen sind verschiedene Studien zu Zuschauergefühl, Affektpoetik und Expressivität, u.a.: Lehmann 2016; Bakels 2017; Grotkopp 2017.

56 Siehe Jacques Aumont 1992; Gertrud Koch: Auge und Affekt. Wahrnehmung und Interaktion. Frankfurt a. M. 1995; Helga Gläser, Bernhard Groß und Hermann Kappelhoff (Hg.): Blick, Macht, Gesicht. Berlin 2001; Christa Blümlinger und Karl Sierek: Das Gesicht im Zeitalter des bewegten Bildes. Wien 2002; Petra Löffler: Affektbilder. Eine Mediengeschichte der Mimik. Bielefeld: 2004.

57 Produktionsästhetische Studien reflektieren dies ebenso: Siehe Christian Mikunda: Kino spüren. Strategien der emotionalen Filmgestaltung. München 1986; Karen Pearlman: Cutting Rhythms. Intuitive Film Editing. (Second Edition.) New York/London 2016.

58 Siehe Jennifer Barker: The Tactile Eye. Touch and the Cinematic Experience. Berkeley 2009; Robin Curtis, Marc Glöde und Gertrud Koch (Hg.): Synästhesie-Effekte. Zur Intermodalität der ästhetischen Wahrnehmung. München 2011; Robin Curtis und Gertrud Koch (Hg.): Einfühlung. Zu Geschichte und Gegenwart eines ästhetischen Konzepts. München 2009; Elena del Rio: Deleuze and the Cinemas of Performance. Powers of Affection. Edinburgh 2008; Tarja Laine: Shame and Desire. Emotion, Intersubjectivity, Cinema. Brüssel 2007 (Rethinking cinema. Bd. 3); Laura Marks: The Skin of the Film. Intercultural Cinema, Embodiment, and the Senses. Durham 2000; Laura Marks: Touch. Sensuous Theory and Multisensory Media. Minneapolis 2002; Thomas Morsch: Medienästhetik des Films. Verkörperte Wahrnehmung und ästhetische Erfahrung im Kino. München 2011; Drehli Robnik: Kino, Krieg, Gedächtnis. Affekt-Ästhetik, Nachträglichkeit und Geschichtspolitik im deutschen und amerikanischen Gegenwartskino. Amsterdam 2007; Vivian Sobchack 1992; Vivian Sobchack: Carnal Thoughts. Embodiment and Moving Image Culture. Berkeley 2004; Christiane Voss: Die leibliche Dimension des Mediums Kino. In: Frank Bösch und Manuel Borutta (Hg.): Die Massen bewegen. Medien und Emotionen in der Moderne. Frankfurt a. M./New York 2006, S. 63-80. 
bzw. hat verschiedene Konzepte ausgearbeitet (zu Expressivität, Immersion oder Verkörperung). ${ }^{59}$ Ihre Schnittpunkte sind die Annahmen zur sinnlichen, affektiven und leiblichen Filmerfahrung durch fluide Adressierungsformen bildlichperzeptiver Ästhetik. ${ }^{60}$

Die zweite Linie betrifft die Vertreter der kognitionswissenschaftlichen (und neoformalistischen) Filmtheorie, welche u.a. aus der Orientierung an der kognitiven Psychologie hervorgegangen ist. ${ }^{61}$ Der kognitive Affektbegriff wird als gefühlter Körperzustand verstanden, der auf der Ebene von Stimulus und Response einer Körperreaktion angesiedelt ist und breiter angelegt ist als der Emotionsbegriff. ${ }^{62}$ Die Forschungsrichtung der kognitiven Filmtheorie fokussiert insbesondere den Begriff der Emotion, der meist intentional als auf ein Objekt ausgerichtet verstanden wird. ${ }^{63}$ Carl Plantinga beschreibt in Moving Viewers seine Auffassung: Er versteht Emotionen als „mental states that are often accompanied by subjective feelings, physiological arousal, and action tendencies“64 Während Plantinga davon ausgeht, dass Emotionen nicht ausschließlich bewusst ablaufen ${ }^{65}$, betonen andere Vertreter der kognitiven Filmtheorie, dass bewusste Vorgänge für Emotionalität notwendig seien. Zudem sehen viele Theoretiker das emotionale Zuschauererleben im Film als grundsätzlich ähnlich zum alltäglichen Emotionserleben, ${ }^{66}$ so als befände man sich als Zuschauer in einem

59 So auch der Begriff der Empathie, der kürzlich als Brückenbegriff für die kognitiven und ästhetischen Zugänge eingesetzt wurde. Vgl. Malte Hagener und İngrid Vendrell Ferran: Einleitung: Empathie im Film. In: Malte Hagener und İngrid Vendrell Ferran (Hg.): Empathie im Film. Perspektiven der Ästhetischen Theorie, Phänomenologie und Analytischen Philosophie. Bielefeld 2017, S. 7-30.

60 Oder wie Raymond Bellour sagt: „Die Emotion entsteht aus dem Rhythmus, aus verschiedenen Rhythmen, sie verhält sich wie die Musik, und diese Musik ist die der Einstellungen.“ Bellour 2005, S. 73.

61 Kurz gefasst betrachte die kognitive Filmtheorie „den Zuschauer vorwiegend als ein Repräsentationen oder Informationen verarbeitendes System“, so Bartsch, Eder und Fahlenbrach 2007, S. 13. Sie bezieht sich dabei u.a. auf die Psychologie und Neurowissenschaft.

62 Siehe Carl R. Plantinga: Emotion and Affect. In: Paisly Livingstone und Carl R. Plantinga (Hg.): The Routledge Companion to Philosophy and Film. Abingdon/Oxon 2009a, S. 86-96, hier: S. 87.

63 Vgl. Plantinga 2009a, S. 86.

64 Carl R. Plantinga: Moving Viewers. American Film and the Spectator's Experience. Berkeley/Los Angeles/London 2009b, S. 55.

65 Plantinga 2009b, S. 56.

66 Die Eckpfeiler der Agenda der kognitiven Medientheorie sind die Vorherrschaft der Rationalität sowie die Perspektive des Naturalismus, welche sich tendenziell an naturwissenschaftlicher Forschung orientiere, so Ted Nannicelli: Cognitivism. In: Mary Celeste Kearney and Michael Kackman (Hg.): The Craft of Criticism. Critical Media Studies in Practice. New York 2018, S. 157-168, hier S. 157. 
außer-medialen Setting. ${ }^{67}$ Die kognitive Filmtheorie geht überwiegend davon aus, dass die Zuschaueraktivität im Rahmen eines Verstehens, Beurteilens oder Bewertens von narrativen, repräsentierten Handlungen, Szenarien und Figurenkonstellationen zustande komme.

Eine Ausnahme stellt Greg M. Smiths Mood-Cue-Approach dar, er sieht eher die Film-Stilistiken und Techniken und nicht allein die narrativen Handlungen als stimmungserzeugend an. ${ }^{68}$ Auch Ed Tans Modell sei hier hervorgehoben: Tan unterscheidet in seinem höchst einflussreichem Modell zwischen zwei Arten von Emotionen, die jedoch beide als kognitiv bewusst realisiert verstanden werden und sich nur durch den Gegenstand unterscheiden. Einmal wird die Aufmerksamkeit auf die Erzählung, die Figur oder das narrative Setting gesetzt: dies nennt er die Fiktions-Emotionen ${ }^{69}$, während die sogenannten Artefakt-Emotionen ein Bewusstwerden der technischen und künstlerischen Mittel mit sich bringen. ${ }^{70}$ Außer bei Tan, wo die Ästhetik selbst zum bewerteten und kognizierten Gegenstand des Gefühls werden kann, werden die audiovisuellen Inszenierungen oft unter dem Begriff style gefasst, wobei dieser getrennt von der Narration gedacht wird, diese aber unterstützen könne. ${ }^{71}$ Diese Form-Inhalt-Auftrennung von Narration auf der einen und Stilistik auf der anderen Seite, hat unter anderem dazu geführt, dass die Figurenintentionen, -motivationen sowie das Erleben von Subjektivität auf der Ebene reiner Repräsentation, als gegebenes Faktum angesehen wird. Die kognitiven Ansätze erklären jedoch nicht, wie es zu diesem basalsten repräsentativen Narrationsverstehen überhaupt kommt. In diesem Sinn ist zwar die Unterscheidung zwischen Figuren- und Zuschauergefühlen äußerst relevant ${ }^{72}$, jedoch erklärt sie dies nur auf der Ebene der Darstellung, als seien die Figurengefühle im Bild gegebene, sichtbare Fakten. Die Konstruktionen solcher Verstehensprozesse werden jedoch kaum eingehender problematisiert.

67 Plantinga 2009b, S. 62-64. Zur Problematik, Alltagswahrnehmungen und Filmwahrnehmungen zu analogisieren, siehe Kappelhoff und Bakels 2011.

68 Greg M. Smith: Film Structure and the Emotion System. Cambridge 2003, S. 41-64.

69 Ed Tan: Emotion and the Structure of Narrative Film. Film as an Emotion Machine (1995). New York 2013, S. 81-82, S. 171.

70 Tan 2013 (1995), S. 83-84.

71 Der film style wird als die jeweiligen Handlungen unterstützend, hervorhebend verstanden, nicht jedoch als eigene Sinndimension im Film. Siehe z.B. Plantinga 2009b, S. 141.

72 Carl Plantinga differenziert das Gefühlerkennen von Figuren vom eigenen Empfinden beim Betrachter. Letzteres sei geprägt von „Gefühlsansteckung“ durch die sichtbaren körperlichen Ausdrucksformen sowie von Empathieprozessen, siehe Carl R. Plantinga: Die Szene der Empathie und das menschliche Gesicht im Film. In: montage/av 13 (2004), H. 2, S. 7-27, hier: S. 17; Anne Bartsch, Jens Eder und Kathrin Fahlenbrach (2007) unterscheiden begrifflich zwischen „Emotionsdarstellung“ und „Emotionsvermittlung“: S. 8-38. 
Zwar haben sich einige Zugänge auf den menschlichen Emotionsausdruck im Film eingelassen. Doch das Problem der Einbettung des Schauspiels in die filmische Inszenierung ist kaum anvisiert worden. Die Vertreter der kognitiven Theorie oszillieren zwischen zwei Polen: Entweder wird der emotionale Gesichtsausdruck allein - ohne Rücksicht auf Schnitt, Kameraarbeit oder Sound Design betrachtet oder aber es zählt rein das narrative Verstehen und die darauf aufbauende Bewertungshaltung, welche eine emotionale Haltung (Sympathie, Empathie oder Antipathie u.a.) zu den narrativen Figuren in Gang setze. ${ }^{73}$

Man kann anhand beider Forschungslinien - der philosophisch-ästhetischen und der kognitiven-psychologischen - Desiderate auf eine gemeinsame Ausrichtung hin formulieren: Die philosophisch-ästhetische Richtung fragt nach den affektiven und verkörperten Wahrnehmungsbedingungen in der Filmerfahrung, beachtet tendenziell aber logisch-kognitive Operationen wie etwa das Entstehen von Narrativität weniger. Die kognitiv-psychologische Richtung der Filmtheorie ist hingegen überwiegend an der repräsentierten Diegese interessiert, die sie zum Ausgangspunkt macht für weitere Untersuchungen zu den kognitivierten und bewussten Emotionen. ${ }^{74}$ Der Schauspielerkörper mit all seinen Ausdrucksformen, seinem Gang, seiner Stimmlichkeit, seiner mimischen und gestischen Performance wird von der kognitiven Theorie meist entweder in Bezug auf eine emotionspsychologische Kategorisierung betrachtet, wobei hier unberücksichtigt bleibt, auf welche Weise die mediale Inszenierung den jeweiligen Emotionsausdruck rahmt, umdeutet, verwischt etc. Oder aber der Schauspielerkörper wird bereits als fiktive Figur, auf die bereits imaginierte Welt und Diegese bezogen, die als ,gegeben' angenommen wird.

Eingedenk der beiden Hauptlinien der Filmtheorie möchte ich die Lücken der jeweiligen Forschungslinien aufeinander beziehen: Sie verbinden sich in der Frage nach dem Zusammenhang von dargestelltem Emotionsausdruck im Schauspiel, fiktiv-imaginiertem Figurengefühl und den Zuschauergefühlen. Dieses Buch wird kaum ansatzweise alle Relationen dieses Desideratgefüges lösen können. Ich werde aber den Zusammenhang von sichtbarem Emotionsausdruck

73 Siehe Torben Grodal: Die Elemente des Gefühls. Kognitive Filmtheorie und Lars von Trier. In: montage/av 9 (2000), H. 1, S. 63-96, hier: S. 63.

74 Eine Ausnahme stellt hier Jens Eders Zugang zu Figurengefühlen bzw. zu Empathie und existentiellen Gefühlen im Film dar. Sein Figurenkonzept umfasst sowohl unbewusste Erlebensformen, präpersonale Affektivität als auch kognitivierte Emotionalität. Siehe Jens Eder: Empathie und existentielle Gefühle im Film. In: Malte Hagener und İngrid Vendrell Ferran (Hg.): Empathie im Film. Perspektiven der Ästhetischen Theorie, Phänomenologie und Analytischen Philosophie. Bielefeld 2017, S. 237-270. 
und Zuschauergefühlen über meine Frage nach den Tempi der Bewegung als Modi des Gefühls anvisieren. Ob sich daraus Schlüsse für theoretische Erörterungen zur Fiktion von Figurengefühlen ergeben, wird immer wieder diskutiert werden.

Dabei situiere ich mich innerhalb der philosophisch-ästhetische Theorielinie, indem ich die Frage nach der Modellierung von Zuschauergefühlen wie folgt spezifiziere: Lassen sich expressive Bewegungsmuster in Filmen über Bewegungsqualitäten (bzw. Tempi) bestimmen und darüber Rückschlüsse auch auf die Modi des Gefühls ziehen? Meinen zweiten Fokus, den der filmischen und schauspielerischen Expressivität, werde ich im Unterkapitel 2.4 entwickeln. Dabei werde ich die oben skizzierte Verbindung von dargestelltem Emotionsausdruck (im Schauspiel) und der Modellierung von Zuschauergefühlen genauer betrachten. Im Folgenden verorte ich die Frageperspektive der Tempi der Bewegung als Modi des Gefühls in der allgemeinen Ausdruckstheorie.

\subsection{Die Tempi - Bewegungsqualitäten und affektive Expressivität}

\section{Grundlinien der Ausdruckstheorie}

Der Begriff des Ausdrucks bezeichnet ein vielfältiges Netz von Bezügen. ${ }^{75}$ In den verschiedenen Verwendungszusammenhängen des Wortes - etwa verbale und nonverbale Äußerungen, künstlerischen Gestaltungsmodi, musikalische, stimmliche oder tänzerische Artikulationen, malerische Kompositorik etc. scheinen die komplexen Bezugspunkte seiner Begriffsgeschichte auf: die Überlagerungen aus Feldern der Ästhetik, Psychologie, Kunst und Medialität rund um die menschliche Affektivität. ${ }^{76}$ Da die umfassende Wiedergabe der Ausdruckstheorie meine Untersuchung übersteigen würde, beschränke ich mich auf Zugänge zu Expressivität im Zusammenhang mit Verkörperung und Gefühl.

75 Zur Begriffsgeschichte siehe Hans Ulrich Gumbrecht: Ausdruck. In: Karlheinz Barck (Hg.): Ästhetische Grundbegriffe. Historisches Wörterbuch in sieben Bänden. Bd. 1. Stuttgart 2000, S. 416-431. Für eine Überblicksdarstellung siehe Bühler 1933.

76 Die alltagssprachliche Bedeutung des Begriffs Ausdruck zeigt seine etymologische Verbindung zu Abdruck, Druck, die eine Form des Einprägens, Manifestwerdens und SichMaterialisierens auf, siehe Hans-Georg Gadamer: Wahrheit und Methode. Grundzüge einer philosophischen Hermeneutik (1960). Tübingen 1975, S. 476; Siehe auch Gumbrecht 2000, S. 417. Karl Bühler resümiert in seiner Geschichte der Ausdruckstheorie, auf welche Weise das Phänomen des Ausdrucks im achtzehnten Jahrhundert sowohl von der Medizin und Physiologie als auch von Ästhetik, Schauspieltheorie und Kunst bearbeitet wurde. Bühler 1933, S. 5. 
Die verschiedenen Positionen, welche sich bis in die antike Rhetorik und Schauspieltheorie verzweigen, möchte ich anhand verschiedener rekurrierender Denkfiguren bündeln und lediglich überblickshaft skizzieren, um dann im Anschluss einige Aspekte herauszugreifen, die für die weitere Untersuchung eine Rolle spielen.

1. Der Begriff des Ausdrucks hat sich, nachdem er im achtzehnten Jahrhundert als ästhetische Kategorie verstanden wurde, im neunzehnten Jahrhundert immer stärker zu einem psychologischen Terminus entwickelt. ${ }^{77}$ Anhand des Begriffs Ausdruck oder Ausdrucksbewegung wurden mit der sich etablierenden Psychologie immer wieder unterschiedliche Vorstellungen von Physischem und Psychischem herangezogen, etwa die Idee einer äußerlichen Körperbewegung und eines inneren Erlebensaspekts des Gefühls. ${ }^{78}$ Ausdruck ist einerseits als Begriff bekannt, der die cartesianische Trennung von Innerlichkeit und Äußerlichkeit meint. ${ }^{79}$ Äußerlich wahrnehmbare Vorgänge, die an der Körperoberfläche stattfinden, werden als Anzeichen, Verbindungen, Entsprechungen oder Korrelate zu gefühlsbedingten Vorgängen im Inneren des Körpers und damit des subjektiven Erfahrens, sinnlichen Erlebens und der Propriozeption verstanden. ${ }^{80}$ Andererseits wurde der Begriff immer wieder verwendet, um diese Zweiseitenauffassung vom Menschen zu überwinden. ${ }^{81}$ Ausdruck wird so auch als holistischer Begriff verwendet, der gerade die Dichotomie von Physis und Psyche in Frage stellt. So eine Auffassung findet sich etwa bei Merleau-Ponty: „Und übrigens fasse ich Zorn oder Drohung nicht als hinter den Gesten verborgene psychische Fakten, ich sehe vielmehr den Zorn der Gebärde an: sie läßt nicht lediglich denken an Zorn,

77 Siehe Gadamer 1975 (1960), S. 475.

78 Siehe Gumbrecht 2000, S. 417.

79 Mit Darwins Buch The Expression of the Emotion in Man and Animals setzte 1872 neben der evolutionstheoretischen Seite, die Psychologisierung des Begriffs ein und löste in der Begriffsgeschichte endgültig die Phase der Ästhetik ab, siehe Gumbrecht 2000, S. 424.

80 Die Zweiseitenauffassung hat sich ganz unterschiedlich entwickelt. Mal ist von einer Analogie die Rede, dann von äußeren „Begleit-“ bzw-. „Korrelatvorgänge(n)“ (siehe Karl Bühler 1933, S. 10, S. 131). Wilhelm Wundt spricht von Ausdrucksbewegungen, „in denen sich die Qualität des Affektes spiegelt“, zitiert nach Karl Bühler 1933, S. 133. Zum Begriff des Ausdrucks im Sinne eines Cartesianischen Innen-Außen-Schemas bzw. zur Analogieschlusstheorie des Fremdverstehens siehe Norbert Meuter: Anthropologie des Ausdrucks. Die Expressivität des Menschen zwischen Natur und Kultur. München 2006, S. 66-72.

81 Helmuth Plessner hat in seiner Ausdruckstheorie dafür den vielleicht umfassendsten Vorschlag gemacht: Plessner 2003 (1945). Siehe auch Thomas Fuchs: Leib, Raum, Person. Entwurf einer phänomenologischen Anthropologie. Freiburg 2000, S. 193-252. 
sie ist der Zorn. “82 In gewissem Sinn kreisen alle Ausdruckstheorien um die Frage, wie sich ein lebendiger Geist, eine Empfindungsbewegung oder die Seele, mit dem Materiellen, Physischen, Sinnlichen verbinden.

2. Neben der psychophysischen Dimension des Ausdrucks lässt sich in einer zweiten Linie der Gegensatz von Intra- vs. Intersubjektivität beschreiben. ${ }^{83}$ Hans-Georg Gadamer skizziert die ästhetische Theorie des achtzehnten Jahrhunderts, in der die Subjektivierung des Ausdrucksbegriffs noch nicht stattgefunden habe; so meine diese nicht, „daß man sich selbst in der Musik ausdrückt, sondern daß die Musik etwas ausdrückt, nämlich Affekte [.. .] Ausdruck ist nicht primär als Ausdruck der eigenen Empfindungen zu verstehen, sondern als Ausdruck, der Empfindungen erregt. “84 Einmal gehen Ansätze von einem Innen-Außen-Korrelat des menschlichen Ausdrucksvermögens aus, dabei ist nur der Mensch allein von Interesse. ${ }^{85}$ Oder aber Expressivität wird gerade als Schnittstelle zwischen Körpern betrachtet: Im Ausdruck teilen sich Menschen einander mit, veranstalten sinnliche Kundgaben von Gefühlen, stecken einander affektiv an. ${ }^{86}$

82 Maurice Merleau-Ponty: Phänomenologie der Wahrnehmung (1945). Berlin 1974, S. 219. Darin insbesondere das Kapitel „Der Leib als Ausdruck und die Sprache“.

83 Die Verwobenheit bzw. Abgrenzung von Mensch und Umwelt ist stets Gegenstand der Ausdruckstheorie gewesen, siehe Erik Porath und Tobias Robert Klein: Zwischen Kinästhetik und Kommunikation. Ausdruck als Grenzphänomen in Theorie und Praxis von Wissenschaften und Künsten seit dem neunzehnten Jahrhundert. In: dies. (Hg.): Kinästhetik und Kommunikation. Ränder und Interferenzen des Ausdrucks. Berlin 2013, S. 7-42, hier: S. 18-19. Auch die Emotionspsychologie legt - etwa in Klaus R. Scherers Modell der Push- und Pull-Faktoren beim menschlichen Ausdruck beide Ausrichtungen an. Klaus R. Scherer: Wir alle spielen Affekttheater. Zur Darstellung von Emotionen im Alltag, in der Politik und auf der Bühne. In: Clemens Risi und Jens Roselt (Hg.): Koordinaten der Leidenschaft. Kulturelle Aufführungen von Gefühlen. Berlin 2009, S. 167-178.

84 Siehe Gadamer 1975 (1960), S. 475-476.

85 Im neunzehnten Jahrhundert sind das z.B. die Mediziner Charles Bell, Theodor Piderit, Guillaume Duchenne de Boulogne und Louis Gratiolet oder der Evolutionsforscher Charles Darwin, siehe Bühler 1933, S. 1-14. Die aktuellen Emotionstheorien zum Ausdruck in der Nachfolge von Darwin, also z.B. Ekman fokussieren den erkennbaren Ausdruck von Emotionen als intrasubjektives Phänomen. Vgl. Norbert Meuter: Die Universalität des Ausdrucks. Zur empirischen Grundlage eines anthropologischen Phänomens. In: Erik Porath und Tobias Robert Klein (Hg.): Kinästhetik und Kommunikation. Ränder und Interferenzen des Ausdrucks. Berlin 2013, S. 53-74.

86 Wundt legte dafür den Grundstein, „,indem er die Ausdrucksbewegung als intersubjektive Mitteilungsform und mithin als soziale und kommunikative Praxis definierte“, Löffler 2004, S. 175. Plessner und Flach perspektivieren Ausdrucksbewegung ebenfalls als intersubjektives bzw. interaffektives Phänomen, siehe Helmuth Plessner: Die Deutung des mimischen Ausdrucks. Ein Beitrag 
3. Eine dritte Linie stellt die Verbindung oder Abgrenzung von Ausdruck und Sprache bzw. zeichenhafter Mitteilung in den Mittelpunkt. ${ }^{87}$ Immer wieder wurde diskutiert, ob „Gebärden zu einer ,Sprache‘ fortgebildet werden können“. ${ }^{88}$ Im achtzehnten Jahrhundert haben Ästhetik- und Theatertheorien den Ausdruck im Spannungsfeld zwischen ,natürlichen' und ,künstlichen“ Zeichen verortet. ${ }^{89}$ Hinzu tritt ein weiterer Aspekt, wobei Repräsentation und Ausdruck einander gegenübergestellt und dabei darstellerische, mimetische Verfahren von solchen der Expression abgegrenzt werden. ${ }^{90}$ Verschiedene Zugänge, z.B. Wilhelm Wundt, Ernst Cassirer und Karl Bühler teilen die Vorstellung, dass Grundformen symbolischer Aktivität in einem Zusammenhang mit Expressivität stehen. Dies lässt sich auch mit der Idee einer konventionalisierten bzw. zeichenhaft gewordenen Geste zusammenfassen. Andererseits haben psychologische Forschungen gerade die Abgrenzung von

zur Lehre vom Bewußtsein des anderen Ichs (1925). In: ders.: Gesammelte Schriften in zehn Bänden. Bd. 7: Ausdruck und menschliche Natur, hg. von Günter Dux, Odo Marquard und Elisabeth Ströker. Frankfurt a. M. 2003, S. 67-130; Auguste Flach: Die Psychologie der Ausdrucksbewegung. Wien 1928. Eine neuere Position aus der Embodiment-Theorie ist z.B. Shaun Gallagher: How the Body Shapes the Mind. Oxford 2005, S. 107-130. Die Interaffektivität über Gesten und andere Ausdrucksphänomene ist auch von Tomasello evolutionswissenschaftlich entwickelt worden. Er nennt dies „Gefühle teilen“ als menschliche Kooperationsform. Michael Tomasello: Die Ursprünge der menschlichen Kommunikation. Frankfurt a. M. 2009, z.B. S. 152-158.

87 Gadamer 1975 (1960), S. 475.

88 Karl Bühler 1933, S. 128; vgl. Christoph Wulf: Geste. In: ders. (Hg.): Vom Menschen. Handbuch historische Anthropologie. Weinheim/Basel 1997, S. 516-524, hier: S. 517. Damit ist auch periphär die Idee der Pathosformeln nach Aby Warburg als „Urworte der Gebärdensprache“ angesprochen, siehe John Michael Krois: Die Universalität der Pathosformeln. Der Leib als Symbolmedium. In: Hans Belting, Dietmar Kamper und Martin Schulz (Hg.): Quel corps? Eine Frage der Repräsentation. München 2002, S. 295-307, hier: S. 295.

89 Siehe Jens Roselt: Seelen mit Methode. Einführung. In: ders. (Hg.): Seelen mit Methode. Schauspieltheorien vom Barock- bis zum postdramatischen Theater. Berlin 2005, S. 8-73, hier: S. 39-41. Die klassifizierenden Zeichnungen der Gesichtsausdrücke von Charles Le Brun, des Hofmalers von Ludwig dem XIV., setzen 1702 eine Diskussionen zum natürlichen und künstlichen Zeichen von Affekt und Ausdruck in Gang, siehe Rüdiger Campe: Affekt und Ausdruck. Zur Umwandlung der literarischen Rede im siebzehnten und achzehnten Jahrhundert. Tübingen 1990, S. 164; Der Gegensatz von „gestischer Rhetorik und unmittelbarem mimischen 'Ausdruck' “ - so Hermann Kappelhoff - war der Idee des Schauspiels in Ästhetik- und Theatertheorien der Empfindsamkeit eingeschrieben. Kappelhoff 2004a, S. 64.

90 Nelson Goodman untersucht den Unterschied zwischen „Repräsentation“ und „Ausdruck“ in seinem kunsttheoretischen Zugang, wobei er für den Ausdruck von Gefühlen Eigenschaften metaphorischer Figuration proklamiert, der Ausdruck sei „ein Modus der Symbolisierung“, siehe Nelson Goodman: Sprachen der Kunst. Entwurf einer Symboltheorie (1968). Frankfurt a. M. 1995, S. 59 . 
Expressivität und Sprache, unter dem Stichwort nonverbaler Kommunikation, betont. ${ }^{91}$

4. Eine vierte Linie lässt sich mit dem Bezug der Expressivität zu den Künsten und Medien fassen. In der Begriffsgeschichte ist Ausdruck von Anfang an im Zusammenhang mit Ästhetik, Malerei, Schauspiel und anderen Medien formuliert worden. ${ }^{92}$ Gerade die zeitbasierten Künste, wie Musik, Schauspiel, Theater, Tanz oder Film wurden als expressive Formen reflektiert. ${ }^{93}$ Einige setzen dabei künstlerische Ausdrucksformen in Analogie zu zwischenmenschlichen Formen des Verhaltens. ${ }^{94}$ Der Stellenwert von Kunstwerken und Medien und ihre Fähigkeit, Wahrnehmungen, Ausdrucksformen und Denkoperationen $\mathrm{zu}$ erschaffen, kann gar nicht hoch genug eingeschätzt werden. ${ }^{95}$ Man kann so weit gehen, zu sagen, dass die Historizität von Gefühlen ohne die kulturellen Praktiken medialer und künstlerischer Expressivität kaum untersuchbar ist. ${ }^{96}$

91 Vgl. Jens Asendorpf und Harald G. Wallbott: Contributions of the German „Expression Psychology“ to Nonverbal Communication Research. In: Journal of Nonverbal Behavior 7 (1982), H. 1, S. 20-32.

92 Gotthold Ephraim Lessing zeigt im Bereich der Ästhetik mit dem Laokoon nicht eine, wie lange Zeit behauptet, rationalistische Sicht auf Kunst, sondern den Zusammenhang von Empfindsamkeit und Kunst, die unterschiedlichen Sinnes- und Wahrnehmungsformen der Künste, Vgl. Kappelhoff: 2004a, S. 92-97; vgl. Petra Löffler 2004, S. 23. Vgl. Luigi Russo: Logiche dell'espressione. Palermo 2009. www.unipa.it/ estetica/download/Espressione.pdf (letzter Zugriff: 04.02.2020).

93 Für den Bereich der Kunst- und Wahrnehmungstheorie siehe Rudolf Arnheim: Kunst und Sehen. Eine Psychologie des schöpferischen Auges (1954). Berlin 2000, S. 447-466; Rudolf Arnheim: Towards a Psychology of Art. Collected Essays. London 1967, S. 51-73, S. 302-319; Konrad Fiedler: Die Ausdrucksbewegung der Wahrnehmung. In: Lambert Wiesing (Hg.): Philosophie der Wahrnehmung: Modelle und Reflexionen. Frankfurt a. M. 2002, S. 170-188; vgl. Erik Porath: Situation und Bewegung. Die Kunst des Ausdrucks bei Fiedler und Freud. In: Erik Porath und Tobias Robert Klein (Hg.): Kinästhetik und Kommunikation. Ränder und Interferenzen des Ausdrucks. Berlin 2013, S. 241-262.

94 Bei den musiktheoretischen Zugängen sind als Theoretiker zu Ausdruck und Gefühlen/ Emotionen folgende Autoren zu nennen: Peter Kivy: The Corded Shell. Reflections on Musical Expression. Princeton 1980; Stephen Davies: Musical Meaning and Expression. Ithaca 1994; Domenica Lentini: Espressività ed emozione nell'esperienza musicale. Orientamento teorici nel dibattito analitico. Palermo 2010.

95 John Dewey fasst Ausdruck als zusammengehörig mit einer „Gefühlsentladung“ (S. 76) aber auch als bedeutungsgenerierenden Akt, der eine gewisse Gestaltetheit von Körperbewegungen oder eben künstlerischen Formungen bereits aufweist. Er sieht Medien als quasi äquivalent mit ,Ausdrucksakten“ an (S. 78). John Dewey: Kunst als Erfahrung. Frankfurt a. M. 1980. 96 Siehe Kappelhoff: 2004a, S. 19-20. 
5. Immer wieder wurde der Ausdruck von Gefühlen auch in Bezug zu Universalität bzw. Kulturspezifik diskutiert, etwa im Feld von Psychologie und Anthropologie. ${ }^{97}$ In eine solche Debatte fließen Fragen nach der künstlerisch-kulturellen Formung von Emotionen, der Aspekt von Sprache und Ausdruck oder die kulturspezifische Auffassung von Gefühlen ein. ${ }^{98}$ Zudem werden damit Grundfragen der Disziplinen von Ethnologie und Anthropologie in Bezug auf Ausdrucksverhalten und Emotionscodes spezifiziert. ${ }^{99}$

6. Eine weitere Linie betont die zeitlich statischen gegenüber den dynamischen Ausdrucksformen, womit letztlich auch eine Auffassung von fixen, distinkten oder fluiden Affekten, Emotionen und Gefühlen einhergeht. Die historische Debatte zwischen Johann Caspar Lavater und Georg Christoph Lichtenberg aus dem achzehnten Jahrhundert, die den Ausgang hatte, dass das bewegliche Ausdrucksverhalten, die Pathognomik und nicht mehr die starren Merkmale menschlichen Aussehens (Physiognomik) zentral behandelt wurden, gilt als Anfang einer neuzeitlichen Betrachtung des Menschen und damit der modernen Anthropologie. ${ }^{100}$ Auch später wiederholte sich diese Bewegung, wenn z.B. im ausgehenden neunzehnten Jahrhundert in Duchenne de Boulognes Lexikon der Affekte ${ }^{101}$ durch die fotografischen Verfahren der statische Gesichtsausdruck zum Bild für Gefühle wurde, andererseits immer wieder Positionen sich gegen solche statischen Auffassungen verwehrten. ${ }^{102}$ Der aktuelle Ansatz $\mathrm{zu}$ Emotionsausdruck und Basisemotionen in der Psychologie lässt sich in diese Tradition einfassen.

Die beschriebenen Linien sind nur einige sich überlagernde Perspektiven im Feld der Ausdrucktheorie, welches freilich viel umfassender ist. Aspekte einzelner Linien, die auch für diese Arbeit zentral sind, greife ich im Folgenden heraus. Erstens fokussiere ich die Linie der ,medialen und künstlerischen Expressivität‘, welche von entscheidender Bedeutung für die Frage nach den

97 Für einen Überblick über die Debatte siehe Meuter 2013.

98 Vgl. Porath und Klein 2013, S. 14.

99 Die Frage, ob man überhaupt allgemein vom menschlichen Ausdruck sprechen kann bzw. nicht eher die je sich ausformenden Differenzierungen von kulturell geprägten Ausdrucksformen benennen sollte, diskutiert Meuter 2006, wobei er u.a. auf die Positionen von Wilhelm Dilthey, Helmuth Plessner, Ernst Cassirer und Max Scheler eingeht.

100 Vgl. Asendorpf und Wallbott 1982, S. 140; vgl. Löffler 2004, S. 42; oder umfassender siehe Bühler 1933.

101 Vgl. Löffler 2004, S. 139-140.

102 Wie die geistesgeschichtlichen Auffassungen zum menschlichen Ausdruck (statisch vs. dynamisch) mit den Aufnahmeverfahren von Fotografie und Film (statisch bzw. dynamisch) zusammenhängen, hat Petra Löffler in ihrer Studie Affektbilder herausgearbeitet. Löffler 2004. 
Tempi der Bewegung in filmischen Bildern ist. Zweitens gehe ich auf die Linie von ,Ausdruck und Gefühl' ein, welche die Grundlage für die Begriffsdiskussion zu Affekt und Gefühl darstellt. Drittens werde ich auf den Zusammenhang von ,Sprachlichkeit, Zeichenhaftigkeit und Ausdruck' hinweisen, wobei die Frage der Einbettung des Schauspiels in die Filmästhetik perspektiviert wird und welche mit dem Zugang zur Metaphorizität und filmischem Denken verbunden wird. Alle drei Linien werden an dieser Stelle allgemein ausdruckstheoretisch entworfen und im Unterkapitel 2.4. zur filmischen Expressivität weitergeführt.

\section{Bewegung, Tempo, Rhythmus -Künstlerische, mediale und ästhetische Ausdrucksformen}

$\mathrm{Zu}$ verschiedenen Zeiten haben die Künste und Medien jeweils eigene Konzepte zu Wirkungsästhetiken, Rhetoriken und Affektpoetiken entwickelt. ${ }^{103}$ Besonders Theoretiker der zeitbasierten Künste haben sich mit dem Zusammenhang von Gefühl und Tempo beschäftigt. Bereits René Descartes fasste die der Musiktheorie bekannten Zusammenhänge von affektiver Gestimmtheit und Zeitlichkeit zusammen:

Was aber die verschiedenen Gemütszustände betrifft, welche die Musik durch die verschiedenen Zeitmaße in uns erregen, sage ich im allgemeinen, daß ein langsameres Tempo in uns träge Empfindungen hervorruft, wie Mattigkeit, Traurigkeit, Furcht, Hochmut; das schnellere hingegen lebhaftere wie Freude usw. ${ }^{104}$

Eine ähnliche Vorstellung, dass unterschiedliche musikalische Tempi den verschiedenen Empfindungen entsprächen, beschreibt der Philosoph Oets K. Bouwsma, wenn er die Ausdrucksqualitäten, die in musikalischer Bewegung wahrnehmbar werden, in Kongruenz mit expressiv-menschlicher Bewegung betrachtet:

103 John Dewey führt etwa pointiert aus, dass Kunstwerke nie universelle Gefühle hervorbringen, sondern Gefühle stets zeitlich zu situieren sind: Dabei macht er eine Unterscheidung zwischen Ausdrucksakt und Ausdrucksobjekt. Er zeigt auf, dass Gefühle in der Kunsterfahrung wie im alltäglichen Leben nicht nach Überbegriffen klassifizierbar sind („Furcht, Haß, Liebe“, S. 82), sondern dass sie sich immer in einer konkreten Situation bzw. in einem spezifischen Kontext ereignen, den es zu berücksichtigen gilt. (S. 82). Er spricht von einer „Neuschaffung des Erfahrungsmaterials im Ausdrucksakt“ (S. 97), welches dann in der „neuen Form“ (S. 104) des Ausdrucksobjekts „durch die Verschmelzung mit einem Gefühl, das der inneren Sicht des ästhetischen Materials angehört, erneuert und wiedergeboren“ wird (S. 104). Ein solches ganzheitliches Gefühl ist das des Betrachters eines Kunstwerkes. Dewey 1980, S. 72-124.

104 Renatus Descartes: Leitfaden der Musik (1656). Herausgegeben, ins Deutsche übertragen und mit Anmerkungen versehen von Johannes Brockt. Darmstadt 1978, S. 9. 
Sad music has some of the characteristics of people who are sad. It will be slow, not tripping: it will be low, not tinkling. People who are sad move more slowly, and when they speak, they speak softly and low. ${ }^{105}$

Die Bewegungseigenschaften musikalischer und körperlicher Ausdrucksformen sind in dieser Auffassung nicht objektiv-messbare Geschwindigkeiten wie schnell und langsam. Bouwsmas Analogie basiert auf der Annahme, dass sich im menschlichen Verhalten Bewegungsdauer, -intensität, Spannkraft und Tempo der ausgeführten körperlichen Aktionen mit den Erlebensformen zu ändern beginnen. Ähnliches stellt auch Ludwig Wittgenstein fest, wenn er über die musikalischen Tempi und einer damit zusammenhängenden Modulation von Wahrnehmung spricht:

Ich glaube, es ist eine wichtige und merkwürdige Tatsache, daß ein musikalisches Thema, wenn es in (sehr) verschiedenen Tempi gespielt wird, seinen Charakter ändert. Übergang von der Quantität zur Qualität. ${ }^{106}$

Das Tempo wird hier mit der Qualität, dem „Charakter“, einer spürbaren Eigenschaft von Bewegung in Zusammenhang gebracht. Damit ist die Art und Weise angesprochen, wie diese sich über einen bestimmten Zeitraum erstreckt, wie sie als Erlebensqualität zum Ausdruck kommt. Eine ähnliche Kongruenz stellen die Theoretiker musikalischer Expressivität fest: Stephen Davies und Peter Kivy gehen von einer Analogie von Musik und menschlichem Bewegungsverhalten aus. Mit dem Begriff des Ausdrucks meinen Kivy und Davies nicht den Gefühlsausdruck des Künstlers in einem Werk, vielmehr trage der musikalische Ausdruck emotive Eigenschaften in sich. In der Musik manifestierten sich expressiv dynamische Formen, die an bewegliche Erregungsmuster des Menschen wie z.B. Gestik, Stimmverlauf oder Mimik erinnerten. ${ }^{107}$

Neben dem Tempo sind in der Musik auch Veränderungen wie Tonhöhe, instrumentale Klangfarbe, Rhythmus bzw. andere Gestaltungsmittel zu nennen, welche für ein ästhetisches Empfinden entscheidend sind. In der Musiktheorie werden Tempo und Rhythmus als sich bedingende Faktoren beschrieben:

105 Oets K. Bouwsma: The Expression Theory of Art. In: Morris Philipson und Paul J. Gudel (Hg.): Aesthetics today (1954). New York 1980, S. 260-265, hier S. 265.

106 Ludwig Wittgenstein: Bemerkungen über die Farben. Über Gewissheit. Zettel. Vermischte Bemerkungen (Werkausgabe Band 8). Frankfurt a. M. 1984b, S. 554.

107 Vgl. Davies 1994; Stephen Davies: Philosophical Perspectives on Music's Expressiveness. In: Patrik N. Juslin und John A. Sloboda (Hg.): Music and Emotion. Theory and Research. Oxford 2001, S. 23-44. Damit schließt Davies an Kivys Idee des „anthropomorphen Hörens“ in der Musik an, vgl. Domenica Lentini 2010, S. 57-83; Kivy 1980. 
Die ausdruckshafte Qualität von Rhythmen ändert sich beispielsweise mit der Geschwindigkeit von deren Ausführung und nur in einem bestimmten Geschwindigkeitsbereich werden Rhythmen in ihrer besonderen Qualität aufgefaßt. Andererseits hängt das Tempoempfinden unter anderem von der rhythmischen Struktur eines Musikstückes ab. ${ }^{108}$

Rhythmus und Tempo sind voneinander abhängige Prinzipien. Das Rhythmusempfinden ist eng mit der Wahrnehmung von Stabilität verbunden. ${ }^{109}$ So weist der Körper ein Spektrum unterschiedlicher verkörperter Formen von Rhythmizität auf: Atmen, Gehen, Zwinkern, Schlafen und Wachen. ${ }^{110}$ Rhythmus und mit ihm das jeweils metrische Schema werden zum Begriff für eine fluide Form des Wiederkehrens. ${ }^{111}$ Das Tempo hingegen überschreitet die unterschiedlichen rhythmischen Einheiten, Schläge und Zäsuren und verleiht dem wiederkehrenden Fluss eine qualitative Prägung. ${ }^{112}$ Unter Rhythmus mag man musiktheoretisch die „Gliederung einer Zeitstrecke durch Ereignisse“"113 verstehen, Tempo sei hingegen „die Geschwindigkeit der Abfolge dieser Ereignisse“. ${ }^{114}$

Neben dieser eher technischen Beschreibung lässt sich das Tempo auch aus ästhetischer Sicht beschreiben: „das Tempo sei ,keine Geschwindigkeit, sondern eine Bewegungsqualität', die mit der ,Kadenzierung unserer Lebensenergie‘ verknüpft ist.“115 Oder auch in der Musikästhetik bei Roger Scruton, der den Rhythmus in Analogie zur Melodie auf seine Virtualität bezieht. Die sich über die Zeit in der Wahrnehmung zusammensetzenden Schläge werden als regelmäßiger Puls

108 Zitat von de la Motte-Haber nach Wolfgang Auhagen: Rhythmus und Tempoempfinden. In: Helga de la Motte-Haber und Günther Rötter (Hg.): Musikpsychologie. Laaber 2005 (Handbuch der systematischen Musikwissenschaft. Bd. 3), S. 231-249, hier: S. 231.

109 Auhagen 2005, S. 230-231.

110 Auhagen 2005, S. 230.

111 Brandstetter et al. beschreiben, dass rhythmos in der Antike als „Form des Veränderlichen" verstanden wurde, im Unterschied zum schema, das keinerlei Dynamik aufweise. Siehe Gabriele Brandstetter, Bettina Brandl-Risi und Kai van Eikels: Übertragungen. Eine Einleitung. In: Gabriele Brandstetter und Bettina Brandl-Risi (Hg.): Schwarm(E)Motion. Bewegung zwischen Affekt und Masse. Freiburg/Berlin/Wien 2007 (Rombach-Wissenschaften Reihe Scenae. Bd. 3), S. 7-64, hier: S. 22-23.

112 Zwar wird das Tempo überwiegend auf den Takt und die Metronomschläge bezogen, ist also mit der Dauer der Notenwerte verbunden. Allerdings sind Tempoveränderungen und Erfahrungsqualitäten komplexer zu bestimmen als allein über eine messbare Geschwindigkeit. Siehe Hans Heinrich Eggebrecht (Hg.): Riemann Musiklexikon. Bd. 3: Sachteil. Mainz 1967, S. 944-945.

113 Auhagen 2005, S. 231.

114 Auhagen 2005, S. 231.

115 Zitat von Ernest Ansermet, nach Klaus Ernst Behne: Tempo. In: Friedrich Blume und Ludwig Finscher (Hg.): Die Musik in Geschichte und Gegenwart. Allgemeine Enzyklopädie der Musik. Bd. 9: Sy-Z. Kassel 1998, S. 458-463. 
verstanden, den wir aus der inneren Wahrnehmung unserer eigenen Vitalität kennen, sich in Aufregung beschleunigend oder in Ruhephasen gemächlich werdend. ${ }^{116}$ Freilich kann man dies auf ganz unterschiedliche Zeitspannen beziehen und damit in unterschiedlichen Zeitsegmenten beobachten. ${ }^{117}$ Zentral ist an dieser Stelle zu erwähnen, dass die Theoretiker wie Kivy und Davies nicht von einer objektiv-technizistischen Auffassung von Zeit, sondern von temporalen Eigenschaften als Wahrnehmungs- und Erlebensformen ausgehen. ${ }^{118}$ Diesen Überlegungen liegt die Auffassung zugrunde, dass äußere Bewegungsformen musikalischer Natur kongruent seien zu inneren Formen des Bewegtseins, des Berührtseins.

Neben den Konzepten zum Ausdruck in der Kunst- und Musiktheorie, ist die Auffassung einer Kongruenz von affektiven und expressiven Dynamiken im menschlichen Ausdrucksverhalten immer wieder beschrieben worden. Hierzu möchte ich eine ältere Position aus der Gestenforschung herausgreifen.

Auguste Flach, eine Schülerin von Karl Bühler, hat die Zeitlichkeit gestischer Ausdrucksbewegungen und die Verlaufsformen von Affektivität in den Mittelpunkt ihrer Forschung gestellt. In ihrer bewegungspsychologischen Studie von 1928 fragt sie danach, wie man den „Ausdruckssinn einer Gebärde“ beschreiben kann. ${ }^{119}$ Flach geht davon aus, dass der seelisch-affektive Verlauf und der dynamische Verlauf körperlicher Ausdrucksbewegungen eine feste Korrelation besitzen. ${ }^{120}$ Die Form oder räumliche Anordnung einer Geste entscheide kaum darüber, welchen Sinn sie ausbilde und wie man sie folglich verstehe. Sie nennt das Beispiel der Bittbewegungen: Das „Symbol allein, die Geste der erhobenen Hand, mit dem Handteller nach oben ist vieldeutig. Eindeutig und überzeugend wird sie erst durch die Dynamik der Bewegung“. ${ }^{121}$ Die Bewegungsqualität zeige die affektive Ausrichtung an. Während das Fordern mit einer heftigen und plötzlichen Qualität das Gegenüber sehr direkt adressiert, entfalten sich

116 Roger Scruton: The Aesthetics of Music. New York 1997, S. 93.

117 Zudem lassen sich größere und kleinere Einheiten unterscheiden: So benennt der musiktheoretische Begriff Zeitmaß das Tempo als grundsätzliche Bewegung, während das Taktmaß kleinere Bewegungen erfasst. Behne 1998, S. 451.

118 Davies 2001, S. 35.

119 Flach 1928, S. 26. Der Begriff der Gebärde wird hier synonym zur Geste verwendet. (Hervorhebungen durch Flach, die über die ganze Schrift sehr häufig eingesetzt werden, sind in den folgenden Zitaten zugunsten einer besseren Lesbarkeit entfernt worden).

120 Flach 1928, S. 60-61.

121 Flach 1928, S. 27; Die „Palm up open hand“ ist zu einem wichtigen Gegenstand der aktuellen Gestenforschung geworden, siehe Cornelia Müller: Forms and Uses of the Palm Up Open Hand. A Case of a Gesture Family? In: Cornelia Müller und Roland Posner (Hg.): The Semantics and Pragmatics of Everyday Gestures. Proceedings of the Berlin Conference April 1998. Berlin 2004, S. 234-256. 
die zögernd und zweifelnd bittenden Gesten in ihrem Verlauf stockend bzw. dosiert, wobei auf das Gegenüber indirekt Bezug genommen wird. ${ }^{122}$

Die Dynamik der gestischen Bewegung versteht Flach als Verschränkung von körperlichen und seelischen Empfindungen, die sie über den Anspannungsgrad $^{123}$ und die Strebungsbewegung zum Gegenüber fasst. ${ }^{124}$ Zwei Aspekte von Bewegung sind in ihrem Konzept zentral:

1. Die Gerichtetheit der Bewegung, zeigt die Art und Weise, wie die Körperbewegung oder Geste in ihrer räumlichen Konfiguration situativ auf das Gegenüber ausgerichtet ist, ob indirekt-zurückhaltend (etwa in einer schlangenförmigen Bewegungskurve), oder direkt nach vorne (in einer zielgeraden Linie auf das Gegenüber zu). Dies fasst sie als „intentionales Moment ${ }^{\text {“125 }}$, das in der Bewegung aufscheint. ${ }^{126}$

2. Der zweite Aspekt meint die affektive Einstellung; sie wird in der Geste über die Bewegungsqualität anschaulich: Das forsche, mutige Nachvornepreschen ist durch die Tempoform des Schnellen und Plötzlichen charakterisierbar. Zögerlichkeit und Vorsicht sind hingegen durch stockende und innehaltende Bewegungsphasen geprägt. ${ }^{127}$

Sie setzt die Gerichtetheit und die Bewegungsqualität als zwei von einander abhängige Prinzipien für den Zusammenhang von Bewegungsintention und affektiver Haltung voraus:

Da ist zunächst eine bestimmte Intention, ein Sich-in-Beziehung-setzen zu einem anderen oder einem Gegenstand; dann die Art dieses Sich-in Beziehung-setzens, die affektive Haltung. Daran schließt sich ein Erleben von Spannungen oder Entspannungen mit einem eigenartigen Ablauf je nach der Art der affektiven Haltung. ${ }^{128}$

Flach hat damit wesentliche Grundelemente von Ausdruckbewegung herausgearbeitet. Sie schreibt besonders der Bewegungsentwicklung eine besondere Rolle zu:

122 Flach 1928, S. 29.

123 Spannung versteht sie als „Spannungsänderung“ oder Wandel des Kraftaufwandes in der Bewegung: Flach 1928, S. 74.

124 Flach 1928, S. 27.

125 Flach 1928, S. 32.

126 Dies wird von aktuellen Gestenforschungen gestützt. So schreibt etwa Adam Kendon: „The intentionality of an action is something that is directly perceived. That is, it is the quality of an action as intentional (not the specific intention, necessarily) that is directly perceived.“ Adam Kendon: Gesture. Visible Action as Utterance. Cambridge 2004, S. 15.

127 Flach 1928, S. 82.

128 Flach 1928, S. 93. 
Was am Bewegungserlebnis bei der Ausdrucksbewegung wesentlich ist, liegt nicht schon in der Anspannung oder Entspannung als solcher, sondern in der Eigenart des Verlaufs. Jeder solche Spannungsverlauf hat eine bestimmte Entwicklung - eine Gestalt. Das ist es, was die Ausdrucksbewegung charakterisiert und von jeder anderen Bewegung wesentlich unterscheidet. ${ }^{129}$

Mit dieser Passage betont sie, dass erst im Gesamtverlauf - der Gestalt - verschiedener Phasen, ${ }^{130}$ die per se mehrdeutigen Körperhaltungen zu eindeutigen Gefühlsphänomenen werden. ${ }^{131}$ Die einfachste Form des Spannungsverlaufs ist dabei durch die Phasen Spannungszunahme, Höhepunkt, Spannungsabnahme beschrieben. Aber es gibt auch Ausdrucksbewegungen, die mit dem Höhepunkt enden. ${ }^{132}$ Die Vorstellung von diskreten (immer gleichen) Emotionsschemata ist Flach fremd: Erst in der zeitlichen Komposition verschiedener Bewegungsphasen tritt die wahrnehmbare Affektivität und damit der Sinn der Geste hervor. ${ }^{133}$ Erst durch die Wechsel verschiedener Bewegungsqualitäten im Verlauf des Gestischen zeigt sich der spezifische Charakter der gefühlsmäßigen Ausprägung. Hinzu kommen weitere sinnliche Qualitäten, die mit dem intentionalen und affektiven Verlauf entstehen, die eine „charakteristische Färbung“ z.B. des „Niederdrückenden, des Beschwertseins, des Gebundenseins“ aufweisen. ${ }^{134}$ Für den Ausdruck im menschlichen Verhalten, ist demnach mehr notwendig als Tempo- und Zeitgestaltungen. Die Art und Weise, ob eine Geste leicht oder schwer erscheint, ob sie eine weiche, runde oder harte eckige Form hat, ob sie in ihrem Fluss unterbrochen ist oder gleichmäBig dahingleitet, in welche Richtung und wie sie sich ausdehnt, ob eng-schlängelnd oder weit und offen sich ausbreitend, und schließlich, worauf sie ausgerichtet ist, das situative Geschehen; alle diese Dimensionen spielen zusammen und verbinden sich in der expressiven Bewegungsfigur.

An diese Position lässt sich Rudolf von Labans und Irmgard Bartenieffs Begriff des efforts (Antrieb) aus der Tanztheorie anschließen: Dieser meint einen inneren Bewegungsantrieb, eine gefühlsmäßige Energie, der sich in der Verlaufsform äußerer und sichtbarer Körperbewegung in Form von dynamischen Qualitäten als kinetische Energie offenbart. ${ }^{135}$ Peggy Hackney definiert den Begriff so:

129 Flach 1928, S. 93-94.

130 Flach 1928, S. 36-37.

131 Flach 1928, S. 33.

132 Flach 1928, S. 80.

133 Flach 1928, S. 38.

134 Flach 1928, S. 78.

135 Rudolf von Laban: Choreutik. Grundlagen der Raumharmonielehre des Tanzes. Wilhelmshaven 1991, S. 40; Irmgard Bartenieff und Dori Lewis: Body Movement. Coping with the Environment. New York 1980, S. 51-68. 
,What is the dynamic quality of the movement - the feeling-tone, the texture?' Effort reflects the mover's attitude toward investing energy in four basic factors: Flow, Weight, Time, and Space. These inner attitudes need not necessarily be conscious to be operative. Effort change is generally associated with change of mood or emotion and, hence, is an inroad to expressivity. ${ }^{136}$

Der Begriff umfasst, wie verschiedene Ausdrucksqualitäten sich verbinden und wie sie affine Beziehungen mit anderen Wahrnehmungseigenschaften eingehen, so z.B. das langsame, aber kraftvolle, stete Gleiten, das mit der Wahrnehmung von Gewicht einhergehen kann.

Den Zusammenhang von Kinästhetik und Gefühlsphänomenen untersucht auch Maxine Sheets-Johnstone, die als Phänomenologin sowie Tanz- und Bewegungstheoretikerin eine Verbindung von Bewegung und affektiver Verkörperung entwirft. ${ }^{137}$ Für Sheets-Johnstone sind es gerade die dynamischen Qualitäten, welche das kinästhetische Empfinden prägen. Sie beschreibt die Variationen körperlicher Bewegung. Dazu stellt sie fest:

What is invariantly there is in each case an overall quality. Whatever the variation, the movement has a distinctive felt qualitative character coincident with that variation, a felt physiognomic aspect which is in fact a constellation of qualitative aspects. ${ }^{138}$

Sie beschreibt diese Bewegungsqualitäten als verkörperte, kinästhetische Prozesse des leiblichen Spürens und Fühlens. Dabei werden, ganz ähnlich wie bei Bartenieff, zwischen verschiedenen Dimensionen, mit denen man die Bewegung perspektivieren kann, unterschieden. Die räumliche Ausdehnung z.B. eines breiten, flächigen, die Flügel ausspannenden Vogels, ist stets mit einer bestimmten Richtung verbunden, so etwa, wenn er direkt und gerade fliegt oder in hohen Bögen und Kurven. Diese räumlichen Facetten des Fliegens sind jedoch ebenfalls zeitlich zu denken: Ist das im hohen Bogen Fliegen schnell, flink und leicht oder behäbig und gemächlich? Sheets-Johnstone definiert in ihrer Bewegungstheorie - ähnlich wie Irmgard Bartenieff und Rudolf von Laban - dass die jeweiligen Kompositionen von Bewegungsqualitäten komplexe Musterungen ausbilden, z.B. ein Explodieren, ein Sich-Zusammenballen oder eine fortlaufende Punktuierung. Solche dynamischen Muster sind aufs Engste an das anschließbar, was mit dem Begriff des

136 Peggy Hackney: Making Connections. Total Body Integration Through Bartenieff Fundamentals. New York 2002, S. 219.

137 Maxine Sheets-Johnstone: Getting to the Heart of Emotions and Consciousness. In: Paco Calvo und Antoni Gomila (Hg.): Handbook of Cognitive Science. An Embodied Epproach. Amsterdam/Boston/London 2008, S. 453-465.

138 Maxine Sheets-Johnstone: The Primacy of Movement. Amsterdam 2011, S. 122. 
Bewegungsbildes beschrieben wurde. ${ }^{139}$ Sheets-Johnstone bringt die dynamischen Muster und ihre Bewegungsqualitäten in Bezug zu verkörperter Affektivität; entsprechend der etymologischen Verwandtschaft von motio und emotio. Im Rekurs auf Daniel Sterns Vitalitätsaffekte und Colwyn Trevarthens Interaktionstheorie versteht sie Affektivität und Bewegung als dynamisch kongruent: ${ }^{140}$

[...] the affective quiverings, tensions, lightnesses, shudderings, pressures, constrictions, extensions, heavinesses, and so on, that one feels in a thoroughly corporal sense in anger, anticipation, compassion, worry, and shame, for example, are ongoing dynamic affective happenings. Hence, whatever the dynamic stirrings and informings, they are qualitatively distinct, which means they have a formally recognizable bodily-felt character. ${ }^{141}$

Affektivität fasst Sheets-Johnstone als etwas auf, das sich an Körpern in Bewegung ereignen kann. Obwohl sie den Begriff der Expressivität nicht verwendet, schließt ihre Verkörperungstheorie an die hier aufgeführten Ausdruckstheorien an. Ihre Beschreibung zielt darauf ab, die Gefühle oder Affekte gerade nicht unabhängig von der Bewegung zu klassifizieren. Vielmehr sind die Intensitäten, Dynamiken und Tempi, die man in einer Bewegung sieht oder spürt selbst das, was die Affektivität ausmacht: (,the affective quiverings [...] that one feels in [...] anger, anticipation [...]“ s.o.). In Rückgriff auf Daniel Stern geht sie davon aus, dass in körperlichen Bewegungen die dynamischen Qualitäten selbst als Eigenschaften des Affektiven aufzufassen sind.

In sum, affects, like movement, are whole-body spatio-temporal-energic phenomena; precisely as Stern indicates, they have distinct spatial contours, intensities, and temporalities. When we explode in anger, burst into song, begin to doubt, nurse a grudge, hesitate to speak out, continue to grieve, turn away in disgust, are seized by fear, and so on, it is experientially evident not only that emotions are manifestations of feelings but that emotions are distinctive in both a bodily-felt and bodily-observable sense and are therefore descriptively declinable. ${ }^{142}$

Ihre These ist, dass man Affektivität formal-bewegungsanalytisch am Körper nachvollziehen kann, dass sie sowohl von einem Körper gefühlt werden kann, dass sie aber auch in wahrnehmbaren Formen beobachtbar und spürbar ist, als sich wandelnde dynamische Kräfte. Dabei setzt sie den Akt der Äußerung und den Akt des Wahrnehmens über die Qualität in eins. ${ }^{143}$

139 Z.B. bei Plessner 2003 (1925), S. 78.

140 Sheets-Johnstone 2008, S. 455.

141 Sheets-Johnstone 2011, S. 456.

142 Sheets-Johnstone 2008, S. 461.

143 Wahrnehmungsobjekt und -subjekt verbinden sich über die Bewegungsqualität, so z.B. in der Akustik: „The activities that define perception, the ,activity of sound“ on the one hand and 
Die Tempi der Bewegung, wie ich sie in dieser Arbeit begreife, sind in diesem Sinn mit den Bewegungsqualitäten aber auch ihren größeren Kompositoriken als dynamische Muster angesprochen. Sie sind nicht auf eine äußerlichmessbare Geschwindigkeit reduzierbar; Bewegungswahrnehmung hängt vielmehr von dem situativen Kontext ab, in dem sie entsteht. Nun finden sich die Tempi in gestischen, mimischen oder ganzkörperlichen Aktionen, aber eben auch in Ereignissen, die von den Zeitkünsten hervorgebracht werden, durch Musikstücke, Filme, Theateraufführungen oder Performances etc.

Bisher war zwar von Affektivität bereits die Rede, doch der Schwerpunkt verband sich vor allem mit den dynamischen Aspekten von Bewegung. Im Folgenden werde ich Zugänge zu Expressivität und Verkörperung aufeinander beziehen, um die Gefühlstermini zu bestimmen.

\section{Gefühl: Dynamische Interaffektivität}

Die Interaffektivität, wofür in der Ausdruckstheorie der Grundstein gelegt worden ist, ist unter anderem von der jüngeren Embodiment-Forschung in ähnlicher Weise perspektiviert worden. Mit seinem Rückgriff auf Merleau-Pontys Phänomenologie überwindet der Philosoph Shaun Gallagher die Trennung von Körper und Geist auch für die Cognitive Sciences. Mit dem Begriff der Ausdrucksbewegung (expressive movement) zielt er auf einen kommunikativen, verhaltensbedingten und sinnlich-affektiven Bereich zwischen Subjekten:

The wrong way to think of expressive movement is to think of it as necessarily expressing something that is internal and already formed - a belief, or thought, or idea. [...] In the case of the neonate, we do not have to posit some prior internal cognition that the infant is attempting to express or externalize through imitation. The infant has seen something, a facial gesture, and it is expressing what it has seen by taking up the capacity it has for that expressive movement on its own face. ${ }^{144}$

Gesten, Gesichtsausdrücke und Stimmlichkeit verbinden die Individuen in ihrem gefühlten Zur-Welt-Sein. Merleau-Pontys Idee einer Sichtbarwerdung von Affekten und Gefühlen in Gebärden greift Gallagher auf:

the ,activity of hearing' on the other hand, for example, are motion-inducing activities.“ Sheets-Johnstone 2011, S. 92.

144 Gallagher 2005, S. 128. 
Affective and emotional states are not simply qualities of subjective experience; rather, they are given in expressive phenomena, i.e. they are expressed in bodily gestures and actions, and they thereby become visible to others. ${ }^{145}$

Den Vorgang der Affizierung versteht er als eine unmittelbare Verbindung von Leib und Umwelt. Im Zitat fasst er stärker die verhaltensbedingte Dimension, dass Menschen sich über expressive Phänomenen in ihrer Affektivität verbinden. Doch er betont auch die subjektiv-erlebte Seite des Gefühls. ${ }^{146}$

Mit diesem Verständnis einer Interaffektivität rekurriert er auf MerleauPonty, der noch weiter geht, wenn er die subjektive-innere Empfindung an den gestischen Ausdruck und die Responsivität des Gegenübers bindet. Merleau-Ponty verdeutlicht sein Verständnis anhand einer Situation, in der er einem Freund ein Zeichen macht, dass er zu ihm rüberkommen möge. Doch er verwehrt sich dagegen, dass dieses Zeichenmachen selbst ein Gedanke sei, zudem erst überlegt werden müsse, wie man diesen umsetze. Vielmehr sieht Merleau-Ponty den Gefühls- und Denkvorgang als Teil der Interaktion. Er macht direkt eine Bewegung, die der Freund sieht:

Der Abstand, der mich von ihm trennt, seine Zustimmung oder Ablehnung spiegeln sich unmittelbar in meiner Bewegung. Es liegt keine Wahrnehmung vor, der eine Bewegung folgte, Wahrnehmung und Bewegung bilden nur ein System, das als Ganzes sich modifiziert. Bemerke ich z.B., dass mein Freund meinem Zeichen nicht folgen will, und mache ich dann eine betontere Geste, so liegen nicht zwei Bewusstseinsakte vor, sondern ich sehe das Nichtwollen meines Gegenüber, und ohne Vermittlung eines Gedankens entspringt dieser Situation meine Geste der Ungeduld. ${ }^{147}$

Was Merleau-Ponty beschreibt, spricht auf extrem einfache Weise das an, was seit Jahrhunderten die Debatte zum Fremdverstehen beschäftigt hat. Indem er die einzelnen Subjekte innerhalb einer Kommunikation nicht mehr voneinander trennt (,so liegen nicht zwei Bewusstseinsakte vor“), sondern Wahrnehmung und Ausdruck beider Gesprächspartner aufeinander bezieht, macht er die Responsivität oder Resonanz zum Hauptaspekt von affektiver Expressivität. ${ }^{148}$ Indem sich

145 Shaun Gallagher und Dan Zahavi: The Phenomenological Mind. An Introduction to Philosophy of Mind and Cognitive Science. New York 2008, S. 182.

146 „We might say that there is something it feels like to be me; something that is sometimes set askew, as when I'm sick, I might say that I don't quite feel myself today. This includes the sense that I am the one who is experiencing, explicated in terms of my senses of ownership and agency. As Depraz (1994: 75) describes it, in auto-affection, I am affected before knowing that I am affected. It is in that sense that affect can be said to be primordial.' This affective tonality is tacit it in the sense that I am not usually or explicitly aware of it.“ Gallagher 2005, S. 201.

147 Merleau-Ponty 1974 (1945), S. 137.

148 Zum Zusammenhang von Ausdruck und leiblicher Resonanz siehe auch Fuchs 2000, S. 197-200. 
das subjektive, innere Wollen des ,Ich-Erzählers' Maurice an die Geste seines Freundes heftet, wird diese auf den eigenen Wunsch und damit als Ablehnung verstehbar. Dadurch wird dem Auffordernden das Nichtwollen in der Geste des Gegenübers deutlich, denn die Geste bezieht er ja tatsächlich auf sein Wollen. ${ }^{149}$

Wie man sich auf die Umwelt ausrichtet, die Art wie man sich bewegt, wie man bittet, fordert, niedergeschlagen ist oder jubiliert, zeigt sich in expressiven Phänomenen, in vokalen, gestischen oder mimischen Dynamiken. Verortet man diese dynamische Auffassung von Ausdrucksbewegung in der Begriffsgeschichte, dann kann Helmuth Plessners Konzept von Expressivität einen Rahmen dafür bilden. Seine Theorie basiert hauptsächlich darauf, dass er den Begriff des Ausdrucks als Verhaltenskategorie bzw. Interaktionsform auffasst. Ausdruck ist demnach eine Schnittstelle des Menschen zu seiner Umwelt sowie ein zweifacher Zugang des Menschen zu seinem Körper (Körper-Sein und Körper-Haben). Die Vorstellung einer dynamischen Kongruenz von Affekt/Gefühl und Bewegung prägt Plessners Begriff der Ausdrucksbewegung und des von ihr hervorgebrachten dynamischen „Bewegungsbilds“: ${ }^{150}$

Diese Ganzheiten gehören zum Organismus durch sein Verhältnis zur Umwelt, seine Morphologie, seine artspezifischen Instinkte als motorische Kategorien, denen er nicht entfliehen kann. Infolgedessen sind die Bewegungsgestalten bildhaft, wenn auch über eine gewisse Zeitdauer erstreckt, dem Beobachter gegenwärtig. Sobald aber der Beobachter dazu übergeht, die Bilder in ihre Aufbauteile zu zerlegen, und deren kinematischen $\mathrm{Zu}$ sammenhang erforscht, der uns nicht gegeben erscheint, verläßt er die Schicht unmittelbaren oder mittelbaren Verstehens und fängt an, kausal zu erklären. Greifen, Fliehen, Abwehren, Suchen, aber auch schon die ,affektlosen“ Formen wie Gehen, Fliegen, Schwimmen [.. .] stellen solche Bewegungsbilder dar. ${ }^{151}$

Der Begriff des Bewegungsbildes wie Plessner ihn hier anspricht zielt auf einen Wahrnehmungsmodus ab: „infolgedessen sind die Bewegungsgestalten bildhaft [...] dem Beobachter gegenwärtig“. ${ }^{152}$ Die Bewegungsbilder in den Formen des „Suchens, Greifens, Abwehrens, Drohens“ werden, so Plessner,

149 Zur Resonanz im affektiven Austausch siehe auch Shaun Gallagher: Understanding Others. Embodied Social Cognition. In: Paco Calvo und Antoni Gomila (Hg.): Handbook of Cognitive Science. An Embodied Approach. Amsterdam 2008, S. 439-452, hier: S. 449.

150 Plessner 2003 (1925), S. 78. Alternativ dazu wird der Begriff der „Bewegungsmelodie“ nach Uexküll verwendet. Plessner 2003 (1925), S. 79, S. 84.

151 Plessner 2003 (1925), S. 78.

152 Siehe oben im Zitat. Hermann Kappelhoff hat darauf hingewiesen, dass Plessners und Deleuzes Begriff beide bei Bergson ihre Wurzeln haben, Kappelhoff 2004a, S. 152. So schreibt Plessner: „Im Bilde des Ausdrucks ruht die Betrachtung. Um die Bergsonsche Antithese zu gebrauchen: Ausdruck liegt im temps durée, Handlung im temps espace.“ Plessner 2003 (1925), S. 91. 
von affektiven Ausdrucksbewegungen hervorgebracht, im Rahmen einer „Umweltintentionalität“: ${ }^{153}$ In Gesten der Ablehnung oder des Wohlwollens wird ein Wille, ein Gefühl, ein Gedanke oder eine Absicht sichtbar, denn in ihnen wird eine Leib-Umwelt-Beziehung offensichtlich. Dies untermauert Plessner durch seine Beschreibung des frühkindlichen Wahrnehmungsmodus, in dem der Säugling mit seiner Umwelt noch eins ist. ${ }^{154}$

In diesem Zusammenhang sind die Gefühlsphänomene mit den Ausdrucksphänomenen als korrelativ, aber nicht als kausal anzusehen. Nicht ein Gefühl löst eine Körperhaltung aus oder umgekehrt. ${ }^{155}$ Es sind Dynamik und Gerichtetheit, das interaktive Eingebundensein in eine Situation, welche die spezifische Gefühlsqualität ausmachen. So ist das Tempo, die wahrnehmbare Geschwindigkeit entscheidend, aber auch die Akzentuierung im „Bewegungsfluß“: ${ }^{156}$ „Der Längenwert des Lachens, Weinens, einer wütenden Verzerrung des Gesichts hat zugleich einen bestimmten Intensitätswert. “157 Nun setzt Plessner den Zusammenhang von räumlicher Gerichtetheit und Dynamik zentral, welcher das Bewegungsbild charakterisiere, ganz ähnlich wie bei Auguste Flach. So zeichne sich z.B. das Fliehen dadurch aus, dass es eine Ausweich- oder Rückzugsbewegung eines Subjekts vor etwas (das Was) ist, aber auch eine hastige Bewegungsqualität (das Wie) in sich trägt. ${ }^{158}$

Eine Weise, die Gefühle zu klassifizieren hat der Phänomenologe Thomas Fuchs vorgeschlagen. Dabei bezieht er die emotiven Dynamiken und die Gerichtetheit von Ausdruck aufeinander:

So entsprechen den expansiven leiblichen Richtungen etwa die Gefühle von Freude, Stolz oder Neid, den expulsiven Richtungen der Zorn, Haß oder Ekel, den emanativen Mitleid oder hingebende Liebe, den rezessiven die Furcht, Scham oder Demut, den attraktiven die Zuneigung oder Sehnsucht, den rezeptiven die erfüllte Zufriedenheit oder (heute seltener) die Andacht. ${ }^{159}$

153 Beide Zitate: Plessner 2003 (1925), S. 78 und 79.

154 Vgl. Meuter 2006, S. 85; Plessner 2003 (1925), S. 75.

155 Fuchs 2000, S. 220.

156 Plessner 2003 (1925), S. 79.

157 Plessner 2003 (1925), S. 91.

158 Dieses intentionale Moment ist nun weniger als Intentionalität einer Emotion in der darwinschen Definition bzw. als evolutionäre Rudimente von Ab- oder Zuwendungen zu beschreiben, sondern als situativ-kontextuelle Formen der Ab- oder Zuwendung in der tatsächlichen dynamischen Ausprägung von Körperbewegung. Bühler nennt dies über den Begriff der Deixis die Bezugswendungen im Ausdruck. Bühler 1933, S. 41-42.

159 Fuchs 2000, S. 220. 
Gefühle seien interpersonal, indem sie sich an umweltliche „Ausdruckscharaktere" knüpfen:

In der Tat sind Gefühle räumlich gerichtete und den Leib auch atmosphärisch einschließende Regungen. Ihre Dynamik läßt sich einer Strömung vergleichen, die im Stimmungsraum wie zwischen Polen eines Magnetfeldes hin und her fließt. Gefühle sind Ausdruck einer Korrespondenz der persönlichen Gerichtetheiten und der Ausdruckscharaktere der Umwelt. Sie haften an gegenwärtigen oder vergegenwärtigten Personen, Gegenständen und Situationen, die sie in ihrem Ausdrucks- und Wertgehalt erfassen, und mit denen wir (sympathisch oder antipathisch) verbunden sind. [. . . Sie erzeugen ein Netz von interpersonalen Verhältnissen der $\mathrm{Zu}$ - und Abneigung, Nähe und Distanz, Vertrautheit und Fremdheit, Über- und Unterordnung etc. [...] Auch entwicklungspsychologisch zeigt sich, daß Gefühle primär Wechselseitigkeitsbeziehungen darstellen. ${ }^{160}$

Gefühle sind nach Fuchs interaktionale Kraftverschiebungen, die nicht mehr allein in einem abgegrenzten Subjekt verortbar sind, sondern sich immer schon auf das ,Zwischen' beziehen. Er definiert sie als Wechselseitigkeitsbeziehungen, die in ähnlicher Weise bei Plessner, bei Sheets-Johnstone, Gallagher, Flach und Merleau-Ponty anzutreffen waren.

Ein Zugang, der ähnlich stark intersubjektiv gedacht ist, ist Brian Massumis Affektbegriff, der auf Spinoza zurückgeht. ${ }^{161}$ Spinoza hatte eine Vorstellung vom Affekt als ansteckende Kraft, als dynamisches, die Menschen verbindendes Phänomenen. Die Berührung ist von beiden Seiten eine Öffnung bzw. Veränderung. Brian Massumi erläutert:

[...] zu affizieren und affiziert zu werden. Diese sind nicht zwei verschiedene Vermögen - sie laufen immer zusammen. Wenn man etwas affiziert, dann öffnet man sich zur gleichen Zeit, um wiederum selbst affiziert zu werden. Und zwar auf eine leicht andere Weise, als im Moment zuvor. So klein der Unterschied auch sein mag, man hat sich verändert. Man hat eine Wandlung durchlaufen und ist über eine Schwelle getreten. Der Affekt ist das Überschreiten einer Schwelle, gesehen aus der Perspektive der Vermögensänderung. Man muss dabei immer im Hinterkopf behalten, dass Spinoza dabei immer über den Körper spricht. Spinoza sagt, dass ein Körper das ist, was er im Verlaufe machen kann. Das ist eine absolut pragmatische Definition. Ein Körper definiert sich über die Vermögen, die er von Schritt zu Schritt in

160 Fuchs 2000, S. 230.

$161 \mathrm{Im}$ Affekt verbinden sich (nach Spinoza) körperliche Erregungen und die Vorstellungen oder Ideen davon: „Unter Affekt (affectus) verstehe ich die Erregungen unseres Körpers, durch welche das Tätigkeitsvermögen eben dieses Körpers vermehrt oder vermindert, gefördert oder gehemmt wurde, und zugleich die Ideen dieser Erregungen." Spinoza, Die Ethik, III, Definitionen, zitiert nach Antonio R. Damasio: Der Spinoza-Effekt. Wie Gefühle unser Leben bestimmen. München 2003, S. 344; Brian Massumi: Parables for the Virtual. Movement, Affect, Sensation. Durham/London 2002, S. 15. Zur Differenz zwischen dem persönlich-individuellen Emotionsbegriff und dem unpersönlichen Affektbegriff siehe Massumi ebd. S. 27-28. 
sich trägt. Welche das genau sind, ändert sich ständig. Das Vermögen eines Körpers zu affizieren und affiziert zu werden - seine affektive Aufladung - ist nichts Festes. ${ }^{162}$

Der Körper ist demnach immer schon an Dynamik gebunden. Eine verkörperte Bewegung, die von einem Körper zu einem anderen wandert und deren Vermögen verändernd gestaltet, verschränkt Fluidität und Affektivität aufs Engste ineinander: ohne das Lebendige, das Fließende gibt es keine Affekte, ohne Bewegung keine Berührung.

An diese Position ist auch Daniel Stern anschließbar, holt er doch eben diese theoretische Setzung einer Vermögensänderung und Resonanz, die sich im gleichzeitigen Affizieren und Affiziert-werden herstellt, durch einen ganz anschaulichen Gegenstand ein: An der Kommunikation zwischen Säugling und Mutter beschreibt er die dynamische Responsivität, die „zeitliche Strukturierung menschlicher sozialer Verhaltensweisen“163 als Grund für eine „Affektabstimmung ${ }^{6164}$ zwischen Mutter und Kind: ${ }^{165}$ Über Synchronisierung der Verhaltensformen, durch Körperbewegungen mit ähnlichen „Zeitkonturen“166, Tempi und Akzentuierungen stimmen sich Mutter und Kind aufeinander ein. ${ }^{167}$ Im Zentrum steht dabei nicht der Einzelkörper mit seinem subjektiven Erleben, sondern das geteilte, affektive Erleben mehrerer Körper über Gesten, Vokalisierungen und Gesichtsausdrücke. ${ }^{168}$ Der Begriff der Vitalitätsaffekte zielt auf das interaktive und expressive Bewegungsverhalten ab. Dabei vermittle die amodale Wahrnehmung zwischen den einzelnen Sinnen und beziehe so die verschiedenen Intensitäten und Bewegungsmuster aufeinander. „Basis für das ,Zusammensein-mit-einemAnderen' ist das gemeinsame Teilen des vitalitätsdynamischen Flusses.“169 und damit der „Takte, die im ,rhythmischen Sinn` durch das Timing, durch ihre

162 Brian Massumi: Ontomacht. Kunst, Affekt und das Ereignis des Politischen. Mit einem Vorwort von Erin Manning. Aus dem Englischen von Claudia Weigel. Berlin 2010, S. 27.

163 Daniel N. Stern: Die Lebenserfahrung des Säuglings. Stuttgart 1996, S. 101. Er bezeichnet das fließende Verhaltenskontinuum der Mutter als vergleichbar mit dem Strom oder Fluss einer Sinfonie (ebd., S. 104).

164 Daniel N. Stern: Ausdrucksformen der Vitalität. Die Erforschung dynamischen Erlebens in Psychotherapie, Entwicklungspsychologie und den Künsten. Frankfurt a. M. 2011, S. 58.

165 Das Wort Mutter verwendet er als Überbegriff für alle engen Betreuungspersonen wie Vater, Großmutter etc.

166 Stern 2011, S. 72.

167 Stern 2011, S. 70-73. Dabei bezieht er sich in seinem Konzept vor allem auf Trevarthens Begriff der „kommunikativen Musikalität“ (S. 70), welchen er als Ausgangspunkt für die zwischenmenschliche Resonanz begreift.

168 Vgl. Stern 2011, S. 58-60. Zum Begriff der Intersubjektivität sagt Stern: „Ich verstehe unter Intersubjektivität die Teilhabe am Erleben eines anderen Menschen“, S. 59.

169 Stern 2011, S. 72. 
Zeitkontur und durch den Einsatz von Kraft in der Zeit zustande kommen. “ ${ }^{170}$ Diese synästhetischen Bewegungsverläufe sind etwa: explodierend, schwebend, pulsierend, lang gezogen. ${ }^{171}$ Er versteht die Qualitäten der Bewegung als Wahrnehmungscharaktere, betrachtet ihren zeitlichen Verlauf:

Schließlich entfaltet sich jedes Ereignis, die komplexen sozialen Verhaltensweisen von Betreuungspersonen und Kleinkindern inbegriffen, in der Dimension der Zeit, und oft liegt im Timing sozialer Verhaltensweisen selbst der Schlüssel zum Signalwert oder Sinn oder Affekt. (...) Zudem scheinen Betreuungspersonen wirkungsvoll mit Steigerungen - bisweilen auch mit plötzlichen, wenngleich geringfügigen Veränderungen - des Tempos zu arbeiten, um den weiteren Erregungs- und Affektzustand des Kleinkindes zu beeinflussen. ${ }^{172}$

Die Zeitlichkeit sei demnach diese Grundform von gelebter Vitalität. Das unterschiedliche Tempo entscheide letztlich über die Weisen der Erregung bzw. der Affektivität. An dem Wandel durch Bewegungsqualitäten zeigt sich selbst der Verlauf der Affekte, wie sie sich abwechseln, wiederholen oder überlagern.

Mit seinem Zugang entwirft Daniel Stern einen Gegenbegriff zur psychologischen Kategorie der Emotion, die meist allein das einzelne Subjekt und die angenommene interiorisierte Gefühlslage in den Blick nimmt. ${ }^{173}$ Im Falle des Gesichtsausdrucks wird die psychologische Kategorie der Emotion als sich in evolutionär verfestigten, universell gedachten Gesichtsmuskelgruppen ausdrückend verstanden. ${ }^{174}$ Die Auffassung einer Interaffektivität, wie sie Stern entwickelt, richtet sich hingegen an einem zwischenmenschlichen Moment aus: $\mathrm{Zu}$ Beginn des Lebens nimmt der Säugling noch keine Objekte wahr, sondern macht „Interaktionserfahrungen“. ${ }^{175}$ Das heißt, dass der Säugling sich noch als körperliche Einheit mit dem Umfeld, der Betreuungspersonen und all den sich verändernden Phänomene erfährt. Erst nach und nach entwickelt er sich zu einem sich

170 Stern 2011, S. 72.

171 Stern 2011, S. 17.

172 Stern 1996, S. 113.

173 Zwar gibt es freilich die Ausrichtung auf das sozial bedingte Ausdrucksverhalten, doch im psychologischen Emotionsmodell bleibt es letztlich am einzelnen Individuum orientiert, vgl. Scherer 2009, S. 169. Emotionen werden als zielgerichtete (intentionale) Handlungstendenzen verstanden. Basis-Emotionen enthielten bestimmte in ihnen verfestigte Rudimente von Handlungsmustern. Die Emotionspsychologie leitet ihre Thesen unter anderem von Darwins Forschung her. Vgl. Meuter 2006, S. 231-239; Damasio 2003, S. 58.

174 Die emotionspsychologischen Modelle werden vor allem für ihre schematische Auffassung sowie für das Auslassen kultureller und historischer Ausprägungen und Kontexte kritisiert. Siehe Hartmut Böhme: Gefühl. In: Christoph Wulf (Hg.): Vom Menschen. Handbuch historische Anthropologie. Weinheim/Basel 1997, S. 525-548, hier: S. 528.

175 Stern 2011, S. 184. 
als eigenständig erlebenden Körper; Schritt für Schritt schälen sich aus Atmosphären und Umgebungen abstrahierbare Dinge, Objekte, Personen heraus. ${ }^{176}$

Die Interaktionserfahrungen menschlicher Kommunikation sind aufs Engste mit den Bewegungsqualitäten gestischen, mimischen und stimmlichen Ausdrucks verbunden. ${ }^{177}$ So sieht der Philosoph Mark Johnson das menschliche Empfindungsvermögen (in der Erfahrung von Bewegungsqualitäten) keineswegs als rein subjektiven, inneren Zustand an:

\begin{abstract}
Subjectively, we would say that we feel these qualitative dimensions. However, they are not just subjective qualities. It would be a mistake to subjectivize these experiences of qualities of motion, as if they were locked up within some private inner world of feelings. On the contrary, they are qualities of organism-enviroment interactions. As such, they are not merely ,subjective feeling' responses (not just ,inner' experiences). They are qualities in the world as much as they are in us. They are the qualities of different experiences that involve both the structure of the organism and the structure of its environment inextricably woven together, and even attuned to one another. Moreover they are qualities experienced and shared by other people, who have bodies like ours and who inhabit the same kind of physical environment that we do. ${ }^{178}$
\end{abstract}

Ohne sich auf Plessner zu beziehen, versteht Johnson doch in ganz ähnlicher Weise die sinnlichen, dynamischen Qualitäten von Körperbewegung als Sichtbarwerdung der Organismus-Umwelt-Beziehung. ${ }^{179}$ Er bindet diese Auffassung kinästhetischer Qualitäten, die er im Rekurs auf Sheets-Johnstone und Stern entwirft, an das gefühlsmäßiges Erleben: „[. . .] emotions are processes of organism-

176 Diese Säuglingswahrnehmung ist in der Ausdruckstheorie immer wieder beschrieben worden, wie etwa bei Plessner 2003 (1925), S. 75. Auch Max Scheler sieht dass, „zunächst ein ,in Hinsicht auf Ich-Du indifferenter Strom der Erlebnisse', der ,Eigenes und Fremdes ungeschieden' enthalte, gegeben sei [...] und uns erst durch einen ,Aktus der Unterscheidung in einem zunächst wenig geschiedenen Ganzen' nachträglich, aber ,gleichzeitig das Eigene und das Fremde‘ zu Bewusstsein komme." Max Scheler im Zitat von Hermann Schmitz: Leib und Gefühl. Materialien zu einer philosophischen Therapeutik. Hg. von Hermann Gausebeck und Gerhard Risch, Paderborn 1992, S. 184. Zum Zusammenhang von Individuierung, Spiel und künstlerischen Formen siehe Kappelhoff 2004a, S. 300-301.

177 Zu Ausdrucks- und Bewegungsqualitäten: Stern 2011, S. 65.

178 Mark Johnson: The Meaning of the Body. Aesthetics of Human Understanding. London/ Chicago 2007, S. 25.

179 Es zeigt sich, dass Johnson in seinem Buch The Meaning of the Body einen Wandel vollzieht. Anstatt entzeitlichte, allgemeingültige Bild- bzw. Bewegungsschemata allein zur Grundlage des konzeptuellen Verstehens zu machen, zieht er nun das Kontextuelle, die konkrete Situation, das Verhalten oder auch den Sprachgebrauch in Betracht, wenn er die Bewegungsqualitäten zentral setzt. Johnson 2007, S. 21. 
environment interactions. They involve perceptions and assessments of situations in the continual process of transforming those situations.“" ${ }^{\text {180 }}$ Gefühlsphänomene und affektive Zustände ordnet er nicht allein einer Interiorisierung zu, sondern fasst sie als situative Umweltbezüglichkeit des Subjekts. Er führt ein Beispiel an: In einer Situation, in der man Angst habe, sei die Angst nicht innerlich in einem selbst, sondern entstehe durch den Bezug zum Außen. Der Ort des Angstgefühls vor der dunklen Straße sei also nicht im Gehirn zu finden, sondern in der Emotion werde die eigene Umweltbezüglichkeit manifest. Gefühlsphänomene würden in gelebten Kontexten, Aktionen, Situationen und konkreten Szenarien überhaupt erst existent, seien mit diesen unauflöslich verwoben: „In short, emotions are both in us and in the world at the same time.“181

Die erläuterten Autorenpositionen, von der älteren Ausdruckstheorie über die Phänomenologie zur aktuellen Embodiment-Forschung, perspektivieren allesamt das Interaktionale und Interaffektive in Abgrenzung zur psychologischen Kategorie der Emotion als rein subjektive Interiorisierung. An dieser Stelle möchte ich die verschiedenen Terme ordnen. In den genannten Positionen werden die Begriffe Emotion, Gefühl, Affekt etc. oftmals synonym verwendet. Um ein klares BegriffsInstrumentarium vorliegen zu haben, werde ich Unterschiede einführen. Affekte verstehe ich im Anschluss an Massumi, Plessner und Stern als situative, dynamische Berührungsformen (hervorgebracht durch Kräfte, Intensitäten, Qualitäten) zwischen einem Körper (zur Umwelt) oder mehreren Körpern in Bewegung. Die Affekte können unpersönlich sein und daher im Falle von Kunstwerken und Medien auch nichtmenschlichen Ursprungs sein; sie sind geprägt durch Gegenwärtigkeit, Vitalität und Werden. ${ }^{182}$ Der Ausdruck verhält sich zum Affekt in einem nicht-arbiträren Verhältnis, beide sind voneinander nicht ablösbar.

Emotion wird als Begriff im Folgenden nur im Sinn der Emotionspsychologie verwendet. ${ }^{183}$ Den Begriff Gefühl verstehe ich nach Fuchs als Wechselseitigkeitsbeziehung zwischen einer Einstellungen zur Welt und den Ausdruckscharakteren in der Welt, als ein durch das Subjekt-Umwelt-Verhältnis (im Sinne Johnsons

180 Johnson 2007, S. 66-67.

181 Johnson 2007, S. 67.

182 Deleuze und Guattari (2000) beschreiben Kunstwerke als vom Künstler geschaffene und damit eigenständig gewordene „Blöcke aus Perzepten und Affekten“ (S. 192), die größer seien als menschliches Erleben und durch die Menschen mit ihren Erfahrungen lediglich „hindurchgehen" (S. 191).

183 Johnsons Begriff der Emotion ist hier eine Ausnahme, da er die Subjekt-Umwelt-Relation hervorhebt. 
und Plessners) und das Selbstverhältnis des Menschen zu sich bestimmtes Erfahrungsereignis. Plessners Definition ist hier wegweisend:

Gefühl ist die wesensmäßige Bindung meiner selbst an etwas, Bindung, die mir eine weit geringere Selbständigkeit gegenüber Dingen, Menschen, Werten, Gedanken, Ereignissen läßt als Anschauung, Wahrnehmung und jede sonstige motivierte Stellungnahme zu Objekten. Gefühle wie Trauer Freude, Empörung, Begeisterung, Verachtung, Bewunderung, Zorn, Rührung, Haß, Liebe sind [...] durchstimmende Angesprochenheiten, denen die Person je nach Temperament mehr oder weniger leicht ausgeliefert ist und sich ihrer gegebenenfalls nur mit aller Kraft erwehren kann. ${ }^{184}$

Das Gefühl verstehe ich in diesem Sinn als dynamische Bindungsform einer Person an etwas, in einer Subjekt-Umwelt-Ausrichtung, wobei sich darin vielfältige Affekte, Stimmungen, Reflexionsweisen, Bewertungen, kognitive Prozesse und bewusste Operationen treffen können. Das Gefühl ist interaktional und verbunden mit umweltlichen „Ausdruckscharakteren“"185, aber es ist persönlich, es aktualisiert, individuiert und situiert die Affekte bezogen auf eine Subjektivität. Den Ausdruck eines Gefühls verstehe ich als Weise, wie eine solche Bindungsform oder Subjektivität im Gesicht oder seinem Äquivalent wahrnehmbar wird.

Diese Terminologie ist an dieser Stelle zur theoretischen Klärung aufgeführt. Erst in Unterkapitel 2.4 werde ich die Begriffe - bezogen auf die Medialität von Film und audiovisuellen Medien - spezifizieren. Darüber hinaus gilt es zu berücksichtigen, wie Gefühle sich historisch und kulturell spezifisch ausprägen. $\mathrm{Zu}$ diesem Zweck werde ich in den Kapitel 3,4 und 5 die ästhetischen Bildtypen der Screwball Comedy in Ausrichtung auf meine Frage nach den Tempi der Bewegung als Modi des Gefühls analysieren. Darin werde ich neben den Bestimmungen allgemeiner Erkenntnisse zu Tempo und Gefühl das ganz spezifische Vergnügen an der Screwball Comedy beschreiben, wie es nur in seinem bestimmten historischen und kulturellen Setting der amerikanischen 1930er und 1940er Jahre sich ausformen konnte und uns über die Filme als Erfahrungsmodus erhalten geblieben ist bzw. durch uns Zuschauerinnen heute aktualisiert wird.

Im Folgenden fokussiere ich eine dritte Linie der Ausdruckstheorie. Dabei werde ich den Zusammenhang von Ausdruck, Sprache und Zeichenhaftigkeit skizzieren. Damit soll ein Aspekt vorbereitet werden, der später noch genauer diskutiert wird: der Zusammenhang von Expressivität und Sinnbildung bzw. Bedeutungskonstitution.

184 Plessner 2003 (1945), S. 347.

185 Fuchs 2000, S. 230. 


\section{Figuration: Expressivität und verkörpertes Denken}

In der Ausdruckstheorie haben viele Theoretiker immer wieder den Zusammenhang von Expressivität und Sprache bzw. Zeichenhaftigkeit betont. Damit ist eine Vielzahl von Theoremen angesprochen, in denen Expressivität als Grundlage für verkörperte Verstehens- oder Denkprozesse angesehen wird.

Merlau-Pontys Kapitel „Der Leib als Ausdruck und die Sprache“ aus Phänomenologie der Wahrnehmung ist hier ein zentraler Bezug. ${ }^{186}$ Ausgangspunkt sind Verhaltensformen des Menschen. Merleau-Ponty beschreibt, wie das Erlernen oder der Gebrauch einer Sprache selbst auf Prinzipien des Gestischen basieren. Er geht davon aus, dass erst im Äußerungsakt, in der gesprochenen Rede die Sprache „ihren Sinn selbst hervorbringt“ (für Zuhörer der jeweilige Sprachgemeinschaft). ${ }^{187}$ Den Denkprozess sieht er als aus der leiblich-verbalen Veräußerung hervorgehend, erst im Akt des Sprechens oder Schreibens präzisiere sich die vage geistige Idee zu einem Sinn. In der sprachlichen Äußerung forme sich ein Zugang zur Welt. Auch beschreibt er, dass man eine Fremdsprache zum großen Teil über die Gewohnheit des Gestischen erlerne. Dabei weist er jedoch schematische Ansichten einer Entwicklung von „natürlichen“ zu „künstlichen“ Zeichen zurück. ${ }^{188}$

Im Hinblick auf eine solche Entwicklung ist die Frage nach dem Verhältnis von Zeichen und Ausdruck im achtzehnten und neunzehnten Jahrhundert immer wieder diskutiert worden; in der Sprachtheorie wurde immer wieder die These aufgeworfen, dass Gestik eine Art universelle und evolutionäre Vorstufe zur Sprache sei. ${ }^{189}$ Die These vertrat z.B. Wilhelm Wundt innerhalb der psychologischen Sprachursprungsdebatte, welche in der Konventionalisierung expressiver Phänomene die Zeichenwerdung und Sprachentstehung begründet sah. ${ }^{190}$ Im Zusammenhang mit der Gebärdensprache stellte er die These von der „Notwendigkeit der Annahme einer Ursprache“ auf, „die Notwendigkeit nämlich, daß es für jede Art natürlich entstandener Sprache einmal eine Zeit gegeben haben muß, in der die Beziehung zwischen dem Zeichen und dem, was es bezeichnet, eine unmittelbar anschauliche war. “191 Neben dieser These betonte Wilhelm Wundt die Unterscheidung zwischen ,willkürlichen` oder ,unwillkürlichen` Affektbewegungen,

186 Merleau-Ponty 1974 (1945).

187 Merleau-Ponty 1974 (1945), S. 220.

188 Merleau-Ponty 1974 (1945), S. 223.

189 Für einen Überblick siehe: Kendon 2004, S. 35-40.

190 Vgl. Löffler 2004, S. 175-176.

191 Zitiert nach Bühler 1933, S. 130. 
welche als Dichotomie lange Zeit einschlägig war, aber auch aufgrund des Schematismus zu Komplikationen führte. ${ }^{192}$

Ausdrucksbewegung wurde in ein dichotomes Verhältnis gesetzt. Die erste Position ist hier die der Konventionalisierung expressiver Muster, wobei dies sowohl auf der Ebene einer Sprachgemeinschaft als auch auf der Ebene einer individuellen Kindesentwicklung verortet wird. Hier kommt die Unterscheidung zwischen reflexiv eingesetztem Ausdrucksverhalten vs. spontan sich ereignenden Ausdrucksmustern hinzu. ${ }^{193}$ Dieser Aspekt ist etwa heute noch in den emotionspsychologischen Ansätzen aufzufinden, welche von einer Dichotomie von authentisch-spontanem vs. absichtlich ausgeführtem Gemütsausdruck ausgehen. ${ }^{194}$ Eine weitere Dichotomie geht zurück auf ältere Debatten, die etwa zwischen Unmittelbarkeit vs. Mittelbarkeit von Ausdrucksbewegungen bzw. von Gestik (rhetorisch oder intentional eingesetzt) vs. einer Mimik (gefühlsmäßigunmittelbar) unterscheiden. ${ }^{195}$

Dabei mögen die Dichotomien höchst unterschiedlich erscheinen: die Konventionalisierungsthese zielt auf eine kollektive Sprachentstehung ab; die Entwicklungsthese fokussiert das Spracherlernen auf der Basis von Gesten und Ausdrucksbewegungen; die Idee der reflexiv eingesetzten Geste differenziert zwischen bewusst und unbewusst eingesetzten Gestentypen. Alle Positionen verbinden sich darin, dass sie Prozesse der Sinnbildung, des Denkens und des Wollens als gegensätzlich zu affektiv-expressiven Formen betrachten.

In jüngster Zeit ist es vor allem die linguistische Forschung zu Gesten, Pragmatik und multimodaler Kommunikation, welche sich der Ausdrucksseite von Sprache wieder verstärkt zuwendet. Bei Cornelia Müller und anderen Vertreterinnen der Sprachwissenschaft werden komplexe Formen des redebegleitenden Körpereinsatzes als Sprachgebrauch untersucht; situierte, kontextbezogene Weisen von Ausdruck, Konventionalisierungen und der Zusammenhang von formund inhaltsbezogenen Prinzipien sind hier angesprochen. Was hier im

192 Vgl. Gumbrecht 2000, S. 425. Löffler 2004, S. 50; vgl. Asendorpf und Wallbott 1982, S. 138. 193 Diese These ist unter ähnlichen Vorzeichen auch in ästhetikorientierten und schauspieltheoretischen Zugängen erörtert worden. Siehe Kappelhoff 2004a, S. 63-64. Zudem hat sich die Debatte in der Ausdruckstheorie mittlerweile in eine Diskussion um universelle vs. kulturbedingte Aspekte gewandelt. Siehe Meuter 2006; Gumbrecht sieht in der Frage nach natürlichen und kulturellen Gegebenheiten des Ausdrucks eine Fortsetzung der Dichotomie „willkürlich“-,,unwillkürlich“ mit anderen Vorzeichen. Gumbrecht 2000, S. 417.

194 Vgl. Paul Ekman: Der Ausdruck und das Wesen von Gefühlen. In: Maria von Salisch (Hg.): Gesichtsausdruck und Gefühl. 20 Jahre Forschung von Paul Ekman. Paderborn 1988 (Innovative Psychotherapie und Humanwissenschaften. Bd. 38), S. 149-179, hier: S. 150, S. 153. Zitiert nach Meuter 2006, S. 270.

195 Vgl. Wulf 1997, S. 517. 
Vordergrund steht ist die Frage, die auch andere Ausdruckstheorien beschäftigt: Wie entstehen aus Bewegungen Bedeutungen? ${ }^{196}$

Die Forschungsrichtung schließt an Bühlers Auffassung von Ausdrucksbewegung an. Bühler schreibt, dass Ausdrucksbewegung „aus der Wechselbeziehung, dem ,Kontakt' der Individuen“ entsteht. ${ }^{197}$ Er beschreibt dies u.a. anhand der Kommunikation von Ameisen und Bienen. Hierbei komme es gerade nicht auf subjektive Verstehensleistungen an, die ohnehin bei Insekten nicht feststellbar sind. Vielmehr verortet er Zeichen, Sinn und Bedeutung in den sichtbaren Verständigungsstrukturen: In den Handlungen und Reaktionen der Insekten träten bestimmte Kommunikationen, Zeichen und Sinndimensionen hervor. ${ }^{198}$ Beim Menschen komme dies seit frühester Kindheit durch Angleichungen von Körperbewegungen mit der Mutter zustande, durch „Gebärdenresonanz“ (ähnlich dem Begriff der Synchronisierung nach Daniel Stern). ${ }^{199}$ Die Art und Weise wie menschliche Kommunikation durch Formen der Expressivität gestaltet ist, weise eine „gemeinschaftstragende Leistung“ auf: ${ }^{200}$ In der Geste sei der Bezug zum Gegenüber sinnlich gegenwärtig. ${ }^{201}$

196 Vgl. Müller und Kappelhoff 2018; Cornelia Müller: Gestures as a Medium of Expression. The Linguistic Potential of Gestures. In: Cornelia Müller et al. (Hg.): Body - Language - Communication. An International Handbook on Multimodality in Human Interaction. Berlin 2013 (Handbooks of Linguistics and Communication Science. Bd. 38.1), S. 202-217; Ellen Fricke: „Ränder“ des sprachlichen Ausdrucks? Wie lautliche und gestische Artikulationen zu Typen werden, die bedeuten können. In: Erik Porath und Tobias Robert Klein (Hg.): Kinästhetik und Kommunikation. Ränder und Interferenzen des Ausdrucks. Berlin 2013, S. 215-237; Dorothea Horst et al.: Gesture as Interactive Expressive Movement. Inter-Affectivity in Face-to-Face Communication. In: Cornelia Müller et al. (Hg.): Body - Language - Communication. An International Handbook on Multimodality in Human Interaction. Berlin 2014 (Handbooks of Linguistics and Communication Science. Bd. 38.2), S. 2112-2126.

197 Zitiert nach Flach 1928, S. 98.

198 „Sinnvoll benehmen sich im semantischen Kontakt mit ihresgleichen die Ameisen und Bienen; das sehen wir und hüten uns, vorschnell ungewisse Aussagen über ihr Erleben zu machen. Ich glaube wir müssen auch den Begriff des Verstehens dem Alleinbesitz des Erlebensaspekts entwinden. Es gibt im semantischen Kontakt der Tiere sichtbare Steuerungen des Benehmens. Folgt das Verhalten eines Tieres dem wahrgenommenen Zeichen, wie das Schiff einer Steuermarke, die der Steuermann in der Ferne erblickt, so werden wir sagen, das Tier habe das Zeichen verstanden, auch wenn über das Erleben dabei noch nicht das mindeste ermittelt ist.“ Karl Bühler: Die Krise der Psychologie. Stuttgart 1929, S. 129-130.

199 Bühler 1929, S. 90.

200 Bühler 1929, S. 128.

201 So wie Auguste Flach dies ausführt als z.B. „widerstrebend, geneigt oder unerbittlich“ Flach 1928, S. 99. 
Dass sich im menschlichen Ausdrucksverhalten ganz verschiedene Ebenen treffen und in der Zeitlichkeit der Geste wahrnehmbar werden, der Bezug des Gestikulierenden zu seinem Gegenüber als auch das Verhalten desjenigen, an den sich die Geste richtet, diese Dimension hat Bühler in seiner Sprach- und Zeichentheorie systematisch weitergedacht. Er hat mit seinem Organonmodell zentrale Formen von sprachlicher und nicht-sprachlicher Kommunikation skizziert. Er fasst darin die Kommunikation in der natürlichen Sprache als durch verschiedene Faktoren geprägt auf: Die Funktionen Ausdruck, Appell und Darstellung seien in kommunikativen Akten oft gleichzeitig gegeben. ${ }^{202}$ Ausdruck bezieht sich auf die affektive Expressivität, appellative Mitteilung auf das Gegenüber und Darstellung ist schließlich auf die Sache bezogen, worüber man spricht bzw. was sprachlich nachgeahmt wird. Bühler erweitert damit das Verständnis des Theatertheoretikers Johann Jakob Engel, dessen Thesen er in seinem Buch zur Ausdruckstheorie zitiert: „Der Mensch hat mit der Sprache zweyerley Absicht; er will die Ideen von den Objekte mittheilen, die ihn beschäftigen, und will die Art und Weise mittheilen, wie er von diesen Objekten gerührt wird.“203

Die Bezugnahme des sprechenden Menschen ist zweifach, er teilt seinem Gegenüber einerseits etwas mit, verständigt sich über die Dinge in der Welt; andererseits zeigt er auf, wie er zu diesen Dingen steht, welche Perspektive er darauf hat, welche affektive Einstellung damit verbunden ist. Engels schauspieltheoretische Unterscheidung von den malenden und den ausdrücklichen Gebärden zeugt von dieser Auffassung: „Malerei ist mir [...] jede sinnliche Darstellung der Sache selbst, welche die Seele denkt; Ausdruck jede sinnliche Darstellung der Fassung der Gesinnung, womit sie sie denkt; des ganzen Zustandes, worin sie durch ihr Denken versetzt wird.“204

Bühler greift nun in seinem Organonmodell auf diese Definition zurück. Er erweitert Engels Vorstellung um die appellative Funktion, die das Gegenüber in den Kommunikationsakt miteinschließt. Dabei sind im Bühlerschen Modell jeweils alle Dimensionen gleichzeitig präsent. Es kann jedoch Schwerpunkte geben. In der Bittgeste tritt etwa die Darstellungsfunktion ganz zurück, während Appel- und Ausdrucksfunktion stark werden. ${ }^{205}$

202 Karl Bühler: Sprachtheorie. Die Darstellungsfunktion der Sprache (1934). Stuttgart 1999, S. 24-33.

203 Zitiert nach Bühler 1933, S. 39.

204 Zitiert nach Bühler 1933, S. 40. Die Unterscheidung der Begriffe Darstellung und Ausdruck findet sich in den meisten Ausdruckstheorien wieder, siehe Bühler 1999 (1934), S. 150.

205 Ein ähnlich orientiertes Modell entwickelt Tomasello, wenn er die „drei allgemeinen Typen von Kommunikationsmotiven“ Auffordern, Informieren und Teilen unterscheidet. Tomasello 2009, S. 99. 
Cornelia Müller hat Bühlers Modell in Bezug zur aktuellen EmbodimentDebatte gesetzt und gezeigt, dass es die Bewegungsqualität ist, das ,Wie“ der Bewegung, die man als affektive oder gefühlsmäßige Qualität beschreiben kann. Anders als das ,Was', die repräsentative Funktion, worauf sich die Geste referentiell bezieht, transportiert die Bewegungsqualität das Zur-Welt-Sein bzw. die ,Gestenresonanz auf das Gegenüber. ${ }^{206}$

Die vorgestellten Ansätze skizzieren eine Linie innerhalb der Ausdruckstheorie, die das Bedeuten, das sinnhafte Verstehen und Symbolisieren starkmacht. Ausdruck wird darin als Begriff holistisch konzeptualisierbar: als komplexer Zugang zu Kommunikation, in dem kognitive Erfahrungen, kommunikative Handlungen und Affektivität sich treffen. Diese Idee einer Verbindung von Ausdruck und verkörpertem Denken werde ich später noch filmtheoretisch vertiefen. Zunächst werde ich den Bogen von den allgemeinen Ausdruckstheorien zu einer spezifischen Problematik spannen: der Expressivität des Lachens bzw. der heiteren Gefühle.

\section{Lachen und Weinen}

Lachen und Weinen haben in der Ausdruckstheorie einen Sonderstatus. Nach Helmuth Plessner sind sie Grenzformen des Ausdrucks, Phänomene, in denen die Gesamtheit des Körperbezugs momenthaft auseinanderfällt. ${ }^{207}$ Die beiden Seiten des Körperbezugs sind ansonsten stets ausgewogen: Einerseits spürt oder ist man sein Körper, mit Gliedmaßen, Rumpf, sensuellen Empfindungen etc. („Körpersein““208). Andererseits hat der Mensch die Möglichkeit zur „Abständigkeit“209, kann seinen Körper instrumentell einsetzen, willentlich Bewegungen ausführen bzw. sich selbst reflexiv betrachten („Körperhaben“). ${ }^{210}$ Doch wenn der Mensch in einer Situation nicht mehr weiß, wie er reagieren soll, kann in einem „Zwang zum Ausdruck “'211 das Körpersein überhand nehmen, der Leib reagiert automatisch auf die Situation. Im Lachen und Weinen hat der Mensch keine Macht mehr über das

\footnotetext{
206 Vgl. Müller 2013, S. 204-207.

207 Plessner 2003 (1945), S. 372.

208 Plessner 2003 (1945), S. 241.

209 Plessner 2003 (1945), S. 206.

210 Plessner 2003 (1945), S. 241.

211 Plessner 2003 (1945), S. 248.
} 
eigene Verhalten, kann seine Körperbewegungen nicht mehr steuern oder zurückhalten. $^{212}$

Anders als in gestischen, mimischen oder stimmlichen Ausdrucksbewegungen, in denen die beiden Ordnungen des Körperbezugs ausgewogen blieben, gerate der Mensch mit dem Lachen und Weinen (als „Ausdrucksformen einer Krise“ ${ }^{213}$ ) aus dem Gleichgewicht. ${ }^{214}$ Mit den zwei Krisenformen beschreibt Plessner die jeweilige Zeitlichkeit sowie damit verbundene Erfahrungsweisen:

1. Das Lachen sei eine Öffnungsbewegung zur Welt. Lacht man, dann sei der Körper mit dem Lachanlass direkt verbunden und reagiere resonant darauf. Die Strukturierung des Ausdrucksbilds im Verhalten weise eine schnelle, kurze, plötzliche Zeitgestalt auf („Eruptivität“). ${ }^{215}$ Indem der Mensch, wenn er lacht, sich von sich selbst und den bindenden Kräften zur Situation ablöse, werde er leicht, frei und gehoben. Dadurch könne er sich wieder mit anderen im gemeinsamen Lachen verbinden. ${ }^{216}$

2. Das Weinen entspreche einer Schließungsbewegung, einem Rückzug von der Welt, da etwas in der Umwelt übermächtig werde. ${ }^{217}$ Das Ausdrucksbild in den Verhaltensformen sei in seiner zeitlichen Artikulation allmählich, langgezogen, andauernd. ${ }^{218}$ Zwar reagiere der Körper für den Weinenden, doch werde der Mensch in dem Vorgang sehr persönlich involviert, er werde schwer, ohnmächtig und verschlossen. ${ }^{219}$

Die Grenzformen des Ausdrucks sind so entscheidend, da sich an ihnen der doppelte Körperbezug überhaupt erst aufzeigen lässt. In ihren Erscheinungen tritt der sonst permanent verflochtene Selbstbezug auseinander - materieller Körper und individuierte Person trennen sich kurzzeitig.

Plessner skizziert, wie der Mensch im Lachen förmlich einen Übergiff durch seine eigene Leiblichkeit erfährt. ${ }^{220}$ Der Körper schüttelt sich, Anspannung und Erregung müssen abgebaut werden. ${ }^{221}$ Dabei unterscheidet Plessner unterschiedliche Lacharten:

212 Plessner 2003 (1945), S. 236.

213 Plessner 2003 (1945), S. 211.

214 Plessner 2003 (1945), S. 364.

215 Plessner 2003 (1945), S. 332 und S. 368-369.

216 Plessner 2003 (1945), S. 332.

217 Plessner 2003 (1945), S. 333.

218 Plessner 2003 (1945), S. 369.

219 Plessner 2003 (1945), S. 368-369.

220 Plessner 2003 (1945), S. 225.

221 Plessner 2003 (1945), S. 252. 
Lustvoll ist es [das Lachen, Anmerkung von sg] als Entladung einer Spannung, die im Überschwang der Freude dem Bewegungsdrang, im Kitzel der sinnlichen Erregungsambivalenz, im Spiel im Zwischenzustand zwischen Freiheit und Bindung, bei Komik und Witz der doppelsinnigen Transparenz der Erscheinung (und damit der Zumutung an unsere Fassungskraft), in Verlegenheit und Verzweiflung schließlich der Überkreuzung zwischen Überblick und Ohnmacht entspringt. ${ }^{222}$

Er kategorisiert auslösende Momente, die allesamt an eine „Mehrsinnigkeit“223 gebunden sind, er unterscheidet die Lachformen wie Freude, Jubel, Kitzel, Spiel, Komik, Witz, Verlegenheit und Verzweiflung. Dabei treten vor allem die verschiedenen Intensitäten als Grade von Affektansprache hervor: Er spricht etwa der Freude, dem Jubel eine außerordentliche affektive Kraft $\mathrm{zu}$, während das Spiel und die Komik eher vorstellungsgebunden seien. ${ }^{224}$ Die wichtigsten Lachformen verbinden sich über einen Zusammenhang, der an die Spannung von Gegensätzen gebunden ist (das Spiel z.B. „zwischen Freiheit und Bindung“, die Verzweiflung „zwischen Überblick und Ohnmacht“") ${ }^{225}$. Der Lachende werde in einen Zustand versetzt, in dem er sich als Person vergessen könne, so wirke das Lachen lösend und befreiend. Diese Argumentation, die zwar tendenziell im Lachen eine Distanzierung sieht, sei aber nicht gleichbedeutend mit einer Abwesenheit von Gefühlen oder Affekten, so Plessner:

Setzt man - was nicht richtig ist - menschliche Distanz zum Anlaß und Kälte des Gefühls einander gleich, dann stimmt die oft geäußerte Ansicht von der Gefühlskälte des Lachens. Tatsächlich handelt es sich aber nicht um Qualität und Tiefe des Gefühls, sondern um eine enge Verbundenheit des Lachens mit dem Bewußtsein, die ihrerseits den Anschein der Gefühlskälte hervorruft. Die Anlässe des Kitzels (in seinen verschiedenen Formen), des Spielens, der Komik und des Witzes bleiben, auch wenn sie unbewußtes Material verarbeiten, menschlich gesprochen - d.h. in Beziehung zum Zentrum der Person, das sie nur erlebt, wenn sie sich für etwas einsetzt - an der Peripherie: des sinnlichen Empfindens und der Sensation, der Anschauung und Phantasie, der Auffassung und des Denkens. So haftet auch dem herzhaftesten, humorvollsten, aus der Tiefe des Gefühls heraufquellenden Lachen etwas Oberflächliches an. Der Mensch antwortet mit ihm direkt, ohne sich in die Antwort mit einzubeziehen. Im Lachen wird er gewißermaßen anonym ein Grund für die ansteckende Kraft, die ihm innewohnt. ${ }^{226}$

222 Plessner 2003 (1945), S. 330.

223 Plessner 2003 (1945), S. 328.

224 Plessner 2003 (1945), S. 277-332.

225 Plessner 2003 (1945), S. 330.

226 Plessner 2003 (1945), S. 331-332. 
Die Gefühlskälte des Lachens weist Plessner also zurück, doch er weist ihm andere Eigenschaften zu: eine stärkere Inbezugnahme durch das Bewusstsein, außerdem eine Oberflächlichkeit, nicht im alltagssprachlichen Sinn, sondern bezogen auf die Erfahrung. ${ }^{227}$ Lachanlass und Lachen seien aufs Engste miteinander verbunden, daher die Ansteckungsfähigkeit sowie die Möglichkeiten, sich von sich selbst zu distanzieren.

Diese Anonymität im Lachen ${ }^{228}$ lässt sich als Offenheit verstehen, erst dies bereite den „rechten Boden, sich der Gewalt der Ausdrucksreaktion zu überlassen. “229:

Unsere Skala [von Lachformen, Anmerkung von sg] trägt allein der Tatsache Rechnung, dass das Lachen mit zunehmender Distanz des Menschen zum Anlaß Freiheit und Heiterkeit, Fülle und Tiefe gewinnt, mit schwindender Distanz, d.h. wachsender Mitgenommenheit und Benommenheit aber sie verliert. ${ }^{230}$

Mit diesen Worten beschreibt Plessner das Lachen als eine Distanz im Sinne einer Gelassenheit und Gehobenheit - durch eine sich weitende Sicht, durch Leichtigkeit, ein Sich-Lösen von der Umwelt, den Dingen, von sich selbst, ein Abstandnehmen; auf der Basis solcher Distanznahmen könne sich der Mensch dann wieder gemeinschaftlich mit anderen verbinden. ${ }^{231}$ Dies kann affektiv als innerliches Explodieren im Jubel und der Freude auftreten oder das Empfinden einer Stärke sein, eines Könnens, einer Wohlgestimmtheit. ${ }^{232}$ Zentral sind die räumliche Einstellung zu einem Gegenüber (Nähe/Distanz), der Gewichtseindruck (Leichtigkeit/Schwere) als auch wechselhafte Bewegungsqualitäten (allmählich/ plötzlich). ${ }^{233}$ Das Lachen setzt Empfindungskräfte der Vitalität und Gehobenheit frei. Für meine Untersuchung sind diese Phänomenbeschreibungen von höchster Bedeutung, besonders aber ist es die Zeitform des Lachens, die ich mit Bezug zu Plessner weiterentwickeln möchte.

227 Plessner 2003 (1945), S. 332.

228 „Im Lachen quittiert der Mensch eine Situation. Er beantwortet sie mit ihm direkt und unpersönlich. Er gerät in einen anonymen Automatismus. Er selbst eigentlich lacht nicht, es lacht in ihm, und es ist gewissermaßen nur Schauplatz und Gefäß für diesen Vorgang.“ Plessner 2003 (1945), S. 280.

229 Plessner 2003 (1945), S. 330.

230 Plessner 2003 (1945), S. 331.

231 Plessner 2003 (1945), S. 332.

232 Plessner 2003 (1945), S. 279.

233 Plessner 2003 (1945), S. 369. 


\section{Zur Zeitlichkeit von Lachen und Weinen}

Plessner fasst für das Lachen und Weinen typische zeitliche Verlaufsgestalten auf: die Eruptivität des Lachens und die Allmählichkeit des Weinens seien besonders charakteristisch für die Ausdrucksbilder. Er beschreibt die Unterschiede:

Ebenso hängen Unvermitteltheit und Eruptivität mit der Struktur des spezifischen Anlasses zusammen. Eine Unterbindung des Verhaltens durch unausgleichbare Mehrsinnigkeit der Anknüpfungspunkte erfährt der Mensch nicht allmählich, nicht als anwachsende Deutlichkeit, Ergriffenheit und Umstimmung, sondern plötzlich, überraschend, im Aufprall und Rückstoß. Natürlich gibt es eine Entwicklung des Lachens, innerlich wie äußerlich. Nur verläuft sie kürzer als die Entwicklung des Weinens. Vor allem tendiert das Lachen dahin, seinen ,Anstieg' rasch hinter sich zu bringen und in den Ausbruch überzugehen, während Weinen einen Zug zum Stationärwerden hat, auch wenn es (falls es nicht zum Schreiweinen, Jammern oder Klagen führt) eine Kurve beschreibt: Anwachsen, Kulmination und Versiegen. Die Charaktere der Unvermitteltheit und Eruptivität des Lachens unterdrücken am Ablauf des Ausdrucks den Zug der Entfaltung und des Verklingens, weil ihr reaktiver Sinn es so erfordert. Labilität und Plötzlichkeit gehören nun einmal zum Anlaß des Lachens. ${ }^{234}$

Plessner zeichnet die Zeitformen und Bewegungsqualitäten beider sich gegensätzlich artikulierender Ausdrucksformen auf. Während das Weinen eine Kurve bilde, weise das Lachen Kürze, Raschheit und Plötzlichkeit auf. ${ }^{235}$ Eruptivität und Allmählichkeit bezeichnen jeweils Zeitformen, ähnlich wie accelerando und rallentando. Dadurch wird es möglich, Tempo, Rhythmus und Zeitgestaltung nicht auf der Ebene eines absoluten Zeitmaßes aufzufassen (schnell/langsam). Vielmehr sind Verläufe in Bezug zu ihren zeitlichen Sequenzen (und wiederum zu ihren Kontextualisierungen) im Ausdrucksgeschehen zu perspektivieren.

Plessners Zugang wird im Laufe der Untersuchung immer wieder aufgegriffen. Die in diesem Unterkapitel hervorgehobenen drei Fluchtlinien der Ausdruckstheorie, die ich als 1. Tempi/Bewegung, 2. Gefühlsbegriffe und 3. Ausdruck/Figuration kurzgefasst habe, werde ich im Folgenden mit film- und medientheoretischen Konzepten zu Expressivität in Zusammenhang bringen.

Dabei dienen die ersten beiden herausgearbeiteten Linien zur Konzeptualisierung der Tempi der Bewegung bzw. der Modi des Gefühls. Die dritte Linie der Figuration soll zu einem „meaning making“ in der Filmrezeption in Beziehung gesetzt werden. Da ich mit meiner Arbeit den Fokus sowohl auf die Formen filmischer Expressivität setze als auch danach frage, wie schauspielerische Formen, d.h. menschliche Bewegungen des Gesichts, der Stimme und der Gestik

234 Plessner 2003 (1945), S. 369.

235 Plessner 2003 (1945), S. 369. 
darin eingebunden sind, benötige ich diese doppelte Perspektive von der allgemeinen Theorie zum Ausdruck (am menschlichen Körper entwickelt) hin zur Spezifik filmischer Expressivität.

\subsection{Filmische Expressivität und die Gestaltung von Zuschauergefühlen}

Stand zunächst die allgemeine Ausdruckstheorie im Zentrum, dann verband sich damit vor allem das menschliche Ausdrucksverhalten, auch wenn bereits von den Zeitkünsten die Rede war. Im Zusammenhang mit dem Film verlagert sich nun der Zusammenhang zwischen Tempo und Gefühl in körperlichen Ausdrucksbewegungen hin zum audiovisuellen Filmbild. Das heißt, dass nicht allein der schauspielerische Körper, sondern die filmischen Inszenierungsformen (von denen das Schauspiel nur ein Element unter vielen ist) betrachtet werden. Ausgehend von den Zugängen zum Affekt- und Empfindungsbild gehe ich davon aus, dass filmische Bilder sich den Zuschauern als zeitliche Kompositorik von Ausdruckselementen präsentieren, dass sie selbst einem Gesicht ähnlich sind. ${ }^{236}$ Dabei verstehe ich das filmische Bild als immer schon zusammengesetzte, komplexe Bewegung, die figürliche und kinematografisch-rahmende Gestaltung ineinander setzt. Dies mündet in einer Vorstellung, welche das Filmbild als Ganzes in seiner zeitlichen Entfaltung meint, in seiner jeweiligen Ausrichtung auf eine schauspielerische Performance (Stimme, Gestik, Gesicht).

Hierzu beschreibe ich in drei Hauptkapiteln für die Screwball Comedy typische Bildformationen, die in den Kapiteln 3, 4 und 5 dargelegt werden. Dabei leitet mich die Annahme, dass verschiedene Gefühlsorchestrierungen im Kino von unterschiedlichen Zeitlichkeiten filmischer Inszenierung abhängig sind. Die schauspielerischen Formen nehmen in der Screwball Comedy eine prominente Rolle ein. Das Bewegungstempo des Filmbilds kann man aber weder allein am Schnitt oder der Kamera, noch allein am Gehen, Rennen oder Schleichen von Menschen im Bild festmachen, sondern nur an dem wahrnehmungsmäßigen Zusammenhang von filmisch-rahmender und schauspielerischer Expressivität.

236 Hermann Kappelhoff: Unerreichbar, unberührbar, zu spät. Das Gesicht als kinematografische Form der Erfahrung. In: montage/av 13 (2004b), H. 2, S. 29-53. Kappelhoff 1998; vgl. Deleuze 1997 (1983), S. 123-170. 


\title{
Kinästhetik und Ausdrucksbewegung
}

Während der Anfänge des Kinos aber auch später in der Zeit des Stummfilms in den 1920er Jahren beobachtete man das neue Medium mit großer Aufmerksamkeit. Dabei interessierte die Filmtheorie vor allem, wie die bewegten Bilder es vermochten, Dinge und Vorgänge dem alltäglichen Blick zu enteignen und an ihnen eine bis dahin neue, unbekannte Dimension aufzuzeigen: Aufgenommene Gegenstände, Antlitze und Räume wurden in ihrer sinnlichen und materiellen Beschaffenheit erlebt, ohne - wie Béla Balázs schreibt - immer schon von der Sprache vermittelt (bzw. zugedeckt) zu sein. ${ }^{237}$ So hat man in den sich bewegenden Ansichten filmischer Bilder eine neue Form des sinnlichen Denkens und Empfindens wahrgenommen. Rudolf Arnheim, Hugo Münsterberg, Sergej Eisenstein und Béla Balázs beschreiben die expressiven Formen filmischer Bewegungsbilder als aufs Engste mit den Gemütsregungen der Zuschauer verbunden. ${ }^{238}$ Aus den filmtheoretischen Positionen möchte ich beispielhaft Arnheim herausgreifen, in einer Textpassage zur ,Bewegung legt er sein Verständnis davon nahe:

\begin{abstract}
Sehen wir etwa, wie eine Mutter ihr Kind zu Bett bringt, so begreifen wir nicht nur diesen Vorgang, sondern in einem guten Film unterrichten uns zugleich die ruhigen oder hastigen, gewandten oder zuckenden, kräftigen oder schwächlichen, sicheren oder zaghaften Bewegungen der Mutter über ihren Charakter, ihr Verhältnis zu ihrem Kind und ihren augenblicklichen Gemütszustand; und der Gegensatz zwischen dem unvernünftigen Zappeln des Kindes und dem selbstbewussten Hantieren der Mutter ergibt eine Art Bewegungskontrapunkt, der den Ausdruckscharakter der Szene mindestens so stark bestimmt, wie das Aussehen der Mutter, des Kindes und der Umgebung, in der sie uns gezeigt werden. ${ }^{239}$
\end{abstract}

237 Siehe: Béla Balázs: Der sichtbare Mensch oder die Kultur des Films (1924). Mit einem Nachwort von Helmut H. Diederichs, Frankfurt a.M. 2001, S. 16-23.

238 Unter dem Stichwort des physiognomischen Denkens siedelt Balázs den Film zwischen körperlichen und geistigen Erlebensweisen an. Balázs 2001 (1924). Ähnliches haben u.a. Münsterberg, Arnheim oder Eisenstein formuliert. Hugo Münsterberg: Das Lichtspiel. Eine psychologische Studie (1916). In: Jörg Schweinitz (Hg.): Das Lichtspiel. Eine psychologische Studie (1916) und andere Schriften zum Kino. Wien 1996, S. 28-40; Hugo Münsterberg: Warum wir ins Kino gehen (1915). In: Dimitri Liebsch (Hg.): Philosophie des Films. Grundlagentexte. Paderborn 2005, S. 28-40; Rudolf Arnheim: Film als Kunst (1932). Frankfurt a. M. 1979; Sergej M. Eisenstein: Montage der Filmattraktionen (1924). In: ders.: Jenseits der Einstellung. Schriften zur Filmtheorie. Hg. von Felix Lenz und Helmut H. Diederichs. Frankfurt a. M. 2005, S. 15-40.

239 Rudolf Arnheim: Bewegung im Film (1934). In: ders.: Kritiken und Aufsätze zum Film, hg. von Helmut H. Diederichs. Frankfurt a. M. 1979, S. 41-46. Hier: S. 42. 
Freilich nimmt seine Beschreibung vor allem die Schauspielbewegungen auf. Dabei betont er die Bewegungsqualitäten, die über einen „Gemütszustand“ Aufschluss gäben. Gerade körperorientierte Adjektive zeigen dies auf: „die ruhigen oder hastigen, gewandten oder zuckenden, kräftigen oder schwächlichen, sicheren oder zaghaften Bewegungen“ machten ein „Verhältnis“ zwischen Mutter und Kind anschaulich. Er nennt ein weiteres Beispiel: Im Film MENSCHEN IM HOTEL etwa sei an Greta Garbos Körper - am Gang, an den Gesten etc. - eine ganz bestimmte Bewegungsmelodie zu erkennen: Entsprechend der Bewegungsqualitäten sei diese mal „sieghaft und kräftig, selig beschwingt, müde, gebrochen, angstvoll oder schwach“. ${ }^{240}$ Wieder beschreibt Arnheim den menschlichen Körper mit all seinen Ausdrucksmöglichkeiten: „die Mimik des menschlichen Gesichts und die Pantomimik des Körpers und der Gliedmaßen in ihnen drückt sich auf die direkteste und gewohnteste Art menschliches Denken und Fühlen aus.“241

Doch nicht nur an den Schauspielkörpern zeichnet Arnheim die Ausdrucksdimension nach. Die kinematografische Formen selbst begreift er als ausdrucksvoll, eine Kamerabewegung zeige bestimmte Wahrnehmungsweisen, z.B. die einer Subjektivität, „eines Taumelnden, Stürzenden, Fliegenden“. ${ }^{242}$ Solche Vorgänge seien gegeben, da die Kamera tatsächlich „konkrete, körperliche Vorgänge festhalten“ könne. ${ }^{243}$ Dadurch werde es möglich, dass das filmische Bild allein aus Aufnahmen von Gegenständen und Natur affektive Atmosphären herzustellen vermag. Er nennt als Beispiele das „Ziehen der Wolken, das Wiegen des Korns, der Sturz eines Wasserfalls“, das Hin und Her des Uhrpendels. ${ }^{244}$

Der Vorführung des Seelischen, die auf der Sprechbühne ein Monopol des Menschen, des Schauspielers ist, dienen beim Film tote Requisiten ebenso wie der mimende Mensch, eine zerbrochene Fensterscheibe ebenso wie ein zuckender Mund, ein Häufchen zerdrückter Zigarettenstummel ebenso wie das Getrommel nervöser Finger. So ergibt sich auch von hier aus die für die Filmkunst so bezeichnende Einordnung des Menschen in die Welt der Dinge. Nicht anders als der Menschenkörper des Darstellers zeigen andre Dinge der Welt die Spuren menschlichen Fühlens und menschlicher Entschlüsse. ${ }^{245}$

240 Arnheim 1979 (1934), S. 43.

241 Arnheim 1979 (1932), S. 173.

242 Arnheim 1979 (1934), S. 45.

243 Arnheim 1979 (1932), S. 167.

244 Arnheim 1979 (1934), S. 43.

245 Arnheim 1979 (1932), S. 181-182. 
Arnheim zeigt auf, dass die dingliche und menschliche Welt im Film gleichermaßen zur Erzeugung „,seelischer“ Vorgänge verwendet werden. Aus Arnheims Betrachtung, welche den Menschen qua Montage in die Welt des Gegenständlichen und die Dinge in die Welt des Empfindens einfügt, spricht der neusachliche Zeitgeist. ${ }^{246}$ Die Kunstfertigkeit schauspielerischer Mimik im Film präge sich je unterschiedlich gerahmt, kontextualisiert, gestaltet und inszeniert in verschiedenen kinematografischen Traditionen aus: Die Groteske stilisiere ein „pompöses Gesichter- und Gliederspiel ${ }^{\star 247}$, Gesichtsausdrücke im russischen Stummfilm behandelten das menschliche Antlitz eher als Requisit ${ }^{248}$ und der Tonfilm bzw. das Sprechen darin, so Arnheim, trage generell zu einer „Abbauarbeit“, zu einer „Entlastung der Mimik“ bei. ${ }^{249}$ Arnheim betrachtet Schauspielkörper und Filmtechnik als stark miteinander verschränkt.

Denkt man mit Arnheim weiter, dann lassen sich äquivalent zu den „zaghaften“, „zuckenden“, oder „kräftigen“ Schauspielbewegungen, die er am Beispiel der Garbo beschreibt, ebenfalls Bewegungsqualitäten auf der Ebene von Kamera, Schnitt oder Lichtdramaturgie finden, welche z.B. ruhig, hastig oder zaghaft sind. Solche Bewegungsqualitäten können den schauspielerischen Bewegungen entsprechen oder widersprechen, sie überlagern, verdecken oder hervorheben.

Wie eine solche Verwebung von Ausdrucksqualitäten des Schauspiels in der filmischen Artikulation stattfinden kann, beschreibt Arnheim anhand einer Szene aus CHICAGO ${ }^{250}$ von 1927; die Sequenz spielt im Zuschauerraum eines Gerichtssaals:

Man sieht in Großaufnahme eine Bank von jungen Mädchen, die mit offenen Augen gespannt der Verhandlung folgen und dabei ihren Kaugummi mahlen: wie Maschinen arbeitende Münder. Und nun geschieht irgendein aufregender Zwischenfall im Prozess, und wieder sieht man die Großaufnahme der kauenden Mädchen im Zuschauerraum, und plötzlich bleibt ihnen wie auf Kommando der Mund stehen - seelischer Vorgang: Spannung, der Atem stockt ihnen! [...] Diese indirekte Form der Darbietung vielmehr ist so neu, dass sie dem im Bilde gemeinten Seelenzustand zu stärkster Gegenwärtigkeit verhilft. Aber diese Einkleidung ist nicht nur neu, sie ist auch höchst schlagend, weil nämlich der Zusammenhang zwischen dem äußeren Vorgang und dem inneren, den er ausdrückt, nicht bloß inhaltlich-gedanklicher, sondern auch anschaulicher Natur ist: wenn die Mädchen ihre Münder anhalten, weiß man nicht bloß, versteht man nicht bloß: Sie sind gespannt! weil einem

246 Vgl. Hermann Kappelhoff: Der möblierte Mensch. G. W. Pabst und die Utopie der Sachlichkeit. Ein poetologischer Versuch zum Weimarer Autorenkino. Berlin 1995, S. 26-28.

247 Arnheim 1979 (1932), S. 176.

248 Arnheim 1979 (1932), S. 177.

249 Arnheim 1979 (1932), S. 176.

250 CHICAGO (Frank Urson, USA 1927). 
etwa aus der Erfahrung bekannt ist, dass Leute, die gespannt sind, plötzlich in ihrer Beschäftigung innehalten, sondern: der anschauliche Vorgang, dass nämlich eine gleichförmige, rhythmische Bewegung plötzlich auf einen Schlag eingestellt wird, enthält auch die charakteristischsten Eigenschaften des inneren Vorgangs, der dargestellt werden soll; auch diesen inneren Vorgang würde man so beschreiben, dass die gelassene Ruhe, mit der die Mädchen dem Vorgang folgen, plötzlich jäh abbricht - eine beklemmende Stauung. Und das ist auf eine geschickte Weise ins Optische transponiert. ${ }^{251}$

Arnheim betont, dass die spezifische zeitliche Gestaltung der Szene entscheidend dafür sei, dass man in einem visuellen, äußeren Vorgang einen inneren Vorgang, einen „Seelenzustand“ wahrnehme (Abb. 1).

Arnheim beschreibt, wie die Aktion des Schauspiels mit dem filmischen Ausdruck verwoben ist. Man sieht nicht nur von außen auf die drei Mädchen. Vielmehr sei „ein seelischer Vorgang: die Spannung“ über die Bewegungsqualität („die gelassene Ruhe“, die „plötzlich jäh abbricht - eine beklemmende Stauung“) „auf geschickteste Weise ins Optische transformiert“ (s.o).

Mit Arnheim kann man somit das Verhältnis von Schauspiel und filmischer Expressivität fokussieren. Einerseits erzeugen die Schauspielerinnen durch ihre Mimik, jede für sich, ein zeitliches Körperbild, das man als Überraschung und Anspannung in komödiantischer Überzeichnung an jeder einzelnen Schauspielerin beschreiben mag. Andererseits sind die Mädchen Teil einer bildlichen Einstellung und diese richtet sich als Ganzes (einer Orchestrierung von drei Frauengesichtern, nah gerahmt) in der Zeit (die Einstellung wird in der Szene über die Montage wiederholt) an den Zuschauer.

Wie dies zustande kommt, lässt sich mit Hermann Kappelhoffs Theorieund Analysekonzept filmischer Expressivität verdeutlichen, zielt es doch auf eben jenen Prozess ab, der ein äußeres Bild in ein inneres Bild transformiert:

So verstanden vollzieht sich die Bewegung des kinematografischen Bildes in drei Dimensionen, in der äußeren Bewegung des Dargestellten (die Bewegung dargestellter Objekte im Raum), in der inneren Bewegung des audiovisuellen Bilds (die Zeit des sich entfaltenden Films) und in der Übertragung der Bewegung des sich entfaltenden Films auf die Empfindungsbewegung des Zuschauers (der Prozess der 'Verinnerlichung'). Als ein solches „Bewegungsbild“ ist der Film zur paradigmatischen Darstellungsform für die Kunst des 20. Jahrhunderts geworden $(. . .)^{252}$

Das Dargestellte (das Schauspiel, die sichtbaren und hörbaren Dinge, Objekte) ist immer schon in die kinematographische Inszenierung eingebettet, es wird innerhalb des filmischen Bewegungsbilds verzeitlicht und richtet sich als

251 Arnheim 1979 (1932), S. 179-180.

252 Kappelhoff 2004a, S. 21. 


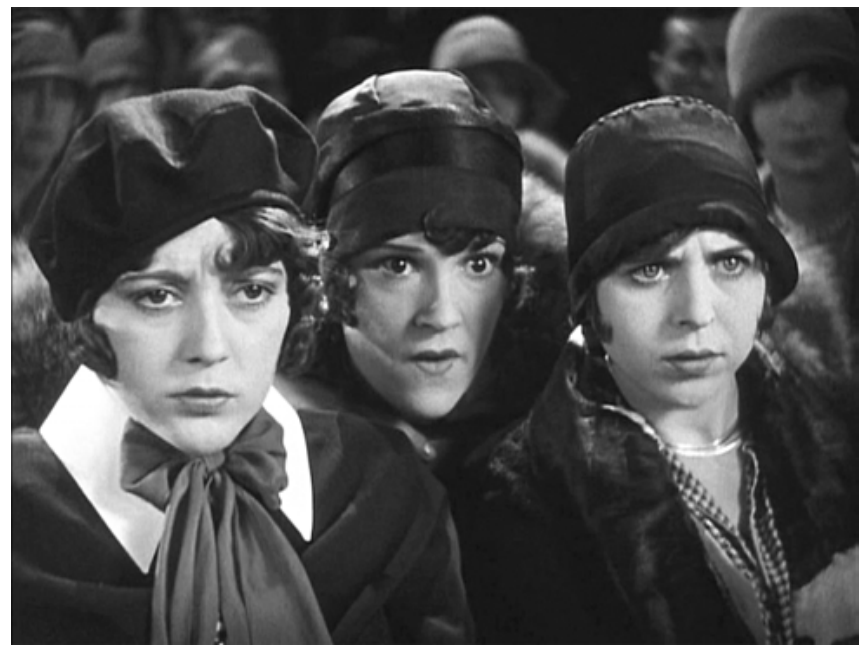

Abbildung 1: Das wohl abgestimmte mimische Spiel und seine Bewegungsqualitäten in CHICAGO.

Wahrnehmungsform an die Zuschauer. Die kinematografische Bewegung - die Ausdrucksbewegung - ist dabei eine modellierende Kraft, eine lenkende, prägende Gestaltung, Konstruktion und Formation von Wahrnehmungs- und Empfindungsprozessen:

Das kinematografische Bild wäre per se als eine mediale Form zu begreifen, die unmittelbar auf die Affektbewegung der Zuschauer durchgreift und sich einzig in der Zeit seiner Wahrnehmung verwirklicht. ${ }^{253}$

Die ästhetisch-fluiden Bildformen sind dementsprechend als bewegliche Energien dieser Affektbewegung zu begreifen. Am Paradigma der Großaufnahme verdeutlicht sich die Ausdrucksdimension des Filmischen besonders deutlich:

Die Großaufnahme transponiert das Mimische der Schauspielkunst, die Ausdrucksdimension des Gesichts, in eine Dimension des kinematografischen Bildes [...]. Sie artikuliert eine Ausdrucksbewegung, die sich über allen Ebenen des Kamerabildes, die Ausleuchtung, die gegenständliche Zeichnung, die Farben ausbreiten mag [...]. Das Mienenspiel des Gesichts bezeichnet die genuine Quelle, den „Ursprung“ dieser Art der Bewegung, nicht aber deren Grenze. ${ }^{254}$

253 Kappelhoff 2004a, S. 19.

254 Kappelhoff 2004b, S. 44-45. 
Dargestellte Objekte und Körper, die man auf der Leinwand sieht, sind immer nur als Teile des filmischen Bildes wahrnehmbar. Doch sie können Qualitäten, Elemente, Intensitäten etc. an andere Inszenierungsformen abgeben oder von diesen aufnehmen. Das ,Transponieren' bezeichnet bei Arnheim und Kappelhoff den Übergang des Gesichts, das einst vor der Kamera stand und in ein Bewegungsbild auf der Ebene der Montage übergeht und dadurch die Zuschauerwahrnehmung orchestriert.

Im Film ist das Ausdrucksspiel des Schauspielers kein für sich bestehendes Element, sondern ein integraler Bestandteil des kinematografischen Bildes. „Schauspielkunst im Film“ bezeichnet letztlich eine rein analytische Kategorie, die auf der Ebene der Darstellung kein für sich bestehendes Bedeutungssystem ausbildet. Sie ist immer in ein komplexes relationales Gefüge der zeitlichen Struktur des kinematografischen Bildes eingefügt. ${ }^{255}$

Schauspielkörper und Gegenstände (bei CHICAGO z.B. die mahlenden Münder, die Schleife, die Hüte der Frauen) sind ohne die Bildgestaltung (Kaderbewegung, Montage, Beleuchtung) nicht zu denken, aber sie lassen sich selbst auch als Inszenierungselemente (als Formen, graphische Elemente) fassen. Die Landschaften, Orte, Dinge und Schauspieler, die in den einzelnen Einstellungen ansichtig werden, werden verzeitlicht und in eine übergeordnete Bewegung eingefasst. Diese ,innere‘ Bewegung in der Zeit wird erst durch einen Zuschauer realisiert, der zum Resonanzkörper für das filmische Bild wird. ${ }^{256}$

Dennoch bleiben die sich bewegenden Körper, die Dinge, die „Bewegung dargestellter Objekte im Raum“257 für den Zuschauer eine Art Ankerpunkt des eigenen Empfindens. Berührt mich eine Szene, etwa die der mahlenden Münder aus CHICAGO, dann genieße ich einerseits die Selbstaffizierung, dass ich meine eigenen Wahrnehmungskräfte spüre. So sind die Gesichter Ursprung des Vergnügens. Von denen im Bild dargestellten Frauengesichtern verweist einerseits jedes auf sich als ganz eigene Körperlichkeit. Andererseits sind sie bildlich so angeordnet - sie kauen und stoppen das Kaugummikauen -, als wären sie ein Gruppenkörper. Die Rahmung, die Kadrierung, der Schnitt, das sich entfaltende Filmbild, stiftet diese Einheit, es lässt die einzelne Körperlichkeit mit den anderen in einer Bildform verschmelzen. Kappelhoff schreibt: „Die schauspielerische Darstellung geht in der Bewegung eines sich entfaltenden Bewegungsbildes auf und bildet doch in ihrer zeitlichen Struktur die Keimform, aus der heraus sich das kinematografische ,Empfindungsbild’ entfaltet.“258 In Anlehnung an diese

255 Kappelhoff 2004b, S. 44.

256 Kappelhoff 2004a, S. 21.

257 Kappelhoff 2004a, S. 21.

258 Kappelhoff 2004b, S. 44. 
Formulierung Kappelhoffs, die er am melodramatischen Bildtypus des Affektbilds aufzeigt, möchte ich diesen Vorgang von der Keimform zur figurativen Verzweigung nennen: Die Bewegung multipliziert sich in ihren Dimensionen, in denen sie wirksam wird. So löst sich die Dynamik von den Einzelgesichtern ab, wird zur Gruppenbewegung, zur Montage und setzt sich als Empfindungsbewegung fort. Doch gleichzeitig bleibt die Bewegung immer noch an ihren Ursprung, an das Bildelement gebunden: an den einzelnen kauenden, mahlenden Mund. Was bleibt ist nicht nur der affektive Vorgang, sondern man realisiert als $\mathrm{Zu}$ schauer die eigene Gestimmtheit als auf die Schauspieler oder andere Gegenstände bezogen. Kleine, kürzere Detailbewegungen können nach Kappelhoff zur ,Keimform,259 von großen sequenzübergreifenden Bewegungen werden. Dieses Prinzip hat Gilles Deleuze etwa am Beispiel der „Globalbewegung“ bei Hitchcock aufgezeigt (er zitiert hierbei Francois Regnault). Dabei gebe es für jeden von Hitchcocks Filmen

[...] eine Globalbewegung oder eine „geometrische bzw. dynamische Grundform“ [...], die in ihrem Reinzustand im Vorspann erscheinen könnte: „die Spiralen in Vertigo, die gebrochenen Linien und die Schwarz-Weiß-Kontraststruktur in Psycho, die cartesischen Pfeilkoordinaten von North by Northwest... “ [...] so kann in Vertigo die große Spirale zum Schwindelfall des Helden werden, aber auch zu der Strecke, die er mit seinem Auto beschreibt, oder auch zur Spange im Haar der Hauptdarstellerin. ${ }^{260}$

Diese dynamischen Grundformen mag man nach Kappelhoff auch als poetologische Prinzipien zwischen Affektbewegung und kognitiver Reflexion auffassen, die als kreativer Akt einer Poesis des Filme-Sehens realisiert werden. ${ }^{261}$ Deleuze fasst sie in ähnlicher Weise als Bildformationen, die einerseits das Wahrnehmen, das Empfinden selbst sind und gleichzeitig an die Figuren rückgebunden werden, wie er anhand von VERTIGO ${ }^{262}$ erklärt:

Vertigo zum Beispiel vermittelt uns ein echtes Schwindelgefühl, und das Schwindelerregende daran ist - im Herzen der Heldin - die Beziehung zu sich selbst als Doppelgängerin $\left[\ldots . . .^{263}\right.$

So gesehen sind die „Globalbewegungen“ des Films nichts Anderes als die Erfahrungsformen des Zuschauers selbst. Sie können sich in einer Szene oder einem ganzen Film fortpflanzen, sie können wachsen und sich ästhetisch verzweigen.

259 Kappelhoff 2004b, S. 44.

260 Deleuze 1997 (1983), S. 39-40.

261 Kappelhoff 2018, S. 11.

262 VERTIGO (Alfred Hitchcock, USA 1958).

263 Deleuze 1997 (1983), S. 274. 
Gemeinsam ist ihnen, dass sie zwar grafischer Art (Spiralen, Linien bei Hitchcock etc.) oder lichtinszenatorischer, formativer oder musikalischer Natur sind, doch meist figürlich gebunden auftreten, zumindest im narrativen Film. Sie keimen auf in Bildformationen, heften sich an Stimmen, Mimiken, Gesten und Worte und werden dann zu komplexen audiovisuellen Kompositionen. Dieser Aspekt, wie die Zuschauererfahrung an bestimmte Inszenierungsweisen gebunden ist, dies jedoch meist an Figuren rückbindet, wird später in den Kapiteln zu Geste und Gesicht weiter vertieft.

\section{Gefühl: Die Affizierung des Zuschauers}

Das Überspringende, Fortpflanzende und Verzweigende von Bildintensitäten, die als leibliche Resonanz erlebbar werden, lässt sich als Vorgang der Affizierung fassen. Die filmischen Affekte mögen auf Zuschauer überspringen, sie sind zunächst jedoch nicht-menschlicher Natur. Sie können sich vielfältig audiovisuell artikulieren, sie können etwa das „Schneidende“, „Zerteilende“264 sein, ein sich Vereinigendes, Explodierendes oder ein Tönen, Leuchten, SichSättigen. Deleuze zeigt in seinen Ausführungen zum Affektbild auf, wie er das Verhältnis von Ausdruck und Affekt denkt:

Der Affekt ist eine Entität, das heißt Potential oder Qualität, Er wird ausgedrückt: Der Affekt existiert nicht unabhängig von etwas, was ihn ausdrückt, auch wenn er sich völlig von ihm unterscheidet. Was ihn ausdrückt, ist ein Gesicht, das Äquivalent eines Gesichts (ein in ein Gesicht verwandeltes Objekt) oder sogar ein Satz. ${ }^{265}$

Deleuze betrachtet die filmischen Formen der Audiovision als Äquivalente des Gesichts. Im Anschluss an Balázs arbeitet er die Expressivität des kinematografischen Bildes heraus. Ist das Filmbild in seiner Gestaltetheit ähnlich arrangiert wie eine mimische Bewegung, dann lässt es sich als Potential oder Qualität beschreiben, als Bewegung, die an dynamische Gesichtszüge gebunden ist (Intensitätsreihen) oder die der bleibenden Flächigkeit des Gesichtsumrisses entspricht (reflektierende Einheit). Die Formen des reflexiven Gesichts und intensiven Gesichts sind Prinzipien dieser Gesichtshaftigkeit des filmischen Bilds ${ }^{266}$ : Einmal ist die Kontur, der Umriss oder die Fläche des

264 Deleuze 1997 (1983), S. 136.

265 Deleuze 1997 (1983), S. 136.

266 Hermann Kappelhoff und Sarah Greifenstein: Feeling Gloomy or Riding High: Timings of Melodrama and Comedy. In: Marie-Luise Angerer, Michaela Ott und Bernd Bösel (Hg.) Timing of Affect. Epistemologies of Affection. Zürich 2014, S. 263-282. 
Gesichts angesprochen, dann verwendet Deleuze den Begriff der Qualität. Dann wieder sind stärker die expressiven Mikrobewegungen als Intensitäten wahrnehmbar: In dieser Hinsicht bezieht sich das Gesichtshafte auf die Züge, die als Potentalitäten zusammenwirken. In diesem Sinn, so Deleuze, existiert das Ausgedrückte nicht unabhängig von seinem Ausdruck. ${ }^{267}$ Der Affekt ist gerade nicht durch eine Zeichenbeziehung zum Ausdrückenden bestimmt, vielmehr sind sie nicht voneinander ablösbar. Die filmischen Affekte sind in dieser Hinsicht unpersönliche, nicht-subjektive und nicht-menschliche Kräfte, die sich wenn man über Deleuze hinaus den Zuschauer mit einbezieht - als dynamische Berührungsformen ${ }^{268}$ ausprägen und dann Filmbewegung und Zuschauerkörper miteinander verbinden. In den wahrnehmungsbedingten Berührungen zwischen Leinwand und Zuschauerkörpern realisieren sich diese Kräfte, Intensitäten und Potentiale, als reine Affekte.

Erst in einer gewissen Dauer setzen sich die Affekte in der Filmerfahrung kompositorisch zusammen, erst über einen gewissen Zeitraum bildet sich die Erfahrung eines Zuschauergefühls. ${ }^{269}$ Dabei ist dieses als Zusammenspiel aus affektiven, perzeptiven und kognitiven Prozessen zu verstehen, es baut darauf auf, dass man sieht, hört und spürt, aber auch sich erinnert, reflektiert und urteilt. Erst in dieser Anordnung zeitlicher Erfahrung wird dem Zuschauer, wie Kappelhoff schreibt,

[...] das kinematografische Bild in der Zeit seiner Entfaltung zu einem Objekt, das Gefühle nicht repräsentiert, sondern sich in ihm als ein ,Ich nehme wahr, ich denke, ich empfinde“ realisiert. Ihm wird das kinematografische Bild in seiner inszenierten Zeitlichkeit zu einem ,inneren Objekt‘, zu einer psychischen Realität. ${ }^{270}$

Während die Affekte kurze Intensitäten oder starke Wechsel der Qualitäten sein können, ist das Zuschauergefühl durch eine andauernde Entfaltung bzw. an eine rezipierende Subjektivität gebunden. Die Affekte sind nicht-persönlich, anonym, erst im Zuschauergefühl realisieren sie sich als ein Zusammenhang von Empfinden, Verstehen und Wahrnehmen. In diesem Sinn verstehe ich das Zuschauergefühl, das sich in der Filmerfahrung konstituiert als dynamische Bindungsform, die an eine wahrnehmende Subjektivität gebunden ist und welches

267 Vgl. Gregg Lambert: Expression. In: Charles J. Stivale (Hg.): Gilles Deleuze. Key Concepts. Chesham 2005, S. 35-42.

268 Siehe Kapitel 2.3.

269 Vgl. Kappelhoff und Bakels 2011.

270 Kappelhoff 2008, S. 206. 
die Umwandlung des kinematografischen Bildes in ein „inneres Objekt“, einen inneren Gefühlsprozess meint. ${ }^{271}$

In diesem Prozess spielt vor allem die Zeitgestaltung selbst eine Rolle. Diese wird durch Tempi, Rhythmizität und andere Dimension der Zeiterfahrung wirksam.

\section{Bewegung: Filmische Tempi und Bewegungsqualitäten}

Die Tempi oder Bewegungsqualitäten sind Präsenzen filmischer Bewegung, sind aber immer schon eingefasst in Wahrnehmungsvorgänge, in Zuschauererfahrung und Affektivität. Die wie oben bei Arnheim skizzierten Bewegungsweisen wie z.B. ruhig, schwankend, das Wiegen, Auf und Ab, hastig, etc. dienen dabei als Zugriff der Beschreibung einer solchen kinästhetischen Affizierung.

Die Bewegungsqualitäten lassen sich als amodale Eigenschaften fassen, die sich im Schnitt, in der Kamera und in den Schauspielbewegungen aber auch in den Atmosphären der Lichtdramaturgie realisieren können, welche die einzelnen Einstellungen miteinander verweben. Alle Bewegungsformen sind hierfür relevant: das Explodieren, das Gleiten, das Verwischen, das Hüpfen, Schleichen, das leichte Trippelnde, das harte und schwere Hackende, das Rutschende, Sichdrehende, Aufsteigende, Drückende etc. Methodisch-deskriptiv fokussiere ich entsprechend Bewegungsverben (oder ihre Substantivierungen) für die gesamte Verlaufsform (z.B. das Klopfen) und Adjektive zur Präzision der sinnlichen Eigenschaften dieser Bewegung (das sanfte Klopfen, das eilighastige Klopfen, das harte-energische Klopfen). Damit ist die Problematik angesprochen, wie sich Tempi des Kinematografischen überhaupt fassen lassen, nämlich nur im Zusammenspiel aller Inszenierungsebenen. Die Tempi sind in gewisser Weise die sich wandelnden Qualitäten und Intensitäten. Mit ihnen sind andere Eigenschaften sinnlicher, wahrnehmbarer Materialität verbunden.

An den Phänomenen der Zeitlupe und des Zeitraffers lässt sich diese Problematik verdeutlichen. So ist in der Zeitlupe das Tempo langsam, gedehnt und damit wird auch die sichtbare Körperbewegung als andere Materialität wahrnehmbar: als schweres Gewicht; minimale Bewegungsdetails werden sichtbar, intensiver wahrnehmbar. Die Zeitlupe vergrößert die Bewegung selbst wie unter einer Lupe, sie ist ein Äquivalent zur „Großaufnahme“, so Jean

271 Zum Film als „Objekt im Übergang zwischen äußerem Bild und innerer Imago“ siehe Kappelhoff 2004a, S. 305. 
Epstein. ${ }^{272}$ Die Zeitlupe verleihe, so Arnheim, der Bewegung eine „eigentümlich gleitende, schwebende, überirdische“ Wirkung. ${ }^{273}$ Anders der Zeitraffer, der eine Art Skizze von körperlichen Bewegungen zu schaffen scheint, in der die Gesten leicht, fast ohne Gewicht und kurz aber auch zerhackt erscheinen: als Abkürzungen, Zuspitzungen vom Gehen, Laufen oder Tanzen, als Andeutung, aber auch Essenz oder Karikatur. Andererseits, so hat es Arnheim betont, könne der Zeitraffer eben auch andere Zeitlichkeiten erst sichtbar machen, die uns sonst nicht zugänglich sind:

[Bei] diesen Aufnahmen [den Zeitrafferaufnahmen von Pflanzen Anm. sg] hat sich herausgestellt, daß die Pflanzen eine Mimik haben, [. . .] Die wiegenden, rhythmischen Atmungsbewegungen der Blätter, der erregte Tanz der Blätter um die Blüte, die fast obszön wirkende Hingabe, mit der eine Blüte sich öffnet - die Pflanzen waren plötzlich lebendig geworden und zeigten Ausdrucksbewegungen von genau der selben Art, wie man sie von Menschen und Tieren kennt. Wie eine emporkletternde Pflanze ängstlich tastend, unsicher, nach Halt sucht, wenn ihre Ranken sich an einem Gitter hochwinden, wie eine welkende Kaktusblüte fast mit einem Seufzer den Kopf neigt und zusammenknickt - es war die unheimliche Entdeckung einer neuen lebendigen Welt in einem Bezirk, aus dem man zwar wußte, daß dort Leben zu Hause sei, es aber niemals ,in Tätigkeit' hatte sehen dürfen. ${ }^{274}$

Die ,Ausdrucksbewegungen“ der Pflanzen, die fast menschlich wirkenden Tast-, Such- oder Öffnungsbewegungen, erscheinen als Verhalten, weil ihre Zeitlichkeit an den menschlichen Zeit-Maßstab einer sichtbaren Bewegung angepasst wird. So ähnelt ihr Wachsen und Aufrichten der Geschwindigkeit eines wesenhaften Sich-Bewegens.

Die Tempi der Bewegung sind demnach nicht als messbare Pole von ,schnell‘ vs. ,langsam‘ zu verstehen, sondern als kinematografische Verfahren, welche - wie Zeitlupe und Zeitraffer - eine spezifische Entfaltung von Zeitlichkeit ermöglichen, die eine ganz eigentümliche Seite der Dinge, eine ganz anders beschaffene körperliche, sinnliche Welt $\mathrm{zu}$ offenbaren vermag, die uns sonst verborgen bliebe. Aus der Beobachtung zur Zeitlupe kann man auch für jede andere langsame-gedehnte Bewegung schließen, dass sie die Bewegung tendenziell vergrößert, dass mit der Verlangsamung all ihre feinsten Nuancen sichtbarer werden, dass kleine Details gewichtiger werden, weil sie anhalten,

272 Zitiert nach Jacques Aumont: The Face in Close-Up. In: Angela Dalle Vacche (Hg.): The Visual Turn. Classical Film Theory and Art History. New Brunswick 2003, S. 127-148, hier: S. 146.

273 Arnheim 1979 (1932), S. 138.

274 Arnheim 1979 (1932), S. 137. Es handelt sich bei Arnheims Beispiel um Das Blumenwunder, ein Film von I.G. Farben / BASF, 1926, der sehr bekannt war, über ihn schrieben auch Max Scheler, Helmuth Plessner und Walter Benjamin. Siehe Gertrud Koch: Die Wiederkehr der Illusion. Der Film und die Kunst der Gegenwart. Berlin 2016, S. 18-21. 
andauern und sich nur graduell verändern. Ebenso kann man aus der Beobachtung zum Zeitraffer sagen, dass Beschleunigungen im Kino ebenso die Gewichtswahrnehmung beeinflussen: so wirken beschleunigte Gesten leicht, klein, luftig, zart oder auch kindlich. Für die Frage nach den Tempi bzw. Bewegungsqualitäten sind also die Wahrnehmungsbedingungen, die phänomenalen Eigenschaften, mit denen eine Bewegung einhergeht entscheidend. Im Zusammenhang mit der Perspektive dieser Untersuchung stellt sich die Frage, wie das Wahrnehmen einer schauspielerischen Geste filmisch kontextualisiert ist; wie eine Geste z.B. von wilder Extase durch das Kinematografische moduliert wird, je nachdem ob sie in einem starren, anhaltenden Kader von weit weg oder in eine dynamische Montagebewegung mit vielen Großaufnahmen eingebettet ist. Als Tempi fasse ich modalitätsunabhängige, dynamische Bewegungsqualitäten, die sich sowohl in menschlich-schauspielerischen als auch filmischen Ausdrucksformen (Schnitt, Kamerabewegung etc., Änderung der Lichtvaleurs etc.) artikulieren. Beispiele für die Bewegungsqualitäten sind: ruhig, schnell, rasch, langsam, beschleunigend, verlangsamend, hastig, eilig, getragen, kontinuierlich, gleitend, unterbrochen, gleichmäßig, wiederholend, zaghaft, zögerlich. Diese werden ergänzt durch sinnliche Attribute des Gewichts, der Form, Richtung und Materialität: zart, leicht, schwer, emporsteigend, weitend, engend, kurvig, glatt etc. Zudem werden auch weitere rhythmische (oder durch exakte Verlaufskonturen bestimmte) Bewegungsformen in die Beschreibung einbezogen: hüpfen, springen, schweben, wirbeln, drücken, verharren, explodieren, pressen, zittern, beben etc. Darüber hinaus wird es darum gehen, wie in audiovisuellen Bildern dynamische Ausdrucksformen synästhetisch beschreibbar werden, wie Klanglichkeit und Visualität interagieren und sich in der Wahrnehmungssynthese zusammensetzen. Ein klassifizierendes Bewegungsvokabular, für die Analyse nutzbar, wird in Kapitel 4 (Geste) entworfen.

Nachdem ich nun die erste und zweite Linie der Ausdruckstheorie zur ,medialen und künstlerischen Expressivität' (im Hinblick auf die Tempi der Bewegung) sowie zu ,Ausdruck und Gefühl' in den Forschungsbezügen verortet habe, möchte ich nun die dritte Linie der Ausdruckstheorie ,Sprachlichkeit, Zeichenhaftigkeit und Ausdruck' im Hinblick auf verkörpertes Denken und Verstehen filmtheoretisch wenden. Dies möchte ich unter dem Stichwort der metaphorischen Figuration erläutern.

\section{Figuration: Cinematic Metaphor und das filmische Denken}

Mit der Komik in den Filmen des Komödiengenres wird oftmals ein Inkongruenzerleben von Zuschauergefühlen und fiktiven Figurengefühlen inszenatorisch 
erzeugt. Da ein überwiegender Teil der Forschungsliteratur zur Screwball Comedy narrative Handlungen, Erzählmuster und fiktiven Figuren als reine Repräsentationen beschreibt, ohne den Prozess einer Entstehung von Fiktionalität zu hinterfragen (siehe Unterkapitel 2.2.), kann dieser Aspekt mit den üblichen Modellen filmwissenschaftlicher Filmanalyse nur unzureichend erklärt werden. Daher möchte ich mit dem Fokus auf filmische Metaphorik rekonstruieren, wie audiovisuelle Figurationen und verkörperte Verstehensprozesse in der Filmerfahrung entstehen. Dies soll in Bezug zu meiner zweiten grundlegenden Perspektive der Arbeit, der Eingebettetheit des Schauspiels in das Filmbild erörtert werden. Ich frage danach, auf welche Weise der Verstehensprozess mit den Zeitinszenierungen zusammenhängt. Ziel dieser Fokussierung ist es, ein vom Zuschauererleben geprägtes Empfinden im Hinblick auf die Figurenkonstruktion zu erschließen. Dabei sind Übertragungsprozesse von Erfahrung angesprochen, die sich aus neophänomenologischer Perspektive im Zusammenhang mit Prozessen des Somatischen, der Affizierung und Leiblichkeit beschreiben lassen. Weniger im Blick waren für die philosophisch-ästhetische Linie der Filmwissenschaft bis vor Kurzem jedoch Prozesse der Semiose, der Sinn- oder Bedeutungsformung sowie Figurenkonstruktion und Narrationsbildung. Als Denkfigur einer Bedeutungswandlung, als Übertragung von Sinnzusammenhängen ist die Metapher - sozusagen als Transportmittel von Erfahrung - in ihrer Bandbreite zentral. ${ }^{275}$

In den letzten 40 Jahren hat sich in der kognitiv-linguistischen Metaphernforschung ein Zugang etabliert, der Metaphorisierungsprozesse als über die Artikulation von Sprachmetaphern hinausgehend versteht. Die Metapher bei George Lakoff und Mark Johnson ist als Akt des Erfahrens und Verstehens zugleich definiert: „the essence of metaphor is understanding and experiencing one kind of thing in terms of another“. ${ }^{276}$ Demnach werden in der Theorie von Lakoff und Johnson Metaphern als kognitive Phänomene aufgefasst, die unserem Denken zugrunde liegen und sich lediglich in unterschiedlichen Modalitäten realisieren. Metaphern sind nach diesem Modell in verkörperten Erfahrungen verwurzelt und können erworbene Erfahrungsschemata aufrufen. Nach den weiteren Entwicklungen zur Metapher rund um das Thema Embodiment und Sprache haben sich verschiedene Schulen bzw. Strömungen gebildet, wovon ich eine näher beleuchten möchte.

Innerhalb der kognitiven Metapherntheorie ist neuerdings besonders ein dynamischer Ansatz von Metaphorizität prominent geworden, der sich durch den Fokus auf Anwendung, Gebrauch und Kontextualität von Metaphorik von universalistischen Zugängen unterscheidet. Die dynamischen Ansätze von

275 Kappelhoff und Müller 2011; Müller und Kappelhoff 2018.

276 George Lakoff und Mark Johnson: Metaphors We Live By. Chicago/London 1980, S. 3. 
Lynne Cameron, Ray Gibbs oder Cornelia Müller betonen die Spezifik und Situiertheit des jeweiligen Metaphernereignisses ${ }^{277}$, dynamische Erzeugungen von Metaphorizität sowie Verkörperungen in Gesprächen und Interaktionen. ${ }^{278}$ Der dynamische Zugang Cornelia Müllers zur Aktivierung von Metaphorizität in verbal-gestischer Kommunikation setzt den Fokus darauf, welche Grade von Metaphorizität durch das Sprecherverhalten moduliert werden. Dabei erweisen sich Metaphern als spezifische als auch wiederkehrende Formationen, die nicht nur den gesamten Diskurs in einem Gespräch strukturieren können, sondern auch im Stande sind Sinn- und Bedeutungskonstitutionen zu etablieren, die sich nicht mehr in rein sprachlichen Substituten auflösen lassen. Dies liegt vor allem an den von Müller beschriebenen und klassifizierten metaphorischen Verkörperungsakten in Gesten. In einem Gespräch werden Sprachmetaphern durch gestische Vergegenwärtigung lebendig, durch Gebärden werden Szenarien etabliert, welche den Bedeutungsgehalt einer Unterhaltung zentral steuern können. Nicht nur können Metaphern nach Müller in unserem Denken verwurzelte Erfahrungsschemata verdeutlichen und aufrufen, sondern der kognitive Prozess selbst wird - wie Müller zeigt - in einem Gespräch durch Formen des Foregroundings und der Aktivierung in der zeitlichen Entfaltung von Metaphern, durch Sprache und Gesten, veranschaulicht bzw. gestaltet. ${ }^{279}$ Metaphorizität fasst Müller demnach als ein dynamisches Phänomen, welches sich in Face-to-face-Kommunikation aber auch in medialer Wahrnehmung, also der Film- und Medienrezeption ausprägen kann. In jüngsten Forschungen haben Hermann Kappelhoff und Cornelia Müller das Phänomen der Metapher in audiovisuellen Bewegungsbildern anhand unterschiedlicher Medienformate untersucht und zeigen können, dass basale Formen des filmischen Verstehens und Denkens mit Rückgriff auf metaphorische Prozesse rekonstruierbar sind. ${ }^{280}$ Sie explizieren damit einerseits Überlegungen zur

277 Lynne Cameron: Metaphor and Reconciliation. The Discourse Dynamics of Empathy in Post-Conflict Conversations. New York 2011; Raymond W. Gibbs: Embodiment and Cognitive Science. Cambridge 2006, S. 121.

278 Cornelia Müller: Metaphors Dead and Alive, Sleeping and Awaking. A Dynamic View. Chicago 2008.

279 Das Foregrounding meint nach Müller eine Art Aufmerksamkeitslenkung durch den Sprechenden; gestische Bildformen unterstreichen und betonen bestimmte Aspekte am Gesprochenen und umgekehrt. Cornelia Müller und Susanne Tag: The Dynamics of Metaphor. Foregrounding and Activating Metaphoricity in Conversational Interaction. In: Cognitive Semiotics (2011), H. 6, S. 85-120. Die Aktivierung von Metaphorizität ist eine zeitlichdynamische Form der multimodalen Wiederaufnahme und Modulation metaphorischer Äußerung. Müller 2008.

280 Müller und Kappelhoff 2018; Kappelhoff 2018. 
Metapher, die von der Filmtheorie angestellt wurden. So hat etwa Sergej Eisenstein mit der Metapher das Zusammenwirken zweier Bilder als Assoziation beschrieben. ${ }^{281}$ Roman Jakobson hat mit seinen Ausarbeitungen zu Metapher und Metonymie auf die Wirksamkeit der beiden Denkprinzipien als Kontiguitätsform (Metonymie) bzw. als Similaritätsprinzip (Metapher) auch für die Künste und den Film hingewiesen. ${ }^{282}$ In den filmtheoretischen Zugängen der 1980er und 1990er sind außerdem semiotische, strukturalistische und narrationsbezogene Ansätze zu vermerken, die das Phänomen intensiv in den Blick nehmen. ${ }^{283}$ Aktuelle Ansätze kommen aus dem Bereich der Rhetorikund Kommunikationsforschung ${ }^{284}$, der kognitiv-philosophischen Filmtheorie (etwa die visuelle Metapher von Noël Carroll ${ }^{285}$ ), der kognitiven Medienwissenschaft (z.B. die multimodale Metapher ${ }^{286}$ oder Fahlenbrachs Arbeiten zur audiovisuellen Metapher ${ }^{287}$ ). Die aktuellen Ansätze beschreiben das Phänomen der Metapher höchst unterschiedlich, sie beziehen sich auf ästhetische, rhetorische, kognitiv-linguistische oder narrative Zugänge. Sie betrachten jedoch in erster

281 Auf den Film bezogen sind Metaphern etwa von Eisensteins als zentral für die bildlichen Systeme und Zeichenbeziehungen angesehen worden. Sergej M. Eisenstein: Dramaturgie der Filmform (1929a) In: ders.: Jenseits der Einstellung. Schriften zur Filmtheorie. Hg. von Felix Lenz und Helmut H. Diederichs. Frankfurt a. M. 2005, S. 88-111; Sergej M. Eisenstein: Dickens, Griffith und wir (1942) In: ders.: Jenseits der Einstellung. Schriften zur Filmtheorie. Hg. von Felix Lenz und Helmut H. Diederichs. Frankfurt a. M. 2005, S. 301-366.

282 Vgl. Roman Jakobson: Zwei Seiten der Sprache und zwei Typen aphatischer Störungen (1956). In: ders.: Aufsätze zur Linguistik und Poetik. Hg. Von Wolfgang Raible. Frankfurt a. M./Berlin/Wien 1979, S. 117-141; zur Metonymie generell siehe auch Irene Mittelberg: Metaphor and Metonomy in Language and Gesture. Discourse Evidence for Multimodal Models of Grammar. Cornell University 2006.

283 Siehe Christian Metz: The Imaginary Signifier. Psychoanalyis and Cinema. Kapitel Metaphor/Metonymy, or the Imaginary Referent. Bloomington 1982, S. 149-228; Jacques Gerstenkorn: La métaphore au cinéma. Les figures d'analogie dans les films de fiction. Paris 1995; Trevor Whittock: Metaphor and Film. Cambridge 1990.

284 Siehe Gesche Joost: Bild-Sprache. Die audiovisuelle Rhetorik des Films. Bielefeld 2008.

285 Siehe Noël Carrol: A Note on Film Metaphor In: ders.: Theorizing the Moving Image. Cambridge 1996, S. 212-223.

286 Siehe Charles Forceville und Marlies Jeulink: The Flesh and Blood of Embodied Understanding. The Source-Path-Goal Schema in Animation Film. In: Pragmatics and Cognition 19 (2011), H. 1, S. 37-59; Charles Forceville und Eduardo Urios-Aparisi (Hg.): Multimodal Metaphors. Berlin 2009; oder das ebenfalls an der kognitiven Metapherntheorie ausgerichtete Modell von Maarten Coëgnarts und Peter Kravanja: The Eyes for Mind in Cinema: A Metaphorical Study of the Viewer's Experience. In: Kathrin Fahlenbrach (Hg.): Embodied Metaphors in Film, Television, and Video Games. Cognitive Approaches. New York/London 2016, S. 129-144.

287 Siehe Kathrin Fahlenbrach: Audiovisuelle Metaphern. Zur Körper- und Affektästhetik in Film und Fernsehen. Marburg 2010. 
Linie offensichtliche, auffallende Formen von Metaphern, entweder in rhetorikorientierter Analogie zur Sprachmetapher oder in Anlehnung an den universalistischen Zugang Lakoffs und Johnsons. Im Zusammenhang mit Film und Medien verorten die Zugänge die Metapher überwiegend in Relation zu repräsentierten Motiven. Was dabei unberücksichtigt bleibt, ist die zeitliche Entfaltung filmischer Bilder sowie die Frage danach, wie Metaphorik nicht nur auf erworbene Erfahrung rückgreift, sondern im Zusammenhang mit ad hoc entstehender Verkörperung in der Filmerfahrung zu fassen ist.

Cinematic Metaphor konzeptualisiert Operationen der Wahrnehmung, der Affizierung und der kognitiven Reflexion in einem dynamischen Verständnis der Bewegungsbilder als verkörperte Akte im Filme-Sehen. Nicht die Darstellung eines Gegenstands oder Motivs, nicht die außerfilmische Realität ist für die Erzeugung einer Metapher notwendig; vielmehr geben Metaphorizitäten Aufschluss darüber, wie das Verstehen und Denken in und mit filmischen Bildern zeitlich auf der Ebene der Zuschauererfahrung organisiert ist. Die Metapher entsteht aus expressiven Bewegungsfigurationen (Ausdrucksbewegung), deren Sinnbezüge sich erst in der zeitlichen Anordnung der Zuschauerwahrnehmung konstituieren. Das Konzept der Cinematic Metaphor berücksichtigt die zeitliche Eigenschaft audiovisueller Bewegungsbilder (als fluide Wahrnehmungsadressierung) und richtet ihr Augenmerk auf emergierende Poetologien filmischer Bilder als ein an perzeptiven Formen organisierter Akt des verkörperten Filme-Sehens. ${ }^{288}$ Die grundlegenden Annahmen für die Cinematic Metaphor sind nach Müller und Kappelhoff folgende:

- Metaphern emergieren aus filmischen Bewegungsbildern

- Filmische Metaphern basieren auf Akten affektiver und verkörperter Erfahrung (die vom Film während der Rezeption moduliert wird) und sind anhand von filmischen Ausdrucksbewegungen rekonstruierbar.

- Der Sinn- und bedeutungsgenerierende Prozess, der mit den entstehenden Metaphern einhergeht, ist verkörpert, intersubjektiv, reflexiv, kulturspezifisch bzw. historisch bestimmbar, da er an die poetologischen Spezifiken der Filme bzw. audiovisuellen Medien gebunden ist und dadurch als Operationen von Wahrnehmung, Affektivität und Kognition einschließt. ${ }^{289}$

Was im Prozess der Metaphorizität hervortritt ist eine Poesis des Filme-Sehens. ${ }^{290}$ Die Zuschauer konstruieren mit den Metaphern, welche als Werkzeuge des

288 Kappelhoff 2018.

289 Alle Spiegelstriche umfassend siehe: Müller und Kappelhoff 2018, S. 7.

290 Müller und Kappelhoff 2018, S. 34. 
Denkens zu fungieren scheinen, ${ }^{291}$ in ihrem Akt der Filmerfahrung Sinnbildungen, in denen gemeinsam geteilte Wirklichkeitsbezüge und -konstruktionen zu verorten sind. ${ }^{292}$

Wenn ich im Folgenden von Metaphorik spreche, verstehe ich diese sowohl im engeren Sinn, dies meint die sofort ins Auge springende Erzeugung eines Sinnbilds. Damit ist etwa die typische Eisensteinsche Metapher gemeint, die sich in zwei Sinnbezirken durch die Montage verbindet, wo durchaus das dargestellte Objekt dominant eine Rolle spielt. ${ }^{293}$ Jedoch in erster Linie perspektiviere ich Phänomene der Cinematic Metaphor, anhand derere ich subtliere Ebenen der Entstehung von Bedeutung rekonstruiere: Im Hinblick auf Prozesse der Wahrnehmungstätigkeit prägen sich figurative Bewegungsformen innerhalb kinematografischer bzw. medial-audiovisueller Kommunikation aus, welche feinste Formationen narrativen Verstehens herstellen. ${ }^{294}$ Metaphern sind für Zuschauerinnen erfahrungsbasiert und lassen sich nicht allein auf Motive, dargestellte Objekte oder Ikonographien etc. zurückführen. Dieser Metapherntypus zielt auf das über die Zeit sich entwickelnde Verstehen von Bewegungsbildern als metaphorischer Prozess. ${ }^{295} \mathrm{Im}$ Nachvollziehen des metaphorischen Prozesses lassen sich basalste narrative oder argumentative Entwicklungen von Bewegungsbildern nachzeichnen. Für den Prozess der Cinematic Metaphor in Filmen und anderen audiovisuellen Medien sind alle Elemente des Bildes relevant: Schnitt, Kamerabewegung, Schauspiel, Sound Design etc. sowie die Rede. Dabei geht es nicht darum, bekannte, universelle Metaphern in Filmen aufzufinden, sondern um die jeweils eigenständigen Sinndimensionen, welche ein Film oder ein

291 Metaphern als „cognitive instruments“ Vgl. Max Black: More about Metaphor (1977). In: Andrew Ortony (Hg.): Metaphor and Thought, Cambridge 1993, S. 19-41, hier S. 37-38. Vgl. Kappelhoff 2018, S. 90. Vgl. auch Christina Schmitt, Sarah Greifenstein und Hermann Kappelhoff: Expressive Movement and Metaphoric Meaning. In: Cornelia Müller et al. (Hg.): Body - Language Communication. An International Handbook on Multimodality in Human Interaction. Berlin 2014 (Handbooks of Linguistics and Communication Science. Bd. 38.2); S. 2092-2112.

292 Kappelhoff 2018, S. 90.

293 Eisenstein 2005 (1929a). Dass figurative Phänomene für den Film wichtig sind, zeigt sich nicht zuletzt daran, dass die Filmpraxis und -theorie immer wieder auf die Metapher zurückgegriffen hat, siehe hierzu Whittock 1990.

294 Vgl. Hermann Kappelhoff und Cornelia Müller: Embodied Meaning Construction. Multimodal Metaphor and Expressive Movement in Speech, Gesture, and Feature Film. In: Metaphor and the Social World 1 (2011), H. 2, S. 121-153; Müller und Kappelhoff 2018.

295 Deleuze sieht darin die Einheit von Bild und Begriff, die Metapher integriere „das Denken in das Bild“. Gilles Deleuze: Das Zeit-Bild. Kino 2 (1985). Frankfurt a. M. 1997, S. 211. 
mediales Bewegungsbild in seiner je spezifischen Form der Artikulation ausbildet. Entscheidend für die Emergenz von Bedeutung und für das SichEtablieren von Metaphorizität - und der damit verbundenen diegetischen Elemente, der Figurenkonstellation, narrativen Handlungen sowie symbolischen Bezugssystemen - ist die filmische Expressivität und die damit verbundene affektive Dimension, welche der metaphorischen Bedeutung zugrunde liegt bzw. diese erst hervorzubringen vermag. Metaphern in der Filmerfahrung zielen unter anderem darauf ab, Abstraktes oder Verdecktes zu versinnlichen. So schreibt Hermann Kappelhoff:

Die metaphorischen Konzepte haben die pragmatische Funktion, verstandesmäßig oder sozial unzugängliche Erfahrungsdomänen durch Analogiebildungen zu erschließen. Sie beziehen sich auf die Grenzen des allgemein geteilten Wissens, auf das Unbekannte und Unverstandene. ${ }^{296}$

Kappelhoff spricht audiovisuelle Bewegungsbilder als medial geteilte Wahrnehmungsformen an. Die Metapher stelle hierbei die „Grenzen des allgemein geteilten Wissens“ (s.o.) dar, sie markiert gewissermaßen den Übergang von bekannten sinnlichen Formen zu geteilten Konzeptualisierungen, Vorstellungen von Welt, die aber nicht mehr im Bereich des Darstellbaren liegen, sie tendiert zum Unbegrifflichen ${ }^{297}$ bishin zum Unverstandenen, Unergründlichen oder Unbekannten. Ziel sei, „unzugängliche Erfahrungsdomänen“ (s.o.) zu ergründen.

In einer Metapher werden zwei Bereiche in eins gesetzt, welche gestisch, sprachlich oder durch andere Modalitäten hervorgebracht, aufeinander bezogen werden. Dadurch werden bestimmte Bedeutungskontexte, Elemente oder auch Semantiken im anderen Bereich hervorgehoben oder dorthin übertragen. Nach dem dynamischen Verständnis Kappelhoffs und Müllers speisen sich diese Bereiche nun nicht mehr nur aus außerfilmischen Konzeptualisierungen, sondern entstehen vielmehr präsentisch im verkörperten Zuschauererleben. Mit einem solchen Verständnis des metaphorischen Quell- und Zielbereichs geht es weniger darum, dass bereits bestehende, erlernte und erworbene Erfahrungsbereiche - source oder $\operatorname{target}^{298}$ bzw. ein „Bildspende- und Bildempfängerbereich“ 299 - aufgerufen werden, sondern dass sich ad hoc ein

\section{Kappelhoff 2018, S. 99.}

297 Im Sinne von Hans Blumenberg: Theorie der Unbegrifflichkeit. Frankfurt a. M. 2007; Kappelhoff 2018. S. 175-176.

298 Im Sinne der konzeptuellen Metapherntheorie nach Lakoff and Johnson 1980.

299 Harald Weinrich: Semantik der kühnen Metapher (1963). In: Anselm Haverkamp (Hg.): Theorie der Metapher. Darmstadt 1983, S. 316-339. 
Sinn herstellt, der in der konkreten filmischen Expressivität angelegt ist und sich in der zeitlichen Erfahrung der Filmrezeption zu realisieren vermag. ${ }^{300}$

In dieser Hinsicht ist für mich Cinematic Metaphor ein theoretisches und analytisches Instrument, um Sinnzusammenhänge an den Screwball Comedies zu fassen, die zwar aus dem konkret Sichtbaren und Hörbaren über die Zeit erzeugt werden, aber an keiner Stelle im Bild objekthaft auftreten, z.B. Fiktionalisierungen von narrativen Handlungen und Figurengefühlen. Im Folgenden werde ich die Methode der Filmanalyse verdeutlichen.

\subsection{Affizierung und filmisches Denken - zur Methodik}

Die in den letzten Unterkapiteln vorgestellten theoretischen Bezüge zur Ausdrucksbewegung konzeptualisieren die Kongruenz von audiovisueller Bewegung und Empfindungsbewegung. Die Frage danach, wie solche wahrnehmungsmodellierenden Bewegungsmuster des Films analytisch identifiziert und beschrieben werden können und wie die affektive Dimension qualifiziert werden kann, möchte ich an dieser Stelle erklären.

\section{Affektmodellierung in audiovisuellen Medien - eMAEX}

Das methodische Instrumentarium, um die Expressivität in der Screwball Comedy zu beschreiben und dadurch die Affizierung bzw. heiteren Gefühle von $\mathrm{Zu}$ schauern zu rekonstruieren, ergibt sich aus der qualitativen, medienästhetischen Analysemethode $e M A E X .^{301}$ Die Methode kennzeichnet die qualitative Beschreibung ästhetischer Kompositorik audiovisueller Inszenierung und perzeptiver Muster; sie wurde im Rahmen eines Forschungsprojekts zum Hollywood-

$300 \mathrm{Zu}$ den unterschiedlichen Zeitlichkeiten filmischer Formate und ihre Beziehung zur Metaphorizität siehe Schmitt 2020.

301 eMAEX wurde am Korpus des Kriegsfilms entwickelt (https://www.empirische-medienaesthetik.fu-berlin.de/emaex-system/index.html, letzter Zugriff am 04.02.2020), ist aber eine allgemeine Methode zur Beschreibung von Bewegungsbildern. Siehe Kappelhoff und Bakels 2011. Zur Anwendung von eMAEX in textlichen Darstellungen siehe Hermann Kappelhoff: Genre und Gemeinsinn. Hollywood zwischen Krieg und Demokratie. Berlin/Boston 2016; Bakels 2017, S. 70-71. Zur genauen Heranführung an die Methode siehe Hermann Kappelhoff, Sarah Greifenstein und Jan-Hendrik Bakels: Die Poesis des Filme-Sehens Methoden zur Analyse audiovisueller Bilder. Berlin/Boston (in Vorbereitung, erscheint voraussichtlich 2020). 
Kriegsfilm in einer webbasierten Infrastruktur entwickelt. ${ }^{302}$ Mit der Methode wird jedoch nicht, wie in Inhaltsanalysen üblich, die narrative Geschichte abstrahiert vom audiovisuellen Geschehen beschrieben bzw. auch keine lediglich unterstützende Funktion der Inszenierung betrachtet. Vielmehr können über ein filmanalytisches Vorgehen die kompositorische Inszenierung von Bewegungsmustern sowie Aspekte der Dramaturgie aufeinander bezogen beschrieben werden. Dabei fokussiert die Beschreibung die verschiedenen Inszenatoriken in Filmen, wie sie sich für die Zuschauerwahrnehmung zu Bewegungsmustern ausformen. Einzelne Artikulationen bilden dabei Muster, die als Gestalt anschaulich werden. Solche audiovisuellen Bewegungsmuster (Ausdrucksbewegungseinheiten) lassen sich mit der Methode identifizieren und filmanalytisch beschreiben, die Deskription gilt der Rekonstruktion perzeptiver, affektiver und kognitiver Anordnungen durch das Bewegungsbild. Die perzeptive Adressierung von Zuschauern wird über die zeitliche Struktur und die ästhetischen Kompositoriken beschrieben, die affektiven Qualitäten und Intensitäten über die Beschreibung der Expressivität einer Szene. Die Aspekte des Verstehens einer Szene werden in der eMAEX-Beschreibung über die narrativen Grundinformationen kurzgefasst. Wie genau es zum Verstehen einer Szene in der Zuschauererfahrung kommt, kann extra in einer Zusatzanalyse über die Metaphernanalyse anvisiert werden. Das Analyseverfahren eMAEX basiert auf verschiedenen Prinzipien zeitlicher Segmentierung innerhalb unterschiedlich großer Zeitspannen. ${ }^{303}$

Drei Ebenen strukturieren den Vorgang der eMAEX-Analyse: Die Makroebene ist eine Beschreibung der Szenen und ihrer Zusammensetzung innerhalb einer Affektdramaturgie des gesamten Films (oder der Gänze des entsprechenden formatspezifischen Zeitsegments). Dafür ist jedoch die Entwicklung oder das Bestehen von Pathosszenen oder anderen affektstrukturierten Einheiten die Voraussetzung. Die Mesoebene kann unabhängig davon durchgeführt werden. Notwendig ist lediglich die möglichst genaue Einteilung von szenischen Einheiten. Die

302 Siehe Kappelhoff und Bakels 2011.

303 Makroanalysen fassen die Dramaturgie des ganzen Films über die Zeit in Form der Anordnung szenischer Komplexe. Mikroanalysen sind zweifach geteilt: die gesamte Szenenkomposition ist $\mathrm{zu}$ beschreiben sowie eine noch feinkörnigere Analyse einzelner Untereinheiten dieser (Ausdrucksbewegungseinheiten). Siehe hierzu Kappelhoff und Bakels 2011 sowie Thomas Scherer, Sarah Greifenstein und Hermann Kappelhoff: Expressive Movements in Audio-Visual Media. Modulating Affective Experience. In: Cornelia Müller et al. (Hg.): Body - Language - Communication. An International Handbook on Multimodality in Human Interaction. Berlin 2014 (Handbooks of Linguistics and Communication Science. Bd. 38.2), S. 2081-2092. Dieses Verfahren wandle ich $\mathrm{ab}$, indem ich mich auf mikroanalytische Aspekte konzentriere und sie an exemplarischen Szenen in Form von textlicher Beschreibung und Grafiken veranschauliche. 
Mesoebene gilt der Rekonstruktion einzelner Szenen in ihren affektpoetischen, narrativen und ästhetisch-wahrnehmungsorientierten Inszenierungen. Eine Szene setzt sich aus verschiedenen Ausdrucksbewegungseinheiten (ABEs) zusammen oder besteht nur aus einer ABE. Die Mikroanalyse betrifft die Beschreibung der jeweils einzelnen Ausdrucksbewegungseinheit. Die unterschiedlichen Beschreibungsebenen sind dabei als ineinandergreifende Modalitäten zu fassen: wie z.B. Kamerabewegungen und Schnitt zeitlich aufeinander abgestimmt sind. Die Beschreibungsebenen stellen verschiedene Parameter der Meso- und Mikro-Analyse dar, sie sind nicht summarisch, sondern sollen holistisch in Bezug zueinander gesetzt werden:

1) Kamera (Einstellungsgröße, -folge, Kamerabewegung und -perpektive, Montage und Montagerhythmus)

2) Akustik / Sound Design (Musik, Geräusche und Rede)

3) Gestik, Stimme und Mimik (auch alle weiteren Aspekte des Schauspiels),

4) Figurenkonstellation (Choreographie / Konstellation von Figuren und Objekten im Sinne eines engen Verständnisses von Mise-en-Scène)

5) Bildkomposition (Kontrast- und Farbverteilung, Licht-Valeurs, visuelle Muster und Bildaufteilung genauso wie Dynamik im Bild)

Das Instrumentarium von $e M A E X$ ist ursprünglich darauf angelegt, es mit Elan oder einer vergleichbaren, zeitbasierten Annotationssoftware zu nutzen. Die Beschreibung der Makroebene ist in Diagrammform darzustellen mit einem Fließtext dazu, der die Affektdramaturgie aufzeigt. Die Meso- und Mikroebene sind filmanalytisch als zwei kurze Fließtexte zu konzipieren, indem das dynamische Muster der einzelnen ABE (Ausdrucksbewegungeinheit) sowie der Zusammensetzung der ABEs zu einem dynamischen Muster innerhalb einer szenischen Komposition deutlich werden. Der Affektbegriff orientiert sich an der im Theorieteil dargelegten Auffassungen zu Ausdrucksbewegung sowie zum Affekt- und Bewegungsbild (nach Kappelhoff und Deleuze). ${ }^{304}$ Die Präsentation der Analyse war im Entstehungsprojekt der Methode als eine CMS-basierte Datenmatrix strukturiert. Diese Darstellung ist für Monographien oder andere wissenschaftliche Textformate oder Vorträge, in denen die Primärquelle - die filmische Szene - nicht anwesend ist, abzuwandeln.

Im Laufe der Arbeit werde ich $e M A E X$ gemäß meiner Frageperspektiven mikro- und mesoanalytisch anwenden ${ }^{305}$ und im Hinblick auf die

304 Siehe Kapitel 2.3 und 2.4.

305 In dieser Untersuchung wird vor allem die Mikroanalyse (von Einzelsequenzen) vertieft, da die Beobachtung gemacht wurde, dass die Komödien ihre Komik überwiegend an kurzen szenischen Anlässen entwickeln, also momenthaft geprägt sind und weniger die ausgedehnten Dramaturgien zum Ausgangspunkt der heiteren Gefühle machen. Meine Beobachtungen 
Bewegungsqualitäten als Affektqualitäten sowie in Bezug zur kinematographischen Einbettung des Schauspiels spezifizieren. Da die Komödien auch stark durch vorstellungsgebundene und sprachbezogene Prozesse gestaltet sind, gilt es, die Erzeugung von Sinn bzw. die Verstehensprozesse, die aus den Verbalisierungen in Verbindung mit den Filmpoetologien erwachsen, ebenfalls in den Fokus zu rücken.

\section{CinMet Procedure: Sprache, Bildlichkeit und dynamische Bedeutungskonstruktion}

Die deskriptive Analysemethode CinMet Procedure basiert auf einem transdisziplinären Verständnis von Metaphorizität, der Cinematic Metaphor - wie oben theoretisch dargelegt -, das filmwissenschaftliche und sprachwissenschaftliche Konzepte (Metaphorik und Ausdrucksbewegung) aufeinander bezieht. Daraus wurde ein Modell filmischen Verstehens und Denkens sowie eine qualitativ-deskriptive Analysemethode entwickelt. ${ }^{306}$ Die Analysen rekonstruieren den Verstehensprozess bzw. die Sinn- oder Bedeutungskonstitution in der Zuschauererfahrung. Das Verfahren baut auf $e M A E X$ auf, sie teilen die grundlegende Annahme, dass in Filmen gesehene und gehörte Bewegungsmuster die verkörperte Wahrnehmung der Zuschauer über die Zeit modulieren und dadurch affektive und kognitive Prozesse gestalten. ${ }^{307}$ Auf der Basis der Beschreibung filmischer Expressivität, Ausdrucksbewegungseinheiten und affektiver Erfahrungsqualitäten, wird es möglich, eine Analogiebewegung an filmischen Bildern nachzuzeichnen, in denen zwei oder mehrere Erfahrungsdomänen aufeinander bezogen werden, wodurch eine Emergenz von Metaphorizität aus sinnlichen, verkörperten Erlebensformen durchlaufen wird. ${ }^{308}$ CinMet Procedure ist als methodisches Vorgehen dreistufig gegliedert. Ausgangspunkt ist eine Makroanalyse, in der szenische Einheiten festgelegt werden, die für die Metapher(n) zentral sind.

decken sich mit Deleuzes Beschreibung von Situation versus Handlung im Aktionsbild der großen und kleinen Form und der damit verbundenen Genres, Deleuze 1997 (1983), S. 193-240, sowie mit Schatz 1981.

306 Siehe Müller und Kappelhoff 2018, S. 226-234; Kappelhoff und Müller 2011; Schmitt et al 2014. Siehe auch Schmitt 2020.

307 Kappelhoff und Müller 2011.

308 Für einen Überblick des methodischen Zugangs siehe Müller und Kappelhoff 2018; Schmitt, Greifenstein und Kappelhoff 2014; Cornelia Müller und Christina Schmitt: AudioVisual Metaphors of the Financial Crisis. Meaning Making and the Flow of Experience. In: Journal of Applied Linguistics 15 (2015), H. 2 (Special Issue: Metaphor and Metonymy in Social Practices, hg. von Raymond W. Gibbs Jr. und Luciane Corrêa Ferreira), S. 311-341. 
Auf einem Zeitpfeil werden die Szenen grafisch so angeordnet, dass ihre Länge sowie ihre metaphorische Thematik darin markiert wird. Dazu wird ein Fließtext formuliert, der die einzelnen Metaphern sowie deren eventuelle Veränderung über die Zeit im gesamten Film beschreibt. Die Mesoebene hat eine Szene im Fokus und adressiert die Art und Weise, wie sich in ihr Metaphorizität zeitlich und in verschiedenen Modalitäten ausprägt. Die Parameter oder Beschreibungsebenen sind äquivalent zu denen in $e M A E X$ als Modalitäten $\mathrm{zu}$ fassen:

1) Kamera (Einstellungsgröße, -folge, Kamerabewegung und -perpektive, Montage und Montagerhythmus)

2) Akustik / Sound Design (Musik, Geräusche)

3) Gestik, Stimme und Mimik (auch alle weiteren Aspekte des Schauspiels),

4) Figurenkonstellation (Choreographie / Konstellation von Figuren und Objekten im Sinne eines engen Verständnisses von Mise-en-Scène)

5) Bildkomposition (Kontrast- und Farbverteilung, Licht-Valeurs, visuelle Muster und Bildaufteilung genauso wie Dynamik im Bild)

6) Rede/Sprache

Lediglich die Dimension der Rede/Sprache tritt in CinMet Procedure bzw. als eigener analytischer Parameter hinzu, da diese für einige Metaphoriken konstitutiv ist. Durch die Beschreibung filmisch-audiovisueller Inszenierungsweisen (den verschiedenen Parametern von eMAEX entsprechend) sowie verbaler Ausdrücke wird die zeitliche Gestalt der Metapher skizziert. Ein Fließtext und eine Grafik dazu zeigen die audiovisuelle Figuration auf. Die Mikroanalyse beschreibt kleinere Einheiten (ABEs), deren Bewegungsqualitäten als affektive Qualitäten sowie ihre Inszenerungsweisen, expressive Eigenschaften, konkrete Erfahrungsbereiche in einem kurzen Fließtext und als Grafik. Ausdrucksbewegung und Metapher werden in der Grafik sowie im Fließtext aufeinander bezogen. ${ }^{309}$

Die Metaphern sind zeitlich unterschiedlich gestaltet, sie können kurz, eindeutig und prägnant in einem Werbefilm auftreten oder sich über zwei Stunden zu komplexen, veränderbaren Bedeutungschichten weiterentwickeln, z.B. in einem langen Spielfilm. ${ }^{310}$ Die Metaphern sind multimodal, sie können gänzlich durch audiovisuelle Kompositionen entstehen oder aber auch stark durch sprachliche Äußerungen geprägt sein. ${ }^{311}$

309 Müller und Kappelhoff 2018, S. 226-238.

310 Vgl. Schmitt 2020.

311 Dorothea Horst: Meaning-Making and Political Campaign Advertising. A CognitiveLinguistic and Film-Analytical Perspective on Audiovisual Figurativity. Berlin/Boston 2018. 
Ebenso wie in der Anwendung von eMAEX konzentriere ich mich in der Anwendung von CinMet Procedure vor allem auf mikroanalytische Beschreibungen von Metaphern. Die szenischen Komplexe werden im Hinblick auf verschiedene Inszenierungsebenen (Modalitäten wie Sprachäußerungen, auditive Kompositionen, visuelle Elemente und Inszenierungen, Schauspiel) beschrieben. Außerdem werden die Metaphern im Hinblick auf ihre Zeitgestaltung untersucht. Damit rückt in den Blick, auf welche Weise sie sich in der Zuschauererfahrung elaborieren. Mit dem Fokus auf Metaphorizität werde ich an verschiedenen Stellen der Untersuchung die verkörperte Bedeutung in den Filmen im Zusammenhang mit kinematografischen Inszenierungen von Mimik, Gestik, Stimmartikulationen sowie Sprachäußerungen rekonstruieren. Erst auf diese Weise kann ich bestimmte figuren- oder narrationsbezogene Dimensionen filmischen Verstehens oder Denkens benennen, die sich mit den temporalen Bewegungserfahrungen und deren Komik verbinden.

Beide analytischen Zugänge sind durch die deskriptive Beschreibung phänomenologischer und ästhetischer Gegebenheiten geprägt. Anders als im interpretatorische Akt gerät mit der Beschreibung von Kompositionen und Ausdrucksmodalitäten die Bewegungsdimension in den Blick: audiovisuelle Inszenierungen, Lichtsetzung, Kamerabewegungen, Sound, Montage, Schauspiel und Mise-en-scène im Verbund mit Sprachäußerungen werden beschreibbar. Dadurch lassen sich die komplexen Schichtungen filmischer Bilder so eng wie möglich an der Zeitlichkeit filmischer Artikulation nachzeichnen. Damit verbunden sind die Anordnungen von Wahrnehmung, die alle Zuschauer im Filme-Sehen und -Hören durchlaufen, sowie affektive Adressierungen und kognitive Operationen, die mit den zeitlichen und perzeptiven Formationen einhergehen können.

\subsection{Ausklang}

Dieses Kapitel legte die theoretischen Bezugspunkte der Arbeit offen, um in den nächsten Teilen einzelne Schwerpunkte zu beleuchten. Wegweisend sind dabei die zwei Perspektiven: die Tempi der Bewegung als Modi des Gefühls sowie die Eingebettetheit des Schauspiels in die filmische Ästhetik. Mit diesen Grundlinien untersuche ich, wie sich spezifische Körperinszenierungen in der Screwball Comedy ausgebildet haben: Stimmbild und Wortkulisse (Kapitel 3), Gestik und filmische Ausdrucksbewegung (Kapitel 4) sowie das kommunizierende Gesicht (Kapitel 5). Im Kapitel 6 werde ich einen Überblick über das Genre geben. 